Prepared for the U.S. Department of Energy under Contract DE-AC05-76RL01830

\title{
Assessment of Differences in Phase 1 and Phase 2 Test Observations for Waste Treatment Plant Pulse Jet Mixer Tests with Non-Cohesive Solids
}

PA Meyer

EBK Baer

JA Bamberger

JA Fort

MJ Minette

October 2010

Pacific Northwest

NATIONAL LABORATORY

Proudly Operated by Battelle Since 1965 


\title{
DISCLAIMER
}

This report was prepared as an account of work sponsored by an agency of the United States Government. Neither the United States Government nor any agency thereof, nor Battelle Memorial Institute, nor any of their employees, makes any warranty, express or implied, or assumes any legal liability or responsibility for the accuracy, completeness, or usefulness of any information, apparatus, product, or process disclosed, or represents that its use would not infringe privately owned rights. Reference herein to any specific commercial product, process, or service by trade name, trademark, manufacturer, or otherwise does not necessarily constitute or imply its endorsement, recommendation, or favoring by the United States Government or any agency thereof, or Battelle Memorial Institute. The views and opinions of authors expressed herein do not necessarily state or reflect those of the United States Government or any agency thereof.

\author{
PACIFIC NORTHWEST NATIONAL LABORATORY \\ operated by \\ BATTELLE \\ for the \\ UNITED STATES DEPARTMENT OF ENERGY \\ under Contract DE-AC05-76RL01830
}

Printed in the United States of America

Available to DOE and DOE contractors from the

Office of Scientific and Technical Information,

P.O. Box 62, Oak Ridge, TN 37831-0062;

ph: (865) 576-8401

fax: $(865) 576-5728$

email: reports@adonis.osti.gov

\author{
Available to the public from the National Technical Information Service, \\ U.S. Department of Commerce, 5285 Port Royal Rd., Springfield, VA 22161 \\ ph: (800) 553-6847 \\ fax: (703) 605-6900 \\ email: orders@ntis.fedworld.gov \\ online ordering: http://www.ntis.gov/ordering.htm
}

This document was printed on recycled paper.

$$
(9 / 2003)
$$




\title{
Assessment of Differences in Phase 1 and Phase 2 Test Observations for Waste Treatment Plant Pulse Jet Mixer Tests with Non-Cohesive Solids
}

\author{
PA Meyer \\ EBK Baer \\ JA Bamberger \\ JA Fort \\ MJ Minette
}

October 2010

$\begin{array}{ll}\text { Test Specification: } & \text { N/A } \\ \text { Work Authorization: } & \text { WA\# 028 } \\ \text { Test Plan: } & \text { TP-WTPSP-001, Rev 0.0 } \\ \text { Test Exceptions: } & \text { N/A } \\ \text { PETD Focus Area: } & \text { Pretreatment } \\ \text { Test Scoping Statement(s): } & \text { NA } \\ \text { QA Technology Level: } & \text { Basic Research }\end{array}$

Prepared for

the U.S. Department of Energy

under Contract DE-AC05-76RL01830

Pacific Northwest National Laboratory

Richland, Washington 99352 
WTP-RPT-208, Rev. 0

\section{Completeness of Testing}

This report describes the results of work and testing specified by Test Plan TP-WTPSP-001"Test Plan for Additional M-3 Testing Support." The work and any associated testing followed the quality assurance requirements outlined in the Test Plan. The descriptions provided in this test report are an accurate account of both the conduct of the work and the data collected. Test Plan results are reported. Also reported are any unusual or anomalous occurrences that are different from expected results. The test results and this report have been reviewed and verified.

\section{Approved:}

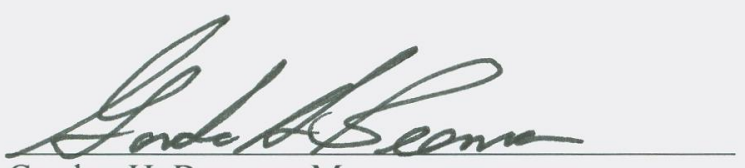

Gordon H. Beeman, Manager

WTP Support Project

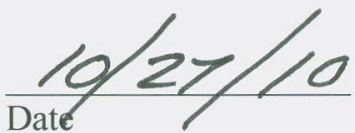




\section{Acronyms and Abbreviations}

$\begin{array}{ll}\text { AEA } & \text { Atomic Energy Authority (UK) } \\ \text { BNI } & \text { Bechtel National, Inc. } \\ \text { DAS } & \text { data acquisition system } \\ \text { DBE } & \text { design basis event } \\ \text { DOE } & \text { Department of Energy } \\ \text { EFRT } & \text { External Flowsheet Review Team } \\ \text { ES } & \text { Energy Solutions } \\ \text { F\&D } & \text { flange and dish } \\ \text { HS } & \text { head shape } \\ \text { ID } & \text { inner diameter; case ID for test conditions } \\ \text { JPP } & \text { jet pump pair } \\ \text { LRB } & \text { laboratory record book } \\ \text { M3 } & \text { EFRT technical issue M3-Inadequate Design of Mixing Systems-Pulse Jet Mixers } \\ \text { MCE } & \text { Mid-Columbia Engineering } \\ \text { MOA } & \text { memorandum of agreement } \\ \text { MR } & \text { multiple regression } \\ \text { PETD } & \text { Process Engineering \& Technology Department } \\ \text { PJM } & \text { pulse jet mixer (mixing) } \\ \text { PNNL } & \text { Pacific Northwest National Laboratory } \\ \text { PSD } & \text { particle-size distribution } \\ \text { PSDD } & \text { particle size and density distribution } \\ \text { RLIH } & \text { return line inlet height } \\ \text { WSU } & \text { Washington State University } \\ \text { WTP } & \text { Hanford Tank Waste Treatment and Immobilization Plant } \\ \text { WTPSP } & \text { Waste Treatment Plant Support Program } \\ & \end{array}$





\section{Symbols}

\begin{tabular}{|c|c|}
\hline $\mathrm{A}_{\mathrm{J}}$ & total jet nozzle area \\
\hline $\mathrm{A}_{\mathrm{PT}}$ & total pulse tube cross-sectional area \\
\hline $\mathrm{A}_{\mathrm{T}}$ & tank area \\
\hline $\mathrm{C}_{0}$ & average solids concentration at the vessel bottom (at elevation 0 ) \\
\hline $\mathrm{C}(\mathrm{Z})$ & solids vertical distribution, concentration as a function of elevation \\
\hline $\mathrm{D}$ & diameter of tank \\
\hline $\mathrm{D}_{\mathrm{PT}}$ & diameter of pulse tube \\
\hline DC & duty cycle $=t_{D} / t_{C}$ \\
\hline $\mathrm{d}_{\mathrm{S}}$ & diameter of solids particle \\
\hline$d_{50}$ & median particle diameter \\
\hline $\mathrm{d}_{50 \text { (by volume) }}$ & median volume-based particle diameter \\
\hline $\mathrm{E}$ & elliptical tank bottom \\
\hline $\mathrm{f}$ & function \\
\hline $\mathrm{Ga}$ & Galileo number \\
\hline $\mathrm{H}$ & fluid height, normal fill level \\
\hline $\mathrm{H}_{\mathrm{C}}$ & average peak cloud height \\
\hline $\mathrm{H}_{\mathrm{F}}$ & fill height of material in tank \\
\hline HS & Head shape Elliptical (E), flange and dish (F\&D), spherical (S) \\
\hline $\mathrm{N}$ & number of installed jets or pulse tubes \\
\hline $\mathrm{N}_{\mathrm{I}}$ & number of operating pulse jets on inner ring \\
\hline $\mathrm{N}_{\mathrm{J}}$ & $\mathrm{N}_{\mathrm{J}}=\mathrm{N}_{\mathrm{O}}+\mathrm{N}_{\mathrm{I}}=$ number of operating pulse jets (number) \\
\hline $\mathrm{N}_{\mathrm{O}}$ & number of operating pulse jets on outer ring \\
\hline $\mathrm{r}$ & radial location \\
\hline $\operatorname{Re}_{J}$ & jet Reynolds number \\
\hline $\mathrm{S}$ & scale; spherical tank bottom \\
\hline s & density ratio, ratio of particle density to liquid density $=\rho_{s} / \rho_{l}$ \\
\hline $\operatorname{sxdx}$ & simulant designator (density\#particle\#) \\
\hline $\mathrm{t}_{\mathrm{C}}$ & cycle time \\
\hline$t_{D}$ & $\begin{array}{l}\text { drive time, discharge time, pulse time, time at end of pressurization during pulse } \\
\text { discharge }\end{array}$ \\
\hline$t_{R}$ & refill time \\
\hline $\mathrm{U}$ & jet velocity \\
\hline$\overline{\mathrm{U}}$ & volume-weighted average settling velocity (Ubar) \\
\hline$\overline{\mathrm{U}}_{\mathrm{n}}$ & $\begin{array}{l}\text { Cumulative volume-weighted average settling velocity for } n \% \text { of the fastest-settling } \\
\text { particles (also expresses as Ubar n) }\end{array}$ \\
\hline $\mathrm{U}_{\mathrm{CS}}$ & critical suspension velocity \\
\hline
\end{tabular}




$\begin{array}{ll}\mathrm{U}_{\mathrm{CS}} \text { cen } & \text { critical suspension velocity at the tank bottom center } \\ \mathrm{U}_{\mathrm{JD}} & \text { average jet drive velocity (also expressed as } \mathrm{U}_{\mathrm{J}} \text { ) } \\ \mathrm{U}_{\mathrm{JR}} & \text { average jet refill velocity } \\ \mathrm{U}_{\mathrm{PA}} & \text { peak average velocity } \\ \mathrm{U}_{\mathrm{TH}} & \text { terminal settling velocity } \\ \mathrm{U}_{\mathrm{TH}} & \text { modified terminal settling velocity (also expresses as } \mathrm{U}^{\prime}{ }_{\mathrm{TH}} \text { ) } \\ \mathrm{U}_{\mathrm{TH}} \text { ’ } & \text { adjusted modified terminal settling velocity (also expresses as } \mathrm{U}^{\prime}{ }_{\mathrm{TH}} \text { ) } \\ \mathrm{V} & \text { nominal volume of tank } \\ \mathrm{V}_{\mathrm{P}} & \text { volume of pulse (per PJM) } \\ \mathrm{V}_{\mathrm{PT}} & \text { volume of pulse tube } \\ \mathrm{V}_{\mathrm{REF}} & \text { reference volume based on the volume of a right circular cylinder of diameter D where } \\ \mathrm{V}_{\mathrm{S}} & \text { height equals diameter, } \mathrm{V}_{\mathrm{REF}}=\left(\pi \mathrm{D}^{3}\right) / 4 \\ \mathrm{x}_{\mathrm{n}} & \text { volume of solid particulate } \\ \mathrm{y} & \text { predictor variable } \\ \mathrm{Z} & \text { response variable } \\ \mathrm{z} & \text { elevation in tank }\end{array}$




\section{Greek Symbols}

\begin{tabular}{|c|c|}
\hline$\alpha$ & scale-up exponent \\
\hline$\alpha_{C}$ & scale-up exponent for concentration, Alpha $C=\alpha_{C}=1-\alpha_{H}$ \\
\hline$\alpha_{\mathrm{H}}$ & scale-up exponent for average peak cloud height \\
\hline$\alpha_{U}$ & scale-up exponent for critical suspension velocity \\
\hline$\phi_{\mathrm{J}}$ & jet density $=\mathrm{Nd}^{2} / \mathrm{D}^{2}$ \\
\hline$\phi_{\mathrm{p}}$ & pulse volume fraction $=\mathrm{N} \mathrm{V} / \mathrm{V}_{\mathrm{REF}}$ \\
\hline$\phi_{\mathrm{PT}}$ & ratio of pulse tube to vessel cross-sectional area $=\mathrm{N} \mathrm{D}_{\mathrm{PT}}{ }^{2} / \mathrm{D}^{2}$ \\
\hline$\phi_{\mathrm{S}}$ & ratio of volume of solids (particulate) to reference volume $=V_{S} / V_{\mathrm{REF}}=V_{S} /\left(\pi \mathrm{D}^{3} / 4\right)$ \\
\hline$\phi_{\mathrm{S} \max }$ & solids fraction corresponding to maximum packing \\
\hline$\rho_{l}$ & liquid density \\
\hline$\rho_{\mathrm{s}}$ & particle density \\
\hline
\end{tabular}





\section{Testing Summary}

The purpose of this work was to assess the apparent discrepancy in critical suspension velocity $\left(\mathrm{U}_{\mathrm{CS}}\right)$ between M3 Phase 1 (Meyer et al. 2009) and Phase 2 testing conducted by Energy Solutions (ES) at Mid-Columbia Engineering (MCE) and to address the applicability of Phase 1 scale-up laws to Phase 2 test results. Three Phase 2 test sequences were analyzed in detail. Several sources of discrepancy were identified including differences in nominal versus actual velocity, definition of model input parameters, and definition of $\mathrm{U}_{\mathrm{CS}}$. A remaining discrepancy was shown to not be solely an artifact of Phase 1 data correlations, but was fundamental to the tests. The non-prototypic aspects of Phase 1 testing were reviewed and assessed. The effects of non-prototypic refill associated with the closed loop operation of the jets, previously known to affect cloud height, can be described in terms of a modified settling velocity. When the modified settling velocity is incorporated into the Phase 1 "new" physical model the adjusted new physical model does a better job of predicting the Phase 2 test results. The adjusted new physical model was bench marked with data taken during three prototypic drive tests. Scale-up behavior of the Phase 1 tests was reviewed. The applicability of the Phase 1 scale-up behavior to Phase 2 prototypic testing was analyzed. The effects of non-prototypic refill caused measured values of $U_{\mathrm{CS}}$ to be somewhat reduced at larger scales. Hence the scale-up exponents are believed to be smaller than they would have been had there been prototypic refill. Estimated scale-up exponents for the Phase 2 testing are 0.40 for 8-tube tests and 0.36 for 12 -tube tests.

\section{Objectives}

Table S.1 summarizes the objectives and results of this testing along with a discussion of how the objectives were met.

Table S.1. Summary of Test Objectives and Results

\begin{tabular}{lll}
\hline \multicolumn{1}{c}{ Test Objective } & $\begin{array}{c}\text { Objective } \\
\text { Met? }\end{array}$ & \multicolumn{1}{c}{ Discussion } \\
\hline $\begin{array}{l}\text { The overall objective of this project is to provide } \\
\text { technical support to the M3 testing. This project }\end{array}$ & $\begin{array}{l}\text { This report completes the Data Reconciliation } \\
\text { task. The work was completed at the Basic } \\
\text { Research Technology Level. } \\
\text { contains four basic tasks: Data Reconciliation, }\end{array}$ \\
M3 Testing Support, Special Studies Support, and & \\
Analytical Support. The first three tasks listed are & \\
classified as Technology Level Basic Research. & \\
The Analytical Support Task is classified as & \\
Technology Level Applied Research. \\
This report completes the Data Reconciliation task.
\end{tabular}

\section{Test Exceptions}

A summary description of the test exceptions applied to these tests is shown in Table S.2. 
Table S.2. Test Exceptions

\begin{tabular}{cc}
\hline Test Exceptions & Description of Test Exceptions \\
\hline None. & None. \\
\hline
\end{tabular}

Deviations from the test specifications are provided in Table S.3.

Table S.3. Deviations from Test Specification

\begin{tabular}{cc}
\hline Test Specification Reference & Exception Taken \\
\hline None. & None. \\
\hline
\end{tabular}

\section{Results and Performance Against Success Criteria}

The success criteria for achieving these objectives are discussed in Table S.4.

Table S.4. Results and Performance Against Success Criteria

\begin{tabular}{|c|c|}
\hline Success Criteria & How Testing Did or Did Not Meet Success Criteria \\
\hline $\begin{array}{l}\text { Complete an analysis to assess the apparent data } \\
\text { difference between the PNNL Phase } 1 \mathrm{M} 3 \text { test data and } \\
\text { the subsequent M3 Phase } 2 \text { data obtained at MCE } \\
\text { (Mid-Columbia Engineering) and WSU (Washington } \\
\text { State University) or if the bias cannot be resolved, then } \\
\text { provide potential factors and conduct a sensitivity } \\
\text { analysis. }\end{array}$ & $\begin{array}{l}\text { Criteria were met. } \\
\text { An evaluation of the MCE data is shown in Section } 2 \\
\text { with the comparison to Phase } 1 \text { testing shown in } \\
\text { Section } 3 \text {. The assessment of the Phase } 1 \text { models is } \\
\text { discussed in Section } 4 \text {, and the impact on the scale-up is } \\
\text { discussed in Section } 5 \text {. Analysis of the WSU data was } \\
\text { not included in this report since it did not include } \\
\text { measurements for off-bottom suspension. }\end{array}$ \\
\hline
\end{tabular}

\section{Quality Requirements}

The quality requirements for this report were established in the SCN-99 and SCN-100 combined Proposal. ${ }^{1}$ The proposed requirements related to this report are as follows:

- All of the subtasks in SCN-099 and SCN-100 are categorized as technology level "Basic Research" in accordance with the WTPSP QA Program.

- The revised QA Plan is included in Attachment F of the proposal [Waste Treatment Plant Support Program Quality Assurance Plan QA-WTPSP-0001, Rev. 0.0]. This QA Plan is a continuation of QA Plan RPP-WTP-QA-001, Rev 3.0. To distinguish the former QA program and implementing procedures from this revision, the project name and document nomenclature have been changed. Effective December 1, 2009, the program was renamed to Waste Treatment Plant Support Program (WTPSP), and this QA Plan was issued under a new document number.

\footnotetext{
${ }^{1}$ Beeman, GH to HR Hazen. Letter November 19, 2009. “Subcontract No: 24590-QL-HC9-WA49-00001 SCN-100 Rev 0 (WA\#2009-028), Proposal.” WTP/RPP-MOA-PNNL-00466, Pacific Northwest National Laboratory, Richland, Washington.
} 
The Pacific Northwest National Laboratory (PNNL) Quality Assurance Program is based upon the requirements as defined in the United States Department of Energy (DOE) Order 414.1C, Quality Assurance and 10 CFR 830, Energy/Nuclear Safety Management, Subpart A -- Quality Assurance Requirements (a.k.a. the Quality Rule). PNNL has chosen to implement the following consensus standards in a graded approach:

- ASME NQA-1-2000, Quality Assurance Requirements for Nuclear Facility Applications, Part 1, Requirements for Quality Assurance Programs for Nuclear Facilities.

- ASME NQA-1-2000, Part II, Subpart 2.7, Quality Assurance Requirements for Computer Software for Nuclear Facility Applications.

- ASME NQA-1-2000, Part IV, Subpart 4.2, Graded Approach Application of Quality Assurance Requirements for Research and Development.

The procedures necessary to implement the requirements are documented through PNNL's HDI (“How Do I...?”) ${ }^{1}$

All work done by the laboratory in support of this report before December 1, 2009 was conducted to QA Plan RPP-WTP-QA-001, and all work completed on or after December 1, 2009 was completed using the Waste Treatment Plant Support Program Quality Assurance Plan, QA-WTPSP-0001, Rev. 0.0 Basic Research Stage of the Technology Life Cycle.

The Waste Treatment Plant Support Project Quality Assurance Manual (QA-WTPSP-0002) describes the technology life cycle stages under the Waste Treatment Plant Support Program Quality Assurance Plan (QA-WTPSP-0001). The technology life cycle includes the progression of technology development, commercialization, and retirement in process phases of basic and applied $R \& D$, engineering and production, and operation until process completion. The life cycle is characterized by flexible and informal quality assurance activities in basic research, which becomes more structured and formalized through the applied R\&D stages.

- BASIC RESEARCH - Basic research consists of research tasks that are conducted to acquire and disseminate new scientific knowledge. During basic research, maximum flexibility is desired in order to allow the researcher the necessary latitude to conduct the research.

- APPLIED RESEARCH - Applied research consists of research tasks that acquire data and documentation necessary to assure satisfactory reproducibility of results. The emphasis during this stage of a research task is on achieving adequate documentation and controls necessary to be able to reproduce results.

- DEVELOPMENTAL WORK - Development work consists of research tasks moving toward technology commercialization. These tasks still require a degree of flexibility, and there is still a degree of uncertainty that exists in many cases. The role of quality on development work is to make sure that adequate controls to support movement into commercialization exist.

- RESEARCH AND DEVELOPMENT SUPPORT ACTIVITIES - Support activities are those which are conventional and secondary in nature to the advancement of knowledge or development of technology, but allow the primary purpose of the work to be accomplished in a credible manner. An example of a

${ }^{1}$ A web-based system for managing the delivery of laboratory-level policies, requirements and procedures. 
support activity is controlling and maintaining documents and records. The level of quality for these activities is the same as for developmental work.

\section{PETD Test Conditions}

The WTP Process Engineering \& Technology Department (PETD) did not establish test conditions for this comparison report. The WTP PETD test conditions are summarized in Table S.5.

Table S.5. PETD Test Conditions

\begin{tabular}{|c|c|}
\hline List PETD Test Conditions & Were Test Conditions Followed? \\
\hline $\begin{array}{l}\text { No PETD test conditions were } \\
\text { established for this comparison report }\end{array}$ & $\mathrm{N}$ \\
\hline
\end{tabular}

\section{Simulant Use}

No simulants were developed for this comparison report.

\section{Discrepancies and Follow-on Tests}

There were no identified discrepancies.

Considerations for follow-on tests were not developed as part of this report. 


\section{Contents}

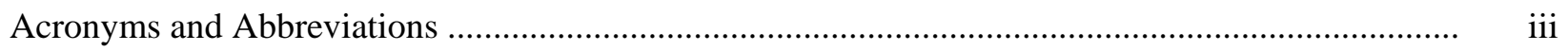

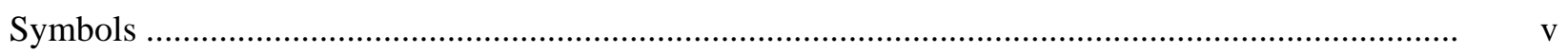

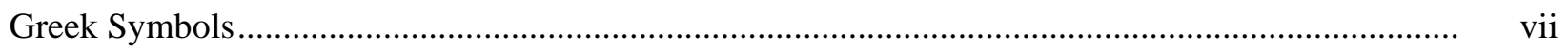

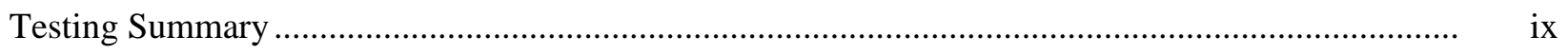

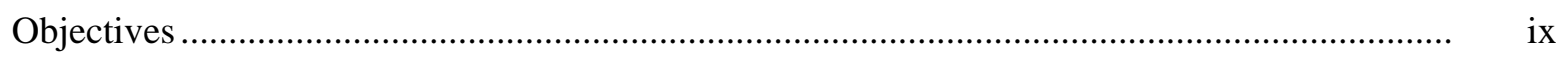

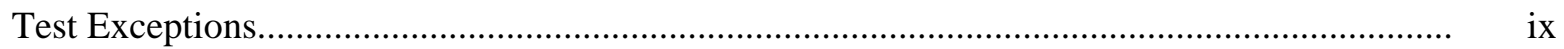

Results and Performance Against Success Criteria ...................................................................

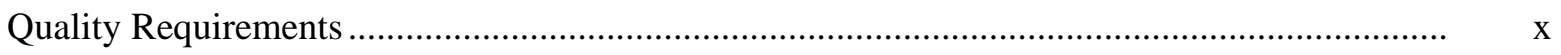

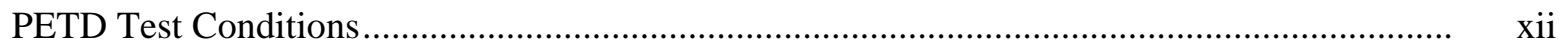

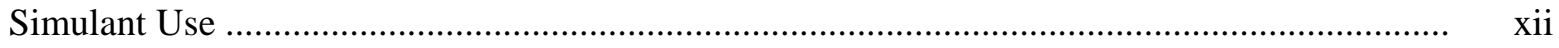

Discrepancies and Follow-on Tests .................................................................................. xii

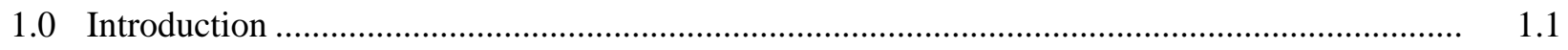

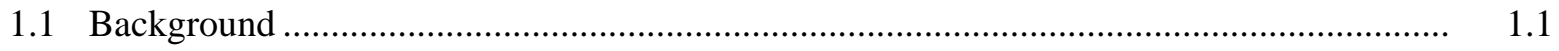

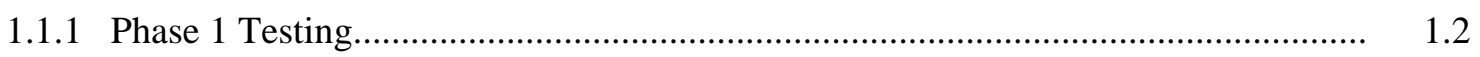

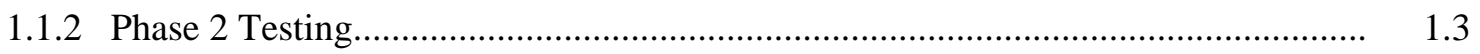

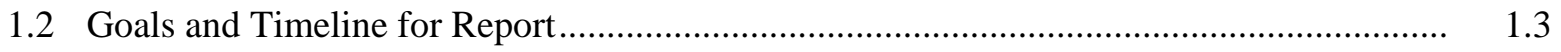

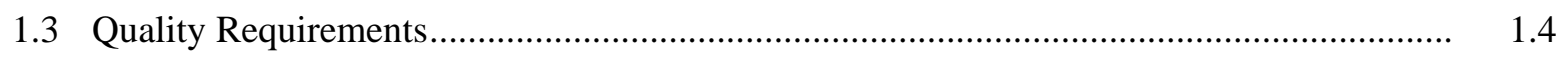

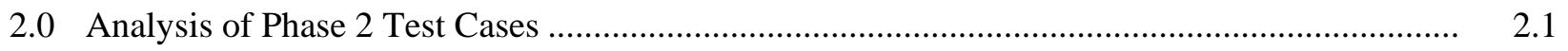

2.1 Test Cases Considered ............................................................................................... 2.1

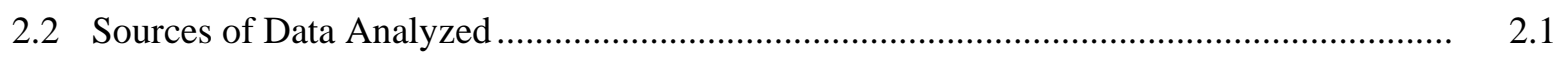

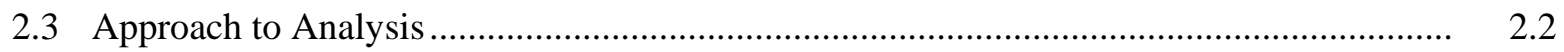

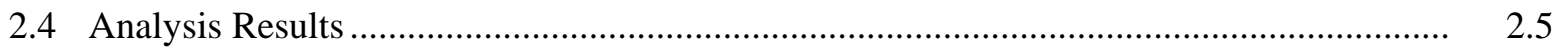

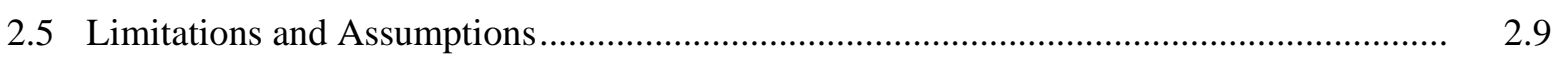

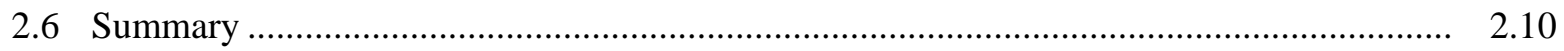

3.0 Comparison of Phase 1 and Phase 2 Data ......................................................................... 3.1

3.1 Overview of Phase 1 Test Conditions ........................................................................

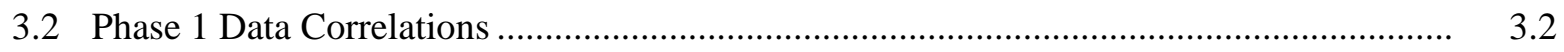

3.3 Phase 1 Predictions versus Observations …................................................................... 3.3

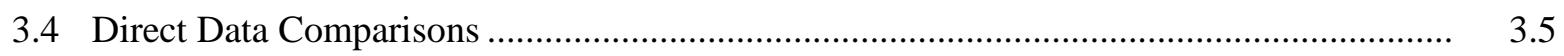

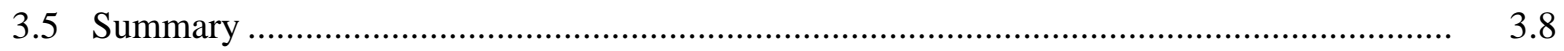

4.0 Assessment of Non-Prototypic Attributes of Phase 1 Testing.................................................

4.1 Overview of Key Differences in Testing ......................................................................... 4.1

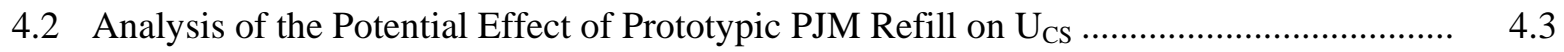

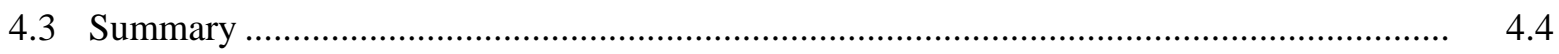

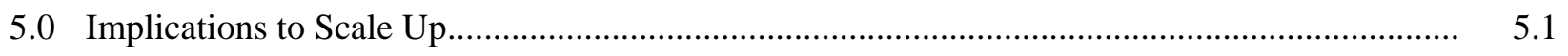

5.1 Summary of Scale-Up Data from Phase 1 Correlations ..................................................... 
5.2 Phase 1 Direct Scale-Up Data .................................................................................... 5.2

5.3 Phase 1 Concentration Data Scale-Up............................................................................ 5.5

5.4 Scale-up Behavior with Prototypic PJM Operation …..................................................... 5.8

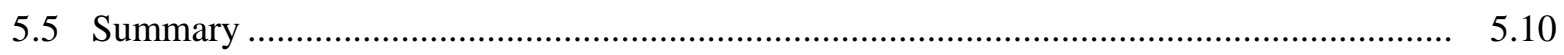

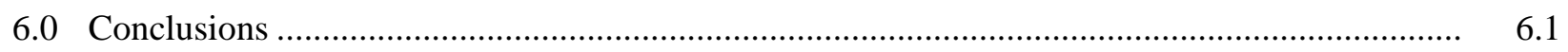

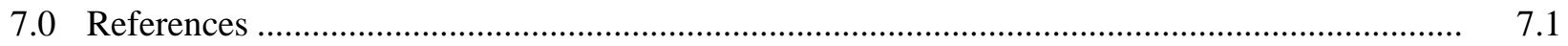

Appendix A - Peak-Average Nozzle Velocities for Phase 2 Test Sequences .................................. A.1

Appendix B - Correlations from Pulse Jet Mixing Tests with Noncohesive Solids........................... B.1

Appendix C - New Physical Model........................................................................................... C.1

Appendix D - Adjusted Settling Velocity ........................................................................... D. 1

Appendix E - Bench Marking the Adjusted New Physical Model with Prototypic Drive Tests.......... E.1

\section{Figures}

3.1 Comparing Test Sequence 3 Measured U Us Directly Against Closest Phase 1 Test Case............ 3.7

3.2 Comparing Test Sequence 13FV1 Measured $U_{\mathrm{CS}}$ Directly Against Closest Phase 1 Test Case.

5.1 Demonstrating the Dependence of the Scale-up Exponent for $\mathrm{U}_{\mathrm{CS}}$ on Solids Loading ................ 5.4

5.2 The Dependence of the Scale-up Exponent for $\mathrm{H}_{\mathrm{CS}}$ on Solids Loading .................................... 5.4

5.3 The Dependence of the Scale-up Exponent for $\mathrm{H}_{\mathrm{CS}} / \mathrm{D}$ on Solids Loading ................................ 5.4

5.4 Centerline Concentration Profiles at $\mathrm{U}_{\mathrm{CS}}$ for Matched Test Cases in the 15- and 70-in. Vessel.

5.5 Scale-up Exponent Dependence on $\mathrm{U}_{\mathrm{CS}}$ for the New Physical Model with Modified Settling Velocity for Conditions Corresponding to Test Sequence 3 and Test Sequence 13FV1

5.6 Predicted $U_{\mathrm{CS}}$ Versus Vessel Scale for the New Physical Model with Modified Settling Velocity for Conditions Corresponding to Test Sequence 3 and Test Sequence 13FV1.

\section{Tables}

S.1 Summary of Test Objectives and Results .......................................................................... ix

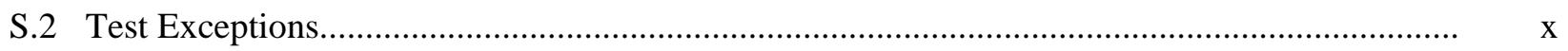

S.3 Deviations from Test Specification ……............................................................................

S.4 Results and Performance Against Success Criteria …........................................................... $\mathrm{x}$

S.5 PETD Test Conditions..................................................................................................... xii

2.1 Phase 2 Data Used in This Report …….................................................................................. 2.2

2.2 Sources Used for Phase 2 Parameters ......................................................................................... 2.3 
2.3 Summary of Data from Test Sequence 1, 8-Tube PJM Array …................................................ 2.6

2.4 Summary of Data from Test Sequence 3, 8-Tube PJM Array ….............................................. 2.7

2.5 Summary of Data from Test Sequence 13FV1, 12-Tube PJM Array ......................................... 2.8

3.1 Test Parameter Ranges during M3 Phase 1 Testing ................................................................

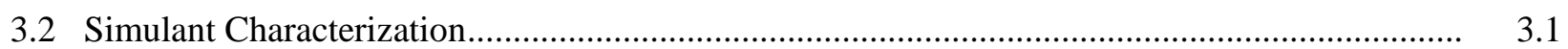

3.3 Phase 1 Data Correlation Summary ……............................................................................. 3.2

3.4 Phase 2 Test Conditions for Use in Applying Phase 1 Correlations ........................................... 3.4

3.5 Predicted $\mathrm{U}_{\mathrm{CS}}$ Values Compared with Observed Values for Phase 2 Tests ................................. 3.5

3.6 Closest Matched Test Cases Used for Direct Data Comparisons between Phase 1 and

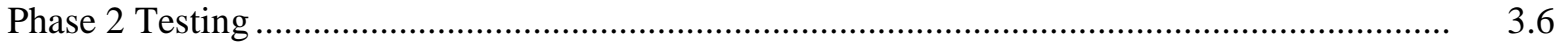

3.7 Closest Matched Test Cases Used for Direct Data Comparisons between Phase 1 and

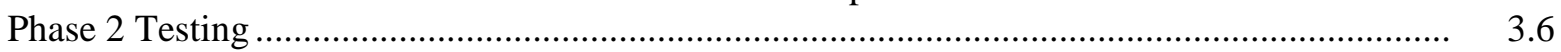

4.1 Results of Using the Adjusted Settling Velocity U”

5.1 Scale-up Exponents from the Various Data Correlations of the Phase 1 M3 Data Set ............... 5.1

5.2 Matched Test Conditions in the 15-in. and 70-in Vessel......................................................... 5.2

5.3 Measured Values of $\mathrm{U}_{\mathrm{CS}}$ and $\mathrm{H}_{\mathrm{CS}}$ and Their Corresponding Scale-up Exponents...................... 5.3

5.4 Test Conditions at $\mathrm{U}_{\mathrm{CS}}$ in the 15-in. and 70-in Vessel Where Concentration Profiles

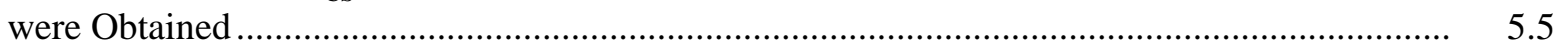





\subsection{Introduction}

This report compares the results of the Phase 1 M3 Pulse Jet Mixing (PJM) Tests with Non-cohesive Solids conducted by Pacific Northwest National Laboratory (PNNL) (Meyer et al. 2009) with the Phase 2 Prototypic Drive Pulse Jet Mixing Test conducted by Energy Solutions.

PNNL conducted the Phase 1 M3 tests during FY 2007 and 2008 to support the design of the mixing systems for the Hanford Waste Treatment and Immobilization Plant (WTP). Tests were conducted at three geometric scales using non-cohesive simulants. PNNL used the test data to develop new mixing models that can be used to predict the mixing performance of full-scale WTP vessels and to assess mixing system designs compared with performance requirements.

The Phase 2 tests were conducted by Energy Solutions at the Mid-Columbia Engineering facility at Horn Rapids Business Center in Richland, Washington. The Phase 2 test system had a functionally prototypic PJM drive system installed in a single 44-in.-diameter test vessel.

\subsection{Background}

The WTP at the Hanford Site is being designed and built to pretreat and vitrify a large portion of the waste stored in Hanford's 177 underground waste storage tanks. Several process vessels will hold the waste at various processing stages in the WTP. These vessels have the mixing ${ }^{1}$ system requirements to maintain conditions in which hydrogen gas accumulation stays below acceptable limits, and the mixing within the vessels is sufficient to ensure that pump transfer and normal operations occur reliably (Olsen 2008).

Some of the WTP process streams are slurries of solid particles suspended in Newtonian fluids that may behave as non-Newtonian slurries. The effects of large particles and rapidly settling slurries may affect mixing and the ability of the slurry to maintain particles in suspension.

WTP uses PJM technology for slurry mixing applications requiring solids suspension, solids mixing, fluid blending, and release of hydrogen gas. PJMs are driven by jet pump pairs (JPPs) that use compressed air as the motive force. The suction phase draws process liquid into the PJM from the vessel. The drive phase pressurizes the PJMs via a JPP. This pressurization discharges the PJM liquid at high velocity into the vessel causing mixing to occur. The drive phase is followed by the vent phase, which allows for depressurization of the PJM by venting through the JPP into the pulse jet vent system. These three phases (suction, drive, and vent) make up the mixing cycle.

The PJMs can be operated in a continuous pulsing mode (e.g., all PJMs on during normal operation) or can be turned off for a time and restarted in the pulsing mode [e.g., for some post-design basis event (DBE) scenarios, vessels that use the 50/50 mixing rack design will only have half their PJMs operational], depending on process requirements. In vessels that contain particulates, solids will settle to the bottom between mixing periods. When the PJMs restart, the settled solids must be resuspended.

${ }^{1}$ Mixing refers to the mobilization and subsequent suspension of undissolved solids within a vessel. Mixing can have varying results: 1) a fully mixed vessel where the solids concentration is uniform throughout the vessel, 2) a partially mixed vessel where there is a solids concentration gradient that is higher at the bottom of the vessel, or 3) a poorly mixed vessel where the solids are disturbed but remain on or near the bottom of the vessel. 
Prior to the start of the Phase 1 tests, Bechtel National, Inc. (BNI) had assessed PJM resuspension capabilities using two available methods. One method used a BNI-controlled proprietary correlation; the other used an approach recommended by Atomic Energy Authority of United Kingdom (AEA) called the "Bathija Off-Bottom Method" (Bathija 1982). Prior to the start of the Phase 1 tests, BNI determined that the proprietary resuspension correlation was the best method available at the time to evaluate potential risks with current PJM mixing system designs. ${ }^{1}$

In October 2005, an External Flowsheet Review Team (EFRT) consisting of experts from industry, national laboratories, and universities was assembled by BNI to conduct a thorough, in-depth review of the process flowsheet for the design of the WTP. Seven issues identified from their review (Smith 2007) were considered relevant to the mixing process. Of those seven issues, M3 is the last to be resolved:

- Issue M3 - Inadequate Design of Mixing Systems-Pulse Jet Mixers: Issues were identified related to mixing system designs that will result in insufficient mixing and/or extended mixing times. These issues include a design basis that discounts the effects of large particles and of rapidly settling Newtonian slurries. There is also insufficient testing of the selected designs.

In response to Issue M3 - Inadequate Design of Mixing Systems-Pulse Jet Mixers, BNI issued Test Specification 24590-PTF-TSP-RT-06-007 (Smith 2007) defining a test program to resolve the PJM issue. Phase 1 tests were conducted to close issues related to mixing system designs that could result in insufficient mixing and/or extended mixing times. These issues included a design basis that discounted the effects of large particles and of rapidly settling Newtonian slurries. After the completion of the Phase 1 tests, Phase 2 tests were started. The Phase 2 tests were conducted with a functionally prototypic drive system installed in a single 44 -in.-diameter test vessel.

\subsubsection{Phase 1 Testing}

The Phase 1 test specification called for performing geometrically scaled tests with simulants to generate data for developing models of vessel mixing performance. The models were used to assess the PJM design basis for WTP vessels. As part of Project No. 53023, PNNL generated Test Plan TP-RPP-WTP-480 (Elmore et al. 2007) ${ }^{2}$ for conducting scaled tests.

In order to expedite the test program, simplified geometries and mixing systems were employed. These simplifications included:

- closed-loop intermittent jet operation instead of pneumatically driven pulse tubes

- straight pipe “pulse tubes” instead of larger ID (inner diameter) prototypic pulse tubes

- straight nozzle sections instead of conical nozzles.

${ }^{1}$ The proprietary method is essentially a correlation of data from small-scale, steady jet mixing tests. While it represented the best available data available at that time for assessing PJM off-bottom suspension capability in solids-containing vessels, the correlation does not specifically account for the effects of pulsation or nozzle geometry. In addition, the correlation database does not cover the range of particle sizes in Hanford waste.

2 Elmore MR, CW Enderlin, and PA Meyer. July 2007. M3 Testing Approach in Support of Tank HLP-22 Issues. TP-RPP-WTP-480, Pacific Northwest National Laboratory, Richland, Washington. 
A parametric test approach was used whereby geometric, operational, and physical test variables were varied over a range of conditions which, in most cases, bracketed the conditions of the prototypic mixing systems in the WTP.

Data for solids cloud height $\left(\mathrm{H}_{\mathrm{C}}\right)$ and off-bottoms suspension velocity $\left(\mathrm{U}_{\mathrm{CS}}\right)$ were collected over a wide range of conditions. Limited data for solids vertical distribution were also collected. The data were correlated by various means to produce mixing models which in turn could be applied to the plant mixing systems as a means to evaluate mixing system adequacy.

The design-basis particle characteristics for mixing have been documented in Wells et al. (2007). These results were used to develop noncohesive simulants for testing PJM vessel mixing. Results of the Phase 1 testing are documented in Meyer et al. (2009).

\subsubsection{Phase 2 Testing}

At the completion of Phase 1 testing, a functionally prototypic PJM drive system and broad particle size distribution simulants were identified as important factors for inclusion in the next step in testing. A new system and program were developed by WTP Process Engineering \& Technology Department (PETD) using Energy Solutions as the prime contractor with TKS (Tessenderlo Kerley Services, Carlsbad, NM) as the system construction contractor and Mid-Columbia Engineering (MCE) as the test facility and test operator. The early test results from the Phase 2 functionally prototypic PJM drive system with mono-disperse and broad particle size distribution simulants indicated different trends in $\mathrm{U}_{\mathrm{CS}}$ than were expected from the WTP PETD application of the correlations in Meyer et al. (2009). Hence, WTP asked PNNL to review the results of the Phase 2 testing performed by Energy Solutions to understand the apparent discrepancy between predicted and actual performance.

\subsection{Goals and Timeline for Report}

There are two primary goals for this work. The first goal is to evaluate the apparent discrepancy between measured values of $U_{C S}$ from Phase 1 and Phase 2 testing in order to 1) determine the magnitude of the difference, and 2) identify the source(s) of the difference. The second goal is to address the applicability of applying the Phase 1 scale-up laws to Phase 2 test results.

This report and investigation was directed by Contractor Change Notice 207178 from Bechtel National, Inc. ${ }^{1}$ The scope of the investigation is:

\section{SCN-099 - M3 Data Reconciliation Scope}

"PNNL will conduct a study to reconcile the apparent data difference between the PNNL Phase 1 M3 test data and the subsequent M3 data obtained at MCE and WSU. More specifically, compared to the MCE/WSU data, the PNNL data appears to under predict the jet velocity needed to obtain off-bottom suspension. Initial analysis by the BNI M3 team indicates a similar functionality but a bias in the mean value. Reconciliation of this difference will aid the use of scaling equations which

${ }^{1}$ Hazen, HR to GH Beeman. Letter October 21, 2009. “Contract No. DEAC27-01RV14136 - Hanford Tank Waste Treatment and Immobilization Plant, Memorandum of Agreement (MOA), 24590-QL-HC-WA49-00001, PNNL R\&T Support, Lifting Suspension for WA28 SCN99,” Bechtel National, Inc., Richland, Washington. 
are planned for use by the BNI M3 team. The PNNL team will have access to all data including any initial analysis done by the BNI M3 team. If the bias cannot be resolved, potential factors should be suggested and sensitivity analysis conducted. In addition to the BNI M3 team, Dr. Dickey, M3 Consultant, will aid the analysis.”

The deliverables included:

- A draft analysis which was provided by October 31, 2009.

- A presentation of the data which was made at the November 4 and 5, 2009 BNI M3 meeting.

The draft version of this report was provided in January 2010. The February 26, 2010 delivery date for the final report was waived by W.L. Tamosaitis so technical staff could focus on supporting Phase 2 testing.

No test objectives were specified for this work.

\subsection{Quality Requirements}

The quality requirements for this report were established in the SCN-99 and SCN-100 combined Proposal. ${ }^{1}$ The proposed requirements related to this report are as follows:

- All of the subtasks in SCN-099 and SCN-100 are categorized as technology level "Basic Research" in accordance with the WTPSP QA Program.

- The revised QA Plan is included in Attachment F [Waste Treatment Plant Support Program Quality Assurance Plan QA-WTPSP-0001, Rev. 0.0]. This QA Plan is a continuation of QA Plan RPP-WTP-QA-001, Rev 3.0. To distinguish the former QA program and implementing procedures from this revision, the project name and document nomenclature have been changed. Effective December 1, 2009, the program was renamed to Waste Treatment Plant Support Program (WTPSP), and this QA Plan was issued under a new document number.

The Pacific Northwest National Laboratory (PNNL) Quality Assurance Program is based upon the requirements as defined in the United States Department of Energy (DOE) Order 414.1C, Quality Assurance and 10 CFR 830, Energy/Nuclear Safety Management, Subpart A -- Quality Assurance Requirements (a.k.a. the Quality Rule). PNNL has chosen to implement the following consensus standards in a graded approach:

- ASME NQA-1-2000, Quality Assurance Requirements for Nuclear Facility Applications, Part 1, Requirements for Quality Assurance Programs for Nuclear Facilities.

- ASME NQA-1-2000, Part II, Subpart 2.7, Quality Assurance Requirements for Computer Software for Nuclear Facility Applications.

- ASME NQA-1-2000, Part IV, Subpart 4.2, Graded Approach Application of Quality Assurance Requirements for Research and Development.

1 Beeman, GH to HR Hazen. Letter November 19, 2009. "Subcontract No: 24590-QL-HC9-WA49-00001 SCN-100 Rev 0 (WA\#2009-028), Proposal.” WTP/RPP-MOA-PNNL-00466, Pacific Northwest National Laboratory, Richland, Washington. 
The procedures necessary to implement the requirements are documented through PNNL's HDI (“How Do I...?”) ${ }^{1}$

All work done by the laboratory in support of this report before December 1, 2009 was conducted to QA Plan RPP-WTP-QA-001, and all work completed on or after December 1, 2009 was completed using the Waste Treatment Plant Support Program Quality Assurance Plan, QA-WTPSP-0001, Rev. 0.0 Basic Research Stage of the Technology Life Cycle.

The Waste Treatment Plant Support Project Quality Assurance Manual (QA-WTPSP-0002) describes the technology life cycle stages under the Waste Treatment Plant Support Program Quality Assurance Plan (QA-WTPSP-0001). The technology life cycle includes the progression of technology development, commercialization, and retirement in process phases of basic and applied R\&D, engineering and production and operation until process completion. The life cycle is characterized by flexible and informal quality assurance activities in basic research, which becomes more structured and formalized through the applied R\&D stages.

- BASIC RESEARCH - Basic research consists of research tasks that are conducted to acquire and disseminate new scientific knowledge. During basic research, maximum flexibility is desired in order to allow the researcher the necessary latitude to conduct the research.

- APPLIED RESEARCH - Applied research consists of research tasks that acquire data and documentation necessary to assure satisfactory reproducibility of results. The emphasis during this stage of a research task is on achieving adequate documentation and controls necessary to be able to reproduce results.

- DEVELOPMENTAL WORK - Development work consists of research tasks moving toward technology commercialization. These tasks still require a degree of flexibility, and there is still a degree of uncertainty that exists in many cases. The role of quality on development work is to make sure that adequate controls to support movement into commercialization exist.

- RESEARCH AND DEVELOPMENT SUPPORT ACTIVITIES - Support activities are those which are conventional and secondary in nature to the advancement of knowledge or development of technology, but allow the primary purpose of the work to be accomplished in a credible manner. An example of a support activity is controlling and maintaining documents and records. The level of quality for these activities is the same as for developmental work.

${ }^{1}$ A web based system for managing the delivery of laboratory-level policies, requirements and procedures. 



\subsection{Analysis of Phase 2 Test Cases}

Three Phase 2 test sequences were selected for analysis in this report; the basis for their selection is described in Section 2.1. Sources of Phase 2 test data used for analysis are listed in Section 2.2. Analysis methodology and results are summarized in Sections 2.3 and 2.4, respectively. Limitations of the analysis approach are discussed in Section 2.5.

The initial steps in the effort to reconcile Phase 2 test results with earlier Phase 1 test results were to look for any major sources of discrepancy in the following: 1) the controlling parameters needed for predicting $U_{\mathrm{CS}}$ at center, 2) the actual nozzle velocities achieved in Phase 2 tests, and 3) the visual determination of $\mathrm{U}_{\mathrm{CS}}$ at center as reported in test observations.

\subsection{Test Cases Considered}

The Phase 2 tests chosen for analysis were those tests where simulant and geometric parameters were the most directly comparable to those used in Phase 1 tests. The simulants represent two types of glass bead simulants used in Phase 1 tests. The geometry factors in the Phase 2 tests selected are also closely matched to those for the 8- and 12- tube arrays used in Phase 1 tests (with slight differences in jet densities $\left.\left[\phi_{\mathrm{J}}\right]\right)$. Thus, the tank fill heights $(\mathrm{H})$ used are approximately 0.7-1.0 H/D (D is the tank diameter) as used in Phase 1 tests, and no flow modifications, such as the addition of flow diverters or bubblers, were made to the tank in the Phase 2 tests selected. The Phase 2 test sequences selected were 8-tube array tests $1 \mathrm{~A}, 1 \mathrm{~B}, 3 \mathrm{D}$, and 3E, and 12-tube array tests 13FV1A and 13FV1B. The operating parameters, such as pulse volume fraction $\left(\phi_{p}\right)$ and duty cycle (DC), used in the selected Phase 2 tests fall within the range of parameters tested in Phase 1 but are not generally direct matches.

\subsection{Sources of Data Analyzed}

Phase 2 test data analyzed was taken from written test documentation, videos and DAS (data acquisition system) files from the raw data packages. Of the selected tests, only Test Sequence 1 data had been presented in a final test report at the time the authors received the data. Geometry data from the client were taken from level correlation data, PJM assembly design drawings, email exchanges and PNNL as-built measurements (recorded in laboratory record book LRB-59732). Data from the client has generally been accepted at face value, without concern regarding its QA review status. Specific sources of information supplied by the client and used for this report are listed in the Table 2.1. 
Table 2.1. Phase 2 Data Used in This Report

\begin{tabular}{|c|c|}
\hline $\begin{array}{l}\text { Type of } \\
\text { Information }\end{array}$ & Description of Client-Supplied Data \\
\hline \multirow[t]{3}{*}{ Geometry } & $\begin{array}{l}\text { PJM assembly design drawings for 8-tube and 12-tube arrays, drawing numbers P2-042V201-1 } \\
\text { (Sheets 1-4) and P2-042V201-2 (Sheets 1-4). }\end{array}$ \\
\hline & $\begin{array}{l}\text { Email from S Thompson to PA Meyer, 10/23/2009, with tank geometry summary (included the } \\
\text { design drawings listed). }\end{array}$ \\
\hline & $\begin{array}{l}\text { Level probe correlation data for each test array: "M3 PJM Test Platform: Vessel V201 } \\
\text { Correlation Using Capacitance and Radar Instruments," RPT-5532-EG-0003, Rev. 1, 8/13/2009 } \\
\text { for 8-tube array; "Vessel Correlation } 12 \text { PJM.xls" (124 KB) in email from A Edmondson to } \\
\text { E Baer, 12/03/2009 for 12-tube array. }\end{array}$ \\
\hline \multirow[t]{18}{*}{$\begin{array}{l}\text { Test } \\
\text { Documentation }\end{array}$} & $\begin{array}{l}\text { "M3 PJM Test Platform: Test Report for Test Sequence 1,” TRPT-5532-OP-0001, Rev. 0, } \\
\text { 9/10/2009. }\end{array}$ \\
\hline & Data file: 090725_124443_01.csv, 28,503 KB, 7/25/2009. \\
\hline & Data file: 20090725_13-13-52.asf, 335,549 KB, 7/25/2009. \\
\hline & Data file: 090725_171945_03.csv, 40,422 KB, 7/25/2009. \\
\hline & Data file: 20090725_21-49-32.asf, 344,628 KB, 7/25/2009. \\
\hline & "Raw Data Package for M3 Test Platform Test Sequence No. 3D,” CCN 204512, 8/28/2009. \\
\hline & Data file: 090803_062131_01.csv, 22, 184 KB, 8/3/2009. \\
\hline & Data file: 20090803_07-05-01.asf, 299,774 KB, 8/3/2009. \\
\hline & "Raw Data Package for M3 Test Platform Test Sequence No. 3E,” CCN 204513, 8/28/2009. \\
\hline & Data file: 090803_095540_01.csv, 34,239 KB, 8/3/2009. \\
\hline & Data file: 20090803_10-40-00.asf, 276,711 KB, 8/3/2009. \\
\hline & "Raw Data Package for M3 Test Platform Test Sequence No. 13FV1A,” CCN 205115, 10/1/2009. \\
\hline & Copies of Test Record Attachments D-N for Test Sequences 13FV1A and 13FV1B. \\
\hline & Data file: 090906_012856_PROCESSED_01.csv, 21,733 KB, 9/6/2009. \\
\hline & Data file: 20090906_02-14-43.asf, 20,040 KB, 9/6/2009. \\
\hline & "Raw Data Package for M3 Test Platform Test Sequence No. 13FV1B," CCN 205110, 9/30/2009. \\
\hline & Data file: 090907_114805_PROCESSED_02.csv, 18,462 KB, 9/7/2009. \\
\hline & Data file: 20090907_13-44-09.asf, 23,244 KB, 9/7/2009. \\
\hline \multirow[t]{2}{*}{ Other } & $\begin{array}{l}\text { A Edmondson, draft version of "Accuracy of Significant M3 Operating Test Parameters," } \\
\text { 11/23/2009; particularly the discussion, in Section 6, of the effect of apparent time delay in the } \\
\text { laser data signal on calculated PJM velocity. }\end{array}$ \\
\hline & $\begin{array}{l}\text { "S1D2 PSD.doc," table summarizing S1D2 particle size distribution (PSD) data from Phase } 2 \\
\text { testing, email from S Thompson, 11/2/2009. Note: PSD data from each test is also included in } \\
\text { test documentation. }\end{array}$ \\
\hline
\end{tabular}

\subsection{Approach to Analysis}

Table 2.2 summarizes the approach used to determine a "best estimate" of the actual values of key parameters used in Phase 2 tests. While some parameters are simply taken from the most reliable source available to the authors, others such as the operational parameters were acquired by standard analysis methods. 
Table 2.2. Sources Used for Phase 2 Parameters

\begin{tabular}{|c|c|}
\hline Parameters Used & Description of Method or Source \\
\hline \multicolumn{2}{|l|}{ Geometry } \\
\hline Vessel diameter (D) & $\begin{array}{l}\text { Estimated actual value taken from PNNL as-built measurement prior to } \\
\text { delivery to BNI (LRB 59732); refers to vessel inner diameter. Values } \\
\text { indicated in Phase } 2 \text { test documentation tend to vary somewhat. }\end{array}$ \\
\hline Nozzle diameter (d) & $\begin{array}{l}\text { Values indicated in client-supplied design drawings; refers to nozzle inner } \\
\text { diameter. }\end{array}$ \\
\hline \multicolumn{2}{|l|}{ Simulant } \\
\hline Solids diameter ( $\left.\mathrm{d}_{50 \text { (by volume) }}\right)$ & $\begin{array}{l}\text { Values taken from Meyer et al. (2009). See Section } 2.5 \text { for further } \\
\text { discussion. }\end{array}$ \\
\hline Solids specific gravity (s) & $\begin{array}{l}\text { Values taken from Meyer et al. (2009). No values are reported in the } \\
\text { Phase } 2 \text { test documentation. }\end{array}$ \\
\hline Solids fraction $\left(\phi_{\mathrm{S}}\right)$ & $\begin{array}{l}\text { Calculated on reference volume basis from simulant mass in test log or } \\
\text { run sheet and solids specific gravity (s). Note that Phase } 2 \text { documentation } \\
\text { uses the slurry volume basis (volume based on fill height) for calculating } \\
\text { volumetric parameters. }\end{array}$ \\
\hline \multicolumn{2}{|l|}{ Operating Parameters } \\
\hline Pulse volume fraction $\left(\phi_{\mathrm{p}}\right)$ & $\begin{array}{l}\text { Calculated on reference volume basis using stroke length from DAS level } \\
\text { or pressure data and tank geometry. Note that Phase } 2 \text { documentation } \\
\text { uses the slurry volume basis (volume based on fill height) for calculating } \\
\text { volumetric parameters. }\end{array}$ \\
\hline Duty cycle (DC) & $\begin{array}{l}\text { Calculated from drive and cycle times determined from DAS level or } \\
\text { pressure data. Drive time determined from portion of cycle for which } \\
\text { nozzle velocity is positive. }\end{array}$ \\
\hline Velocity: manual check (U) & $\begin{array}{l}\text { Manual method of nozzle velocity check from test documentation. } \\
\text { Checked values only at } 60 \text { minutes of mixing. }\end{array}$ \\
\hline Velocity: peak average ( $\left.\mathrm{U}_{\mathrm{PA}}\right)$ & $\begin{array}{l}\text { Calculated from DAS data by numerical differentiation of PJM or tank } \\
\text { level versus time or from pressure data using the Bernoulli equation with } \\
\text { flow loss (however no flow loss is assumed during drive in order to } \\
\text { approximate a bounding nozzle velocity), and standard atmospheric } \\
\text { pressure is assumed above the open tank. Tank geometry data is used to } \\
\text { determine cross-sectional area ratios used in these calculations. }\end{array}$ \\
\hline \multicolumn{2}{|l|}{ Measured Parameters } \\
\hline $\mathrm{U}_{\mathrm{CS}}$ at center & $\begin{array}{l}\text { This is the critical suspension velocity at the tank bottom center. Test } \\
\text { documentation records nominal nozzle discharge velocity at which center } \\
\text { clearing was observed; examination of available test video showed } \\
\text { particle motion in excess of that considered to be } U_{\mathrm{CS}} \text { at center for } \\
\text { Phase } 1 \text { testing. Therefore, } U_{\mathrm{CS}} \text { at center is considered to occur between } \\
\text { the velocity for center clearing and the next lower velocity (where settled } \\
\text { solids remain at the tank center at the end of the PJM drive). }\end{array}$ \\
\hline
\end{tabular}


Calculations of the operating parameters and peak-average nozzle velocity from DAS level and pressure data were performed in the same manner as used by S. Yokuda for the PJM analyses of data obtained during pretreatment tests (Kurath et al. 2009). These methods averaged DAS data for ten PJM cycles to reduce the effects of noise and individual cycle variations. Choosing an appropriate and stable period of PJM operation for analysis is important. Thus, we attempted to examine the video (viewed from the bottom of the tank) at or near the time that mixing observations were recorded and then used DAS data from the observation time period for analysis. If mixing observations were not recorded at the target velocity of interest, the end of the one-hour mixing period was used to ensure that tank conditions were stable and video and DAS data from that time were analyzed.

For the operating parameters calculated from DAS level and pressure data, each source of data has advantages and disadvantages (see plots in Appendix A). For duty cycle calculations, pressure data is considered to be the best source as it most closely represents the driving force experienced by the fluid, and the velocity curve is much smoother than that produced from differentiation of the level data signals. For pulse volume fraction (from stroke length) and peak-average nozzle velocity calculations, level data is considered the best, most direct data source and does not depend on the assumptions inherent in the use of the Bernoulli equation. However, velocity acquired from the numerical differentiation of level data is vulnerable to the amplification of noise and other sources of signal error. PJM level varies over a greater range during the cycle than does tank level, and therefore is less susceptible to noise issues; so in general, PJM level would be the preferred source for pulse volume fraction and peak-average nozzle velocity.

The observer instructions for identifying the $\mathrm{U}_{\mathrm{CS}} \mathrm{cen}$ (Phase 1) metric, the Off-bottom Suspension (Phase 2) metric, and the $\mathrm{U}_{\mathrm{CS}} \mathrm{cen}$ metric for Phase 2 determined by PNNL are below.

\section{Phase 1 Ucs Metric Definition}

Phase 1 used two $\mathrm{U}_{\mathrm{CS}}$ metrics: the first was established by visual observation; and the second used the settled solids layer thickness determined by the Ultrasonic Dopler velocimetry (UDV) instrumentation. The instructions from Phase 1 are documented in Meyer (2009). Visual observations were conducted by trained PNNL staff and were recorded during testing along with documentation of the operating conditions (including velocity) and time from the NQA-1 Data Acquisition System. The visual observation $\mathrm{U}_{\mathrm{CS}}$ cen condition was determined using the following criteria:

Particle Motion Descriptors for Visual Observations - The observers recorded one of four particle motion descriptors to describe the conditions observed for a given test velocity. Critical suspension at tank center, $U_{C S} c e n$, (condition \#2 from Table 5.6 , Meyer 2009) was the initial state of complete solids suspension (all particles moving off bottom) occurring at the center of the tank at the end of the fluid pulse while unsuspended particles may exist elsewhere on tank bottom. It should be noted that for the 70 inch tank, this was the default condition when clearing was observed at the center through the view port; it could not be assumed that all particles were suspended over the entire tank bottom. However, in testing with the 34 inch vessel, Condition 2 was rarely observed, rather it was typical for the tank center to be the last place for solids suspension to occur during the fluid pulse. Overall critical suspension (Condition \#3) was the initial state for which complete suspension occurred over the entire tank bottom at the end of the fluid pulse. 


\section{Phase 2 EnergySolutions’ Off-Bottom Suspension Metric}

Energy Solutions used the Off-bottom Suspension metric that was documented in M3-PJM Test Platform Test Sequence 2 - PJM Mixing Performance with G(70-24) Simulant in Test Vessel \#2 (V201). ${ }^{1}$ The metric is established by visual observation only. The metric is defined as follows:

Off-bottom suspension is achieved if there are no settled solids on the bottom of the Test Vessel and the solids on the bottom of the vessel do not move as a coherent bed. By looking at a video display of the bottom of the Test Vessel, determine whether suspension is achieved.

\section{Phase 2 Pacific Northwest National Laboratory Review to Establish the $\mathrm{U}_{\mathrm{cs}}$ Metric}

The Pacific Northwest National Laboratory used the following instructions to conduct the review to establish the $\mathrm{U}_{\mathrm{CS}} \mathrm{Cen}$ metric for Phase 2 tests. Since instrumentation was not available for the Phase 2 testing, the $\mathrm{U}_{\mathrm{CS}} \mathrm{cen}$ metric was established by visual observation only.

PNNL trained visual observers watched the videos from the vessel bottom camera with time stamps. The $\mathrm{U}_{\mathrm{CS}} \mathrm{cen}$ condition was determined using the following criteria:

Particle Motion Descriptors for Visual Observations - Critical suspension, $\mathrm{U}_{\mathrm{CS}} \mathrm{cen}$ at tank center, is the initial state for which complete solids suspension (all moving off bottom) occurs at the center of the tank at the end of the fluid pulse while unsuspended particles may exist elsewhere on tank bottom. [This is Condition \#2 from Table 5.6 (Meyer 2009).]

When $\mathrm{U}_{\mathrm{CS}} \mathrm{cen}$ (or near $\mathrm{U}_{\mathrm{CS}} \mathrm{cen}$ ) conditions were observed, the time was documented. The velocity and operating conditions for the observed period of time were then recovered from the Test Instructions and the data acquisition system.

\subsection{Analysis Results}

The results of our analyses of the Phase 2 test data are summarized in Tables 2.3, 2.4, and 2.5. Test values reported in the Phase 2 test documentation are given in the left-hand column of data, labeled "Indicated Values." DAS data from test vessel probe readings of PJM level, tank level, and PJM pressure were each used to calculate pulse volume fraction, duty cycle, and peak-average nozzle velocity; these results are given in the columns indicated by the data source. In the far right-hand column, "Phase 1 Equivalent Value" shows the values the authors found from calculations and review of test documents to best represent the actual values; these are the values that are used for correlation input values.

It should be noted that for Test Sequences 1 and 3, PJM level data is affected by overfilling of the PJMs, which produces a non-linear region of level data at the beginning of the drive cycle. The result is a non-physical spike in the nozzle velocities calculated for the start of the drive; hence, PJM level data is not used to determine estimated actual values of pulse volume fraction $\left(\phi_{\mathrm{p}}\right)$ and peak average velocity for these tests.

$1 \quad$ Watson, N. July 2009. M3-PJM Test Platform Test Sequence 2 - PJM Mixing Performance with G(70-24)

Simulant in Test Vessel \#2 (V201). TPR-5532-OP-0003 Rev 0, Bechtel National Incorporated, Richland, Washington. 
Table 2.3. Summary of Data from Test Sequence 1, 8-Tube PJM Array

\begin{tabular}{|c|c|c|c|c|c|}
\hline $\begin{array}{l}\text { Test Sequence } 1 \\
\text { (8-tube array) }\end{array}$ & $\begin{array}{l}\text { Indicated } \\
\text { Value }\end{array}$ & $\begin{array}{c}\text { Values } \\
\text { from PJM } \\
\text { Level Data }\end{array}$ & $\begin{array}{c}\text { Values from } \\
\text { Tank Level } \\
\text { Data }\end{array}$ & $\begin{array}{c}\text { Values from } \\
\text { PJM Pressure } \\
\text { Data }\end{array}$ & $\begin{array}{l}\text { Phase } 1 \\
\text { Equivalent } \\
\text { Value }\end{array}$ \\
\hline \multicolumn{6}{|l|}{ Geometry } \\
\hline Vessel diameter (in.), D & 43.2 & & & & 43.31 \\
\hline Pulse tube outer diameter (in.), $\mathrm{D}_{\mathrm{PT}}$ & 6.625 & & & & 6.625 \\
\hline Nozzle diameter (in.), d & 0.655 & & & & 0.655 \\
\hline \multicolumn{6}{|l|}{ Simulant } \\
\hline Solids diameter $(\mu \mathrm{m}), \mathrm{d}_{50 \text { (by volume) }}$ & $\mathrm{n} / \mathrm{a}$ & & & & 178.0 \\
\hline Solids specific gravity, s & $\mathrm{n} / \mathrm{a}$ & & & & 2.45 \\
\hline Solids fraction, $\phi_{\mathrm{S}}$ & 0.0075 & & & & 0.0072 \\
\hline
\end{tabular}

1A Target Velocity $=8 \mathrm{~m} / \mathrm{s}$

\begin{tabular}{|l|c|c|c|c|c|}
\hline \multicolumn{7}{|l|}{ Operating Parameters } \\
\hline Pulse volume fraction, $\phi_{\mathrm{p}}$ & 0.0915 & 0.096 & 0.081 & 0.093 & 0.081 \\
\hline Duty cycle, DC & 0.32 & 0.294 & 0.338 & 0.307 & 0.307 \\
\hline Velocity: manual check (m/s), U & n/a & -- & -- & -- & -- \\
\hline Velocity: peak average (m/s), $\mathrm{U}_{\mathrm{PA}}$ & n/a & 7.86 & 8.02 & 8.47 & 8.02 \\
\hline
\end{tabular}

1B Target Velocity $=9 \mathrm{~m} / \mathrm{s}$

\begin{tabular}{|c|c|c|c|c|c|}
\hline \multicolumn{6}{|l|}{ Operating Parameters } \\
\hline Pulse volume fraction, $\phi_{\mathrm{p}}$ & 0.0915 & 0.097 & 0.080 & 0.093 & 0.080 \\
\hline Duty cycle, DC & 0.32 & 0.330 & 0.391 & 0.350 & 0.350 \\
\hline Velocity: manual check (m/s), U & $\mathrm{n} / \mathrm{a}$ & -- & -- & -- & -- \\
\hline Velocity: peak average (m/s), $\mathrm{U}_{\mathrm{PA}}$ & $\mathrm{n} / \mathrm{a}$ & 8.42 & 8.18 & 8.59 & 8.18 \\
\hline $\mathrm{U}_{\mathrm{CS}}$ at center $(\mathrm{m} / \mathrm{s})$ & 9 & -- & -- & -- & $8.0-8.2$ \\
\hline
\end{tabular}


Table 2.4. Summary of Data from Test Sequence 3, 8-Tube PJM Array

\begin{tabular}{|c|c|c|c|c|c|}
\hline $\begin{array}{l}\text { Test Sequence } 3 \\
\text { (8-tube array) }\end{array}$ & $\begin{array}{l}\text { Indicated } \\
\text { Value }\end{array}$ & $\begin{array}{c}\text { Value from } \\
\text { PJM Level } \\
\text { Data }\end{array}$ & $\begin{array}{c}\text { Value from } \\
\text { Tank Level } \\
\text { Data }\end{array}$ & $\begin{array}{c}\text { Value from } \\
\text { PJM Pressure } \\
\text { Data }\end{array}$ & $\begin{array}{l}\text { Phase } 1 \\
\text { Equivalent } \\
\text { Value }\end{array}$ \\
\hline \multicolumn{6}{|l|}{ Geometry } \\
\hline Vessel diameter (in.), D & 43.2 & & & & 43.31 \\
\hline Pulse tube outer diameter (in.), $\mathrm{D}_{\mathrm{PT}}$ & 6.625 & & & & 6.625 \\
\hline Nozzle diameter (in.), d & 0.655 & & & & -- \\
\hline \multicolumn{6}{|l|}{ Simulant } \\
\hline Solids diameter $(\mu \mathrm{m}), \mathrm{d}_{50}$ (by volume) & 65.4 & & & & 69.3 \\
\hline Solids specific gravity, s & $\mathrm{n} / \mathrm{a}$ & & & & 2.48 \\
\hline Solids fraction, $\phi_{\mathrm{S}}$ & 0.015 & & & & 0.0138 \\
\hline
\end{tabular}

3D Target Velocity $=7 \mathrm{~m} / \mathrm{s}$

\begin{tabular}{|l|c|c|c|c|c|}
\hline \multicolumn{7}{|l|}{ Operating Parameters } \\
\hline Pulse volume fraction, $\phi_{\mathrm{p}}$ & 0.0915 & 0.098 & 0.083 & 0.096 & 0.083 \\
\hline Duty cycle, DC & 0.32 & 0.311 & 0.354 & 0.327 & 0.327 \\
\hline Velocity: manual check (m/s), U & 6.7 & -- & -- & -- & 6.7 \\
\hline Velocity: peak average (m/s), U & n/a & 6.52 & 6.72 & 7.01 & 6.72 \\
\hline
\end{tabular}

3E Target Velocity $=8 \mathrm{~m} / \mathrm{s}$

\begin{tabular}{|c|c|c|c|c|c|}
\hline \multicolumn{6}{|l|}{ Operating Parameters } \\
\hline Pulse volume fraction, $\phi_{\mathrm{p}}$ & 0.0915 & 0.090 & 0.077 & 0.091 & 0.077 \\
\hline Duty cycle, DC & 0.32 & 0.301 & 0.352 & 0.320 & 0.320 \\
\hline Velocity: manual check (m/s), U & 7.6 & -- & -- & -- & 7.6 \\
\hline Velocity: peak average $(\mathrm{m} / \mathrm{s}), \mathrm{U}_{\mathrm{PA}}$ & $\mathrm{n} / \mathrm{a}$ & 7.49 & 7.79 & 7.94 & 7.79 \\
\hline $\mathrm{U}_{\mathrm{Cs}}$ at center $(\mathrm{m} / \mathrm{s})$ & 8 & -- & -- & -- & $6.7-7.8$ \\
\hline
\end{tabular}


Table 2.5. Summary of Data from Test Sequence 13FV1, 12-Tube PJM Array

\begin{tabular}{|c|c|c|c|c|c|}
\hline $\begin{array}{c}\text { Test Sequence 13FV1 } \\
\text { (12-tube array) }\end{array}$ & $\begin{array}{l}\text { Indicated } \\
\text { Value }\end{array}$ & $\begin{array}{l}\text { Value from } \\
\text { PJM Level } \\
\text { Data }^{(\mathrm{a})}\end{array}$ & $\begin{array}{c}\text { Value from } \\
\text { Tank Level } \\
\text { Data }\end{array}$ & $\begin{array}{c}\text { Value from PJM } \\
\text { Pressure } \\
\text { Data }\end{array}$ & $\begin{array}{c}\text { Phase } 1 \\
\text { Equivalent } \\
\text { Value }\end{array}$ \\
\hline \multicolumn{6}{|l|}{ Geometry } \\
\hline Vessel diameter (in.), D & $42.3-43.2$ & & & & 43.31 \\
\hline Pulse tube outer diameter (in.), $\mathrm{D}_{\mathrm{PT}}$ & 5.563 & & & & 5.563 \\
\hline Nozzle diameter (in.), d & 0.379 & & & & -- \\
\hline \multicolumn{6}{|l|}{ Simulant } \\
\hline Solids diameter $(\mu \mathrm{m}), \mathrm{d}_{50 \text { (by volume) }}$ & 65.4 & & & & 69.3 \\
\hline Solids specific gravity, s & $\mathrm{n} / \mathrm{a}$ & & & & 2.48 \\
\hline Solids fraction, $\phi_{\mathrm{S}}$ & 0.015 & & & & 0.0086 \\
\hline
\end{tabular}

13FV1A Target velocity $=6 \mathrm{~m} / \mathrm{s}$

\begin{tabular}{|l|c|c|c|c|c|}
\hline \multicolumn{7}{|l|}{ Operating Parameters } \\
\hline Pulse volume fraction, $\phi_{\mathrm{p}}$ & 0.081 & 0.047 & 0.044 & 0.052 & 0.047 \\
\hline Duty cycle, DC & 0.236 & 0.243 & 0.260 & 0.248 & 0.248 \\
\hline Velocity: manual check (m/s), U & 5.9 & -- & -- & - & 5.9 \\
\hline Velocity: peak average (m/s), U & n/a & 5.91 & 5.93 & 6.45 & 5.91 \\
\hline
\end{tabular}

13FV1B Target velocity $=13 \mathrm{~m} / \mathrm{s}$

\begin{tabular}{|l|c|c|c|c|c|}
\hline Operating Parameters \\
\hline Pulse volume fraction, $\phi_{\mathrm{p}}$ & 0.081 & 0.048 & 0.042 & 0.050 & 0.048 \\
\hline Duty cycle, DC & 0.236 & 0.290 & 0.344 & 0.290 & 0.290 \\
\hline Velocity: manual check (m/s), U & 11.1 & -- & -- & - & 11.7 \\
\hline Velocity: peak average (m/s), U $\mathrm{PA}_{\mathrm{PA}}$ & $\mathrm{n} / \mathrm{a}$ & 11.92 & 11.32 & 12.28 & 11.92 \\
\hline
\end{tabular}

\begin{tabular}{|c|c|c|c|c|c|}
\hline $\mathrm{U}_{\mathrm{CS}}$ at center ${ }^{(\mathrm{b})}$ & 10 & -- & -- & -- & $8.3-9.9$ \\
\hline
\end{tabular}

Notes

(a) PJM level correlation data taken for the 12-tube array shows a bias that is $2 \%$ high compared to a standard tape measure. We have not corrected for this in the table; the correction would lower PVF values shown by $0.1 \%$, and the velocities would become $5.79 \mathrm{~m} / \mathrm{s}$ and $11.67 \mathrm{~m} / \mathrm{s}$ respectively for Sequences 13FV1A and 13FV1B.

(b) In the prior cases examined, Test Sequences 1 and 3, full test data was available for $\mathrm{U}_{\mathrm{Cs}}$ at center and the next lower velocity, which in this case would have been at $10 \mathrm{~m} / \mathrm{s}$ and $9 \mathrm{~m} / \mathrm{s}$ respectively. Therefore the range of estimated actual $U_{C S}$ velocities is interpolated from the available data for target velocities of $6 \mathrm{~m} / \mathrm{s}$ and $13 \mathrm{~m} / \mathrm{s}$. 
Three main discrepancies between the indicated and the estimated actual values in Tables 2.3, 2.4, and 2.5 were:

- calculation of the volumetric parameters (solids fraction and pulse volume fraction) were based on actual tank fill level in the test documentation, while the estimated actual values are calculated on reference volume basis ${ }^{1}$ as is expected in the correlation (for fill heights near $\mathrm{H} / \mathrm{D}=1$ the values do not change significantly; in the cases examined above, only parameters in Table 2.5 show large differences when calculated on reference volume basis);

- the indicated target nozzle velocity tends to be higher than the nozzle velocity actually achieved in the test, particularly at the higher test velocities (this tendency is also evident in the manual velocity checks performed in testing);

- based on video of particle motion on the tank bottom during testing, we found that the Phase 2 test observers' reporting of center clearing by the end of the pulse was at higher velocities than would have been reported for $\mathrm{U}_{\mathrm{CS}}$ at center in the Phase 1 tests.

The last two differences contribute to the reporting of elevated Phase 2 values for $\mathrm{U}_{\mathrm{CS}}$ at center. There is also the discrepancy in the definition used for $\mathrm{U}_{\mathrm{CS}}$ between Phase 2 and Phase 1: we have used the term " $U_{\mathrm{CS}}$ at center" to refer to the critical suspension velocity definition used in Phase 1 , to try to avoid confusion; $\mathrm{U}_{\mathrm{CS}}$ as used in Phase 2 documentation only refers to the condition when by the end of the pulse no solids remain on any portion of the tank bottom out to the wall. This is well beyond the velocity required for $U_{\mathrm{CS}}$ at center. In Test Sequence $13 \mathrm{FV} 1$, it was reported that $\mathrm{U}_{\mathrm{CS}}$ was not achieved even at the $13 \mathrm{~m} / \mathrm{s}$ target velocity, while center clearing was reported at the $10 \mathrm{~m} / \mathrm{s}$ target velocity (the 8-tube array tests analyzed did not show this large of a difference between the velocity for center clearing and $\left.\mathrm{U}_{\mathrm{CS}}\right)$.

\subsection{Limitations and Assumptions}

There are a number of limitations to this analysis, in the approach or in the data used, which should be acknowledged. The authors are grateful to Scott Thompson and Al Edmonson for their discussions of a number of data issues encountered in the Phase 2 tests; these include the Phase 2 particle size distribution (PSD) results, and issues affecting PJM level data from the 8-tube array tests and internal averaging of the tank radar signal.

In Phase 2, PSD analysis results from grab and flow-loop samples show an apparent shift in PSD for the s1d2 simulant for particles larger than $\mathrm{d}_{50}$; the shift is apparent for Test Sequence 13FV1, but not in earlier Phase 2 tests with s1d2 simulant. This remains an unresolved issue. We have chosen to use the particle size $d_{50}$ values from Meyer et al. (2009) and feel these results best represent the bulk simulant PSD.

1 Note that $\mathrm{U}_{\mathrm{CS}}$ values predicted from the correlation are directly proportional to solids concentration, but inversely proportional to pulse volume fraction; these changes tend to off set each other somewhat. Therefore, predicted $U_{\mathrm{CS}}$ values are not strongly affected by the different volumetric basis used in reporting the Phase 2 parameter values. 
An issue affecting DAS level data in early 8-tube array cases is also discussed in Section 2.4: PJMs were filled past the cylindrical section and past the calibrated region of the capacitance probes, leading to overestimation of the actual level and nozzle velocity early in the PJM drive (the effects on velocity can be seen in the plots shown in Appendix A). Thus PJM level data was not considered for calculating pulse volume fraction or peak average nozzle velocity for Test Sequences 1 and 3.

A more general issue affects the tank radar level data, namely internal signal averaging within the probe. This will tend to reduce the tank stroke length by smoothing out the level extremes. Peak nozzle velocities calculated from tank radar level will not be affected unless the drive time is too short. This is the case for Test Sequence 13FV1B, at $13 \mathrm{~m} / \mathrm{s}$, where the peak average velocity is clearly underestimated as seen in the plot in Appendix A.

\subsection{Summary}

Three Phase 2 test sequences were selected for analysis and comparison to Phase 1 test results on the basis of the similarity of the controlling parameters (geometric, simulant, and operational) to parameters used in Phase 1 tests. We looked for major sources of discrepancy in the following: 1) the controlling parameters needed for predicting $U_{\mathrm{CS}}$ at center, 2) the actual nozzle velocities achieved in Phase 2 tests, and 3) the visual determination of $U_{C S}$ at center as reported in test observations. Two major sources of discrepancy contributed to the reporting of elevated Phase 2 values for $U_{\mathrm{CS}}$ at center: 1) the nominal nozzle velocity tends to be higher than the nozzle velocity actually achieved in the test, particularly at the higher test velocities, and 2) the Phase 2 test observers' reporting of center clearing by the end of the pulse was at higher velocities than would have been reported for $\mathrm{U}_{\mathrm{CS}}$ at center in the Phase 1 tests.

Compounding these differences was a difference in the definition of the critical suspension velocity: $\mathrm{U}_{\mathrm{CS}}$ as used in Phase 2 documentation refers to the condition when by the end of the drive no solids remain on any portion of the tank head out to the wall, while the Phase 1 tests required the tank bottom center to be clear of solids by the end of the drive, here called " $\mathrm{U}_{\mathrm{CS}}$ at center." 


\subsection{Comparison of Phase 1 and Phase 2 Data}

In this section selected data collected during Phase 2 testing is compared with similar data collected during Phase 1 testing. An overview of the Phase 1 test conditions is presented in Section 3.1. Various correlations of the data are reviewed, and a new physical model correlation is presented in Section 3.2. The Phase 1 correlations are applied with the Phase 2 test conditions evaluated in Section 3.3. Additionally, direct comparisons of Phase 2 data with specific closely matched Phase 1 data are made in Section 3.4.

\subsection{Overview of Phase 1 Test Conditions}

Testing in Phase 1 was performed at three scales with a broad range of physical, geometric, and operational parameters. Table 3.1 summarizes the parameter ranges or nominal values during the Phase 1 tests.

Table 3.1. Test Parameter Ranges during M3 Phase 1 Testing

\begin{tabular}{lcl}
\hline \multicolumn{1}{c}{ Parameter } & Symbol & \multicolumn{1}{c}{ Values or Range } \\
\hline Vessel diameter (in.) & $\mathrm{D}$ & $147 / 16$ (nominal 15), 33 7/8 (nominal 34), 70 \\
Full-scale nozzle diameter (in.) & $\mathrm{d}$ & 4,6 \\
Number of jets & $\mathrm{N}$ & $4,8,12$ \\
Head shape & $\mathrm{HS}$ & Elliptical (E), flange and dish (F\&D), spherical (S) \\
Solids size $(\mu \mathrm{m})$ & $\mathrm{d}_{50}$ & $43.9,69.3,75.6,89.5,164.2,166.4,178.0,766.2$ \\
Density $\left(\mathrm{g} / \mathrm{cm}^{3}\right)$ & $\rho_{\mathrm{S}}$ & $2.45,2.46,4.18$ \\
Solids fraction (concentration) & $\phi_{\mathrm{S}}=\left(\mathrm{V}_{\mathrm{S}} / \mathrm{V}_{\mathrm{REF}}\right) ;$ & $0.0005,0.00155,0.005,0.01,0.0143,0.015,0.03,0.045$, \\
& $\mathrm{V}_{\mathrm{REF}}=\pi \mathrm{D}^{3} / 4$ & 0.06 \\
Pulse volume fraction & $\phi_{\mathrm{p}}=\left(\mathrm{N} \mathrm{V}_{\mathrm{P}} / \mathrm{V}_{\mathrm{REF}}\right)$ & $0.05,0.1,0.15$ \\
Duty cycle & $\mathrm{DC}$ & $0.18,0.33,0.5,0.66,1$ \\
Discharge Velocity $(\mathrm{m} / \mathrm{s})$ & $\mathrm{U}$ & $1-16.1 \mathrm{~m} / \mathrm{s}$ \\
\hline
\end{tabular}

Tests were conducted using seven simulants summarized in Table 3.2.

Table 3.2. Simulant Characterization

\begin{tabular}{cccllr}
\hline $\begin{array}{c}\text { Simulant } \\
\text { Designation }\end{array}$ & $\begin{array}{c}\text { Density } \\
\mathrm{g} / \mathrm{cm}^{3}\end{array}$ & $\begin{array}{c}\text { Packing } \\
\text { Fraction }\end{array}$ & \multicolumn{1}{c}{ Vendor } & \multicolumn{1}{c}{ Product } & $\begin{array}{c}\mathrm{d}_{50} \\
\mu \mathrm{m}\end{array}$ \\
\hline s1d1 & 2.46 & 0.59 & XLSciTech & XLSL150180 & 166.4 \\
s1d2 & 2.48 & 0.63 & XLSciTech & XLSL063075 & 69.3 \\
s1d5 & 2.50 & 0.60 & XLSciTech & XLSL038063 (sieved <45 $\mu \mathrm{m})$ & 43.9 \\
s2d1 & 4.17 & 0.60 & XLSciTech & XLHD150180 & 164.2 \\
s2d2 & 4.18 & 0.63 & XLSciTech & XLHD067080 & 75.6 \\
p1d8 & 2.45 & 0.57 & Potters & Ballotine - 12 & 89.5 \\
p1d7 & 2.45 & 0.57 & Potters & Ballotine - 8 & 178.0 \\
p2d6 & 2.46 & 0.59 & Potters & Ballotine - 3 & 766.2 \\
\hline
\end{tabular}


Tests were conducted using three head shapes at three scales ( $\mathrm{S}=$ small, $\mathrm{M}=$ =medium, $\mathrm{L}=$ large) where only a subset of head shapes was tested at each scale: elliptical (S, L), spherical (M), and flange and dish $(\mathrm{F} \& \mathrm{D})(\mathrm{L})$.

\subsection{Phase 1 Data Correlations}

Several different correlations of the Phase 1 data are presented in Meyer et al. (2009). These correlations are summarized in Appendix B and C of this report, listed in Table 3.3, and are briefly described below.

Table 3.3. Phase 1 Data Correlation Summary

\begin{tabular}{|c|c|c|c|c|}
\hline Correlation & $\begin{array}{c}\text { Critical Suspension } \\
\text { Velocity } \\
\mathrm{U}_{\mathrm{CS}}\end{array}$ & $\begin{array}{c}\text { Cloud } \\
\text { Height } \\
\mathrm{H}_{\mathrm{C}}\end{array}$ & $\begin{array}{c}\text { Solids Concentration at } \\
\text { Tank Bottom } \\
\mathrm{C}_{0}\end{array}$ & $\begin{array}{c}\text { Concentration as a } \\
\text { Function of Elevation } \\
\mathrm{C}(\mathrm{Z})\end{array}$ \\
\hline Physical Model & Eq. B.1 & Eq. B.2 & Eq. B.3 & Eq. B.4 \\
\hline Dimensional Model & Eq. B.7 & Eq. B.8 & NA & NA \\
\hline Generalized Model & Eq. B.5 & Eq. B.6 & NA & NA \\
\hline Interaction Model & Eq. B.9 & Eq. B.10 & NA & NA \\
\hline New Physical Model & Eq. B.11 & Eq. B.12 & Eq. B.13 & Eq. B.14 \\
\hline
\end{tabular}

Physical Model - developed based on hydrodynamic behavior. The hydrodynamic behavior observed in a scaled system is related to the behavior that would be observed in the full-scale system because the behavior in both systems is controlled by the same physical laws.

Dimensional Model - developed based on a reduced model which removed statistically insignificant terms. Because the model is dimensional it resulted in a dimensional constant with units that differ from those of the subsumed physical constants.

Generalized Model - developed based on multiple regression analysis of the data. The generalized model establishes the relationship in the experimental data between a response variable (y) and multiple predictor variables $\left(\mathrm{x}_{1}, \mathrm{x}_{2}, \ldots \mathrm{x}_{\mathrm{n}}\right)$. The predictor variables are developed based on dimensionless groups formed systematically as products or ratios of subsets of dimensional variables.

Interaction Model (not used in this analysis) - developed to include interactions between predictor variables. Interaction terms may improve the predictive performance of mixing models within the region of experimental data. However, models with interaction terms can yield inaccurate predictions when extrapolated significantly outside the experimental region of data used to develop them.

New Physical Model - developed based on hydrodynamic behavior. The new physical model includes the Fall 2007 data set which included a limited number of tests with 4 and 8 jets. It was determined that the fit of cloud height $\left(\mathrm{H}_{\mathrm{C}}\right)$ model to the complete data set was significantly improved by simply introducing into the $\mathrm{H}_{\mathrm{C}}$ physical model the number of operating tubes $(\mathrm{N})$ as an unconstrained correlating parameter in the model. 


\subsection{Phase 1 Predictions versus Observations}

In this section the Phase 1 correlations for $\mathrm{U}_{\mathrm{CS}}$ are applied to the test conditions of the selected Phase 2 tests. Table 3.4 summarizes the relevant test conditions discussed in Section 2. The ranges shown for duty cycle (DC) and pulse volume fraction $\left(\phi_{\mathrm{p}}\right)$ correspond to the values calculated for the various test sequences for which the measured $U_{\mathrm{CS}}$ condition was met. Table 3.5 shows the results predicted by the correlations, together with our estimates of the observed $U_{\mathrm{CS}}$ values. For the 8-tube cases (case 1 and case 3), the predicted values from the new physical model correlation are about $40 \%$ lower than the Phase 2 test values. For the 12-tube case (Test Sequence 13FV1) the predicted values from the new physical model correlation are about $30 \%$ lower. 
Table 3.4. Phase 2 Test Conditions for Use in Applying Phase 1 Correlations

\begin{tabular}{|c|c|c|c|c|c|c|c|c|c|c|c|c|}
\hline $\begin{array}{c}\text { Test } \\
\text { Sequence }\end{array}$ & $\begin{array}{c}\text { Tank } \\
\text { Diameter } \\
\text { D } \\
\text { (in.) }\end{array}$ & $\begin{array}{c}\text { Jet } \\
\text { Diameter } \\
\mathrm{d} \\
\text { (in.) }\end{array}$ & $\begin{array}{c}\text { Number } \\
\text { of Pulse } \\
\text { Tubes } \\
\text { N } \\
(-)\end{array}$ & $\begin{array}{c}\text { Solids } \\
\text { Diameter } \\
\mathrm{d}_{\mathrm{s}} \\
(\mu \mathrm{m})\end{array}$ & $\begin{array}{c}\text { Density } \\
\text { Ratio } \\
\text { S } \\
(-)\end{array}$ & $\begin{array}{c}\text { Viscosity } \\
\mu \\
(\mathrm{cP})\end{array}$ & $\begin{array}{c}\text { Galileo } \\
\text { Number } \\
\text { Ga } \\
(-)\end{array}$ & $\begin{array}{c}\text { Terminal } \\
\text { Settling } \\
\text { Velocity } \\
\mathrm{U}_{\mathrm{T}} \\
(\mathrm{m} / \mathrm{s})\end{array}$ & $\begin{array}{c}\text { Ratio of Solids } \\
\text { Volume to } \\
\text { Reference Volume } \\
\phi_{\mathrm{S}} \\
(-)\end{array}$ & $\begin{array}{c}\text { Pulse } \\
\text { Volume } \\
\phi_{\mathrm{p}} \\
(\%)\end{array}$ & $\begin{array}{c}\text { Duty Cycle } \\
\text { DC } \\
(\%)\end{array}$ & $\begin{array}{c}\text { Jet } \\
\text { Density } \\
\phi_{\mathrm{J}} \\
(-)\end{array}$ \\
\hline 1 & 43.3 & 0.655 & 8 & 178 & 2.45 & 0.001 & 80.2 & 0.0167 & 0.720 & $8.0-8.1$ & $30.7-35.0$ & 0.0018 \\
\hline 3 & 43.3 & 0.655 & 8 & 69.3 & 2.48 & 0.001 & 4.83 & 0.0034 & 1.38 & 7.7-8.3 & $32.0-32.7$ & 0.0018 \\
\hline 13FV1 & 43.3 & 0.379 & 12 & 69.3 & 2.48 & 0.001 & 4.83 & 0.0034 & 0.864 & $4.7-4.8$ & $24.8-29.0$ & 0.0009 \\
\hline
\end{tabular}


Table 3.5. Predicted $U_{C S}$ Values Compared with Observed Values for Phase 2 Tests

\begin{tabular}{cccccc}
\hline Test & $\begin{array}{c}\text { New Physical } \\
\text { Estimated Actual } \\
\text { Value } U_{\text {CS }} \\
(\mathrm{m} / \mathrm{s})\end{array}$ & $\begin{array}{c}\text { Podel Correlation } \\
\text { Prediction } \\
(\mathrm{m} / \mathrm{s})\end{array}$ & $\begin{array}{c}\text { Podel Correlation } \\
\text { Prediction } \\
(\mathrm{m} / \mathrm{s})\end{array}$ & $\begin{array}{c}\text { Dimensional } \\
\text { Model } \\
\text { Correlation } \\
\text { Prediction } \\
(\mathrm{m} / \mathrm{s})\end{array}$ & $\begin{array}{c}\text { Generalized } \\
\text { Model Correlation } \\
\text { Prediction } \\
(\mathrm{m} / \mathrm{s})\end{array}$ \\
\hline 1 & $8.0-8.2$ & $4.9-5.1$ & $5.1-5.3$ & $4.6-4.7$ & $5.2-5.3$ \\
3 & $6.7-7.8$ & $4.4-4.5$ & $4.6-4.7$ & $4.2-4.3$ & $4.5-4.6$ \\
$13 F V 1$ & $8.3-9.9$ & $6.6-7.0$ & $6.6-6.9$ & $6.4-6.7$ & $6.4-6.6$ \\
\hline
\end{tabular}

\subsection{Direct Data Comparisons}

It is evident from the preceding section that the Phase 1 correlations appear to under predict the values of $U_{\mathrm{CS}}$ observed in the Phase 2 tests. It is important to understand whether this difference is fundamental to the actual mixing performance or is an artifact of limitations of the correlations to accurately describe the Phase 2 test data.

To address this question, we sought to identify individual test cases from Phase 1 which closely matched the Phase 2 test conditions. Only Test Sequences 3 and 13FV1 were considered as there was no Phase 1 test which closely matched Test Sequence 1. Table 3.6 shows the closest matched test conditions from Phase 1 testing along with parameter values for Test Sequence 3. Data from Phase 1 are available for both the 15-in. and 70-in test vessels. To account for the minor differences in some of the parameter values, the Phase 1 values of $U_{\mathrm{CS}}$ were adjusted by applying the functionality from the new physical model correlation. As can be seen from Table 3.6, these adjusted values of $\mathrm{U}_{\mathrm{CS}}$ are approximately $10 \%$ lower than the original Phase 1 values.

Table 3.7 shows the closest matched test conditions with Test Sequence 13. Data from Phase 1 were again available for both the 15 -in. and 70 -in test vessels. The parameter values are quite close for these tests, and the adjustment procedure produced $U_{\mathrm{CS}}$ values approximately $3 \%$ higher than the original Phase 1 values. 
Table 3.6. Closest Matched Test Cases Used for Direct Data Comparisons Between Phase 1 and Phase 2 Testing

\begin{tabular}{|c|c|c|c|c|c|c|c|c|c|c|c|}
\hline Test Sequence & $\begin{array}{c}\text { Tank } \\
\text { Diameter } \\
\text { D } \\
\text { (in.) }\end{array}$ & $\begin{array}{c}\text { Jet } \\
\text { Diameter } \\
\mathrm{d} \\
\text { (in.) }\end{array}$ & $\begin{array}{c}\text { Number } \\
\text { of Pulse } \\
\text { Tubes } \\
\text { N } \\
(-)\end{array}$ & $\begin{array}{c}\text { Solids } \\
\text { Diameter } \\
d_{\mathrm{S}} \\
(\mu \mathrm{m})\end{array}$ & $\begin{array}{c}\text { Density } \\
\text { Ratio } \\
\text { S } \\
(-)\end{array}$ & $\begin{array}{c}\text { Ratio of Solids } \\
\text { Volume to } \\
\text { Reference } \\
\text { Volume } \\
\phi_{\mathrm{S}} \\
(\%)\end{array}$ & $\begin{array}{c}\text { Pulse } \\
\text { Volume } \\
\text { Fraction } \\
\phi_{\mathrm{p}} \\
(\%)\end{array}$ & $\begin{array}{l}\text { Duty } \\
\text { Cycle } \\
\text { DC } \\
(\%)\end{array}$ & $\begin{array}{c}\text { Jet } \\
\text { Density } \\
\phi_{J} \\
(-)\end{array}$ & $\begin{array}{c}\text { Critical } \\
\text { Suspension } \\
\text { Velocity } \\
\mathrm{U}_{\mathrm{CS}} \\
(\mathrm{m} / \mathrm{s})\end{array}$ & $\begin{array}{c}\text { Adjusted } \\
\text { Critical } \\
\text { Suspension } \\
\text { Velocity } \\
\mathrm{U}_{\mathrm{CS}} \text { adjusted } \\
(\mathrm{m} / \mathrm{s})\end{array}$ \\
\hline Average of 3A \& 3B & 43.3 & 0.655 & 8 & 69.3 & 2.48 & 1.38 & 8.0 & 32.4 & 0.0018 & 7.25 & - \\
\hline 15E8_6s1d2Vc_2 & 14.375 & 0.191 & 8 & 69.3 & 2.48 & 1.43 & 10.0 & 33.1 & 0.00138 & 4.4 & 4.0 \\
\hline 70E8_6s1d2Vc_2 & 70 & 0.92 & 8 & 69.3 & 2.48 & 1.43 & 10.0 & 33.1 & 0.00138 & 6.4 & 5.9 \\
\hline
\end{tabular}

Table 3.7. Closest Matched Test Cases Used for Direct Data Comparisons Between Phase 1 and Phase 2 Testing

\begin{tabular}{|c|c|c|c|c|c|c|c|c|c|c|c|}
\hline Test Sequence & $\begin{array}{c}\text { Tank } \\
\text { Diameter } \\
\text { D } \\
\text { (in.) }\end{array}$ & $\begin{array}{c}\text { Jet } \\
\text { Diameter } \\
d \\
\text { (in.) }\end{array}$ & $\begin{array}{c}\text { Number } \\
\text { of Pulse } \\
\text { Tubes } \\
\text { N } \\
(-)\end{array}$ & $\begin{array}{c}\text { Solids } \\
\text { Diameter } \\
\mathrm{d}_{\mathrm{S}} \\
(\mu \mathrm{m})\end{array}$ & $\begin{array}{c}\text { Density } \\
\text { Ratio } \\
\text { S } \\
(-)\end{array}$ & $\begin{array}{c}\text { Ratio of Solids } \\
\text { Volume to } \\
\text { Reference } \\
\text { Volume } \\
\phi_{\mathrm{S}} \\
(\%)\end{array}$ & $\begin{array}{c}\text { Pulse } \\
\text { Volume } \\
\text { Fraction } \\
\phi_{\mathrm{p}} \\
(\%)\end{array}$ & $\begin{array}{c}\text { Duty } \\
\text { Cycle } \\
\text { DC } \\
(\%)\end{array}$ & $\begin{array}{c}\text { Jet } \\
\text { Density } \\
\phi_{\mathrm{J}} \\
(-)\end{array}$ & $\begin{array}{c}\text { Critical } \\
\text { Suspension } \\
\text { Velocity } \\
\mathrm{U}_{\mathrm{CS}} \\
(\mathrm{m} / \mathrm{s})\end{array}$ & $\begin{array}{c}\text { Adjusted } \\
\text { Critical } \\
\text { Suspension } \\
\text { Velocity } \\
\mathrm{U}_{\mathrm{CS}} \text { adjusted } \\
(\mathrm{m} / \mathrm{s})\end{array}$ \\
\hline $\begin{array}{l}\text { Average of } \\
\text { 13FV1A \& 13FV1B }\end{array}$ & 43.3 & 0.379 & 12 & 69.3 & 2.48 & 0.86 & 4.8 & 26.9 & 0.0009 & 9.1 & -- \\
\hline 15E_4s1d2Rc_1 & 14.375 & 0.126 & 12 & 69.3 & 2.48 & 1.0 & 10.0 & 33.1 & 0.0009 & $5.3-5.4$ & $5.4-5.6$ \\
\hline 70E_4s1d2Rc_1 & 70 & 0.613 & 12 & 69.3 & 2.48 & 1.0 & 5.0 & 33.5 & 0.0009 & $6.6-7.2$ & $6.8-7.4$ \\
\hline
\end{tabular}


The results of these direct data comparisons for Test Sequences 3 and 13 are presented graphically in Figures 3.1 and 3.2, respectively. In each of the plots, the yellow circle symbol is the estimated $U_{\mathrm{CS}}$ value from the Phase 2 test. The brown square symbols are the closest matched data points from the Phase 1 tests, which have been slightly adjusted as previously described earlier in this section. The dashed red line represents a power-law interpolation between the 15-inch and 70-inch vessel diameter. The four solid lines represent the four correlations applied with the Phase 2 test conditions as inputs.

In both figures, we see the correlation results are fairly tightly grouped, with the measured Phase 2 value being well above the values predicted by the correlations. In Figure 3.1, the direct data interpolation is seen to also be above the correlation predictions. This suggests that the original correlations did not capture the 8-tube data well. This is reasonable since the amount of 8-tube test data was quite small in comparison to 12-tube data.

It is also clear that the Phase 2 data points are well outside the variability of the original correlations. For example, the new physical model predicted values within $\pm 27 \%$ of measured values for $95 \%$ of the test conditions. The Phase 2 data point for test sequence 3 is about $65 \%$ larger than the average of the Phase 1 correlations ( 4.4 m/s). The Phase 2 data point for test sequence $13 \mathrm{FV} 1$ is about $35 \%$ larger than the average of the Phase 1 correlations ( 6.7/s).

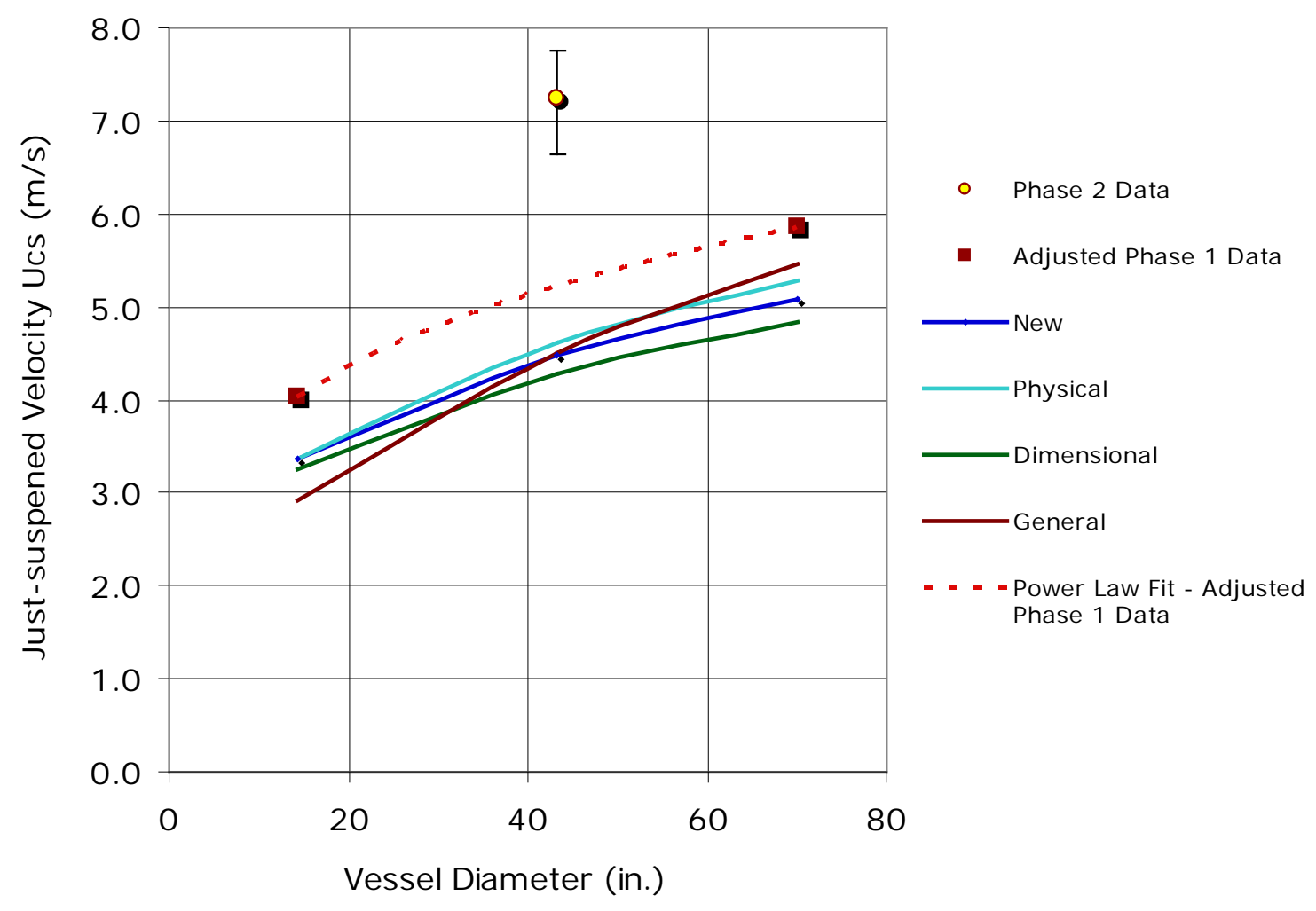

Figure 3.1. Comparing Test Sequence 3 (8 Pulse Tubes) Measured $U_{C S}$ Directly Against Closest Phase 1 Test Case. Also shown is a power-law curve fit between the the Phase 1 data, as well as the correlation predictions. 


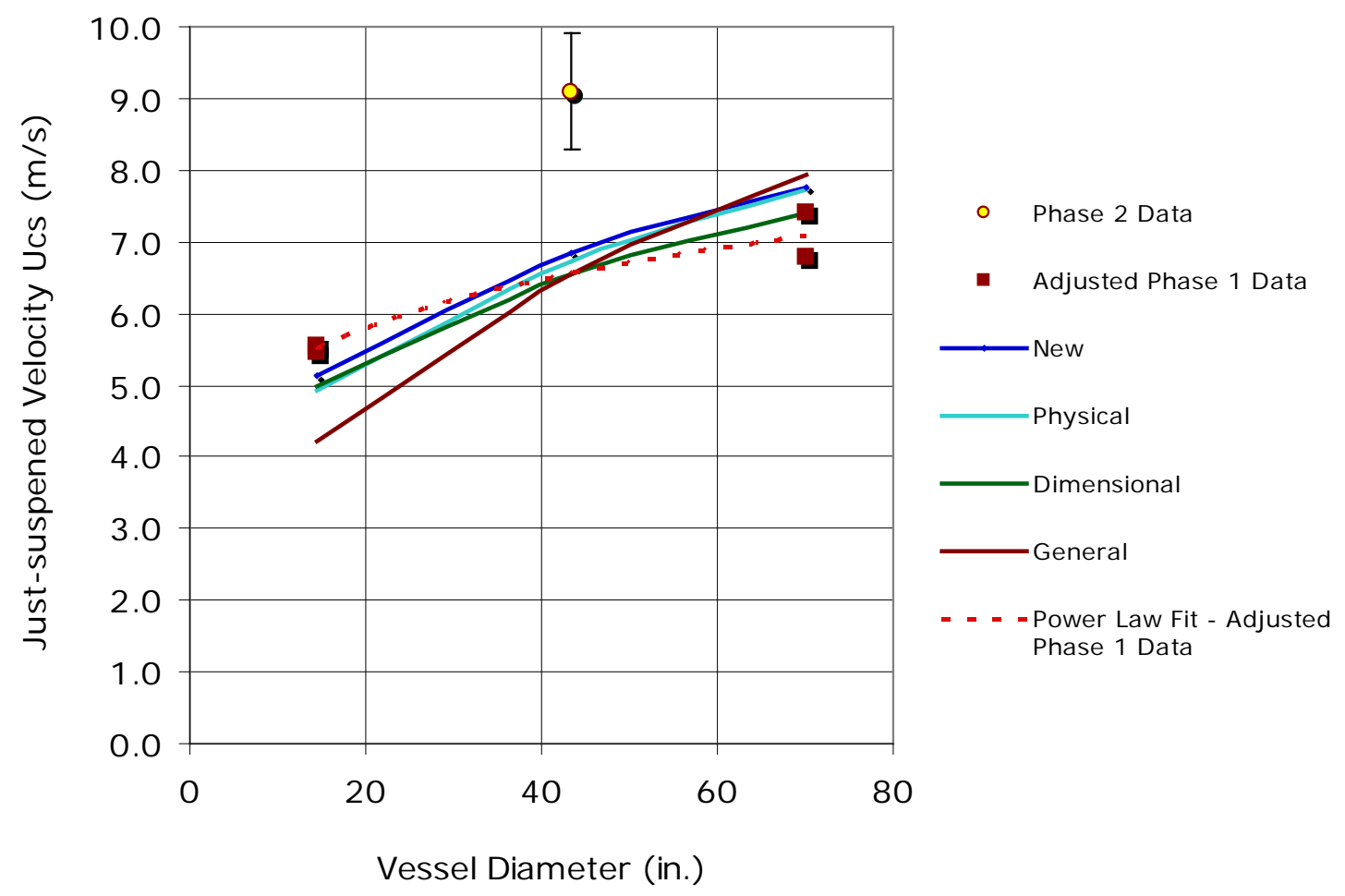

Figure 3.2. Comparing Test Sequence 13FV1 (12 Pulse Tubes) Measured $U_{\mathrm{CS}}$ Directly Against Closest Phase 1 Test Case. Also shown is a power-law curve fit between the the Phase 1 data, as well as the correlation predictions.

\subsection{Summary}

In this section we have established that the observed values of $\mathrm{U}_{\mathrm{CS}}$ for three Phase 2 test sequences are considerably higher than would be expected from Phase 1 testing. We have also established that this is not solely an artifact of data correlation limitations (how well the correlations predict the data from which they were derived). The correlations do appear to do a better job for geometries with twelve tubes than those with eight tubes, as would be expected due to the limited amount of 8-tube test data in Phase 1. However, direct data comparisons reveal that the difference between the Phase 1 and Phase 2 test results are fundamental to the actual test data, and not an artifact of the correlations of the data set. 


\subsection{Assessment of Non-Prototypic Attributes of Phase 1 Testing}

The testing equipment used to produce the data for Phase 1 had some features that were not prototypic of PJM mixing designs, and some of the differences would be expected to affect the data. This section reviews the assessment of the key differences and their potential impact on mixing.

\subsection{Overview of Key Differences in Testing}

Assessments of the effects of non-prototypic PJM operation were discussed in detail in the Phase 1 report (Meyer et al. 2009) and are summarized as follows:

- Jet slurry density: The jet slurry density during discharge will be higher with prototypic PJMs than with the pulse tubes tested, which discharged liquid only. Actual densities will be 5 to $10 \%$ higher with slurry being discharged from the PJM, as long as the designs are able to suspend solids. ${ }^{1}$ To estimate the effect of higher jet density, we can examine the effect of increased liquid density on $U_{C s}$ and $H_{C}$. For typical conditions, a $5 \%$ increase in density increases $\mathrm{U}_{\mathrm{CS}}$ by about $1 \%$ and decreases $\mathrm{H}_{\mathrm{C}}$ by about $3 \%$; hence, the effect of applying the models to prototypic systems which discharge slurries should be minor.

- Suction effects on flow-field: The flow field resulting from suction during the PJM refill has little effect on the mixing within the vessel. The induced velocity during suction at some distance (z) from the nozzle (with diameter, d) decreases away from the nozzle in proportion to $(\mathrm{d} / \mathrm{z})^{2}$; whereas, during discharge the velocity decreases by $(\mathrm{d} / \mathrm{z})$. When the relationship between drive and refill flow rates are considered, the ratio of the suction velocity to the jet velocity is approximately $[\mathrm{DC} /(1-\mathrm{DC})](\mathrm{d} / \mathrm{z})^{2}$, where DC is the duty cycle. For a $10.2-\mathrm{cm}$ (4-in.) nozzle and a $33 \%$ DC, the ratio is 0.02 at $50.8 \mathrm{~cm}$ (20 in.) from the nozzle. The suction-induced flow field becomes larger closer to the nozzle.

However, the area closest to the nozzle is also the area most impacted by the jet flow. Thus, the effect of disregarding the suction-induced flow field should be negligible in applying the models to prototypic systems which have refill suction.

- Nozzle geometry: Prototypic PJMs have conical nozzles, unlike the straight nozzles used for testing. The effect of nozzle geometry was explored by BNI using the FLUENT ${ }^{2}$ CFD model. Floor shear stress profiles were computed for both nozzle types. While there was some difference near the nozzle, far from the nozzle the differences were negligible. This finding is consistent with the wellaccepted observation that the detail of nozzle cross-section geometry is lost far from the orifice, with the hydraulic diameter being the controlling parameter. The effect of applying the models to prototypic systems that have conical nozzles should thus be negligible.

$1 \quad$ Actual jet density may be much higher for designs that are unable to suspend solids well. Hence high densities would be associated with inadequate designs, and the effect of higher jet densities would only exacerbate problems in those vessels. For vessels that mix well, the impact of this approximation would be relatively small.

2 http://www.fluent.com/. 
- Pulse tube outer diameter: Prototypic pulse tubes have much larger diameters than the straight pipes used during testing. There are two potential effects of this simplification to consider: flow-field effects and volumetric displacement effects. The effect of pulse tube diameter on the overall flow field in the vessel should be negligible. For off-bottom suspension, the primary flow is at the vessel bottom, beneath the nozzles, and is therefore unaffected by pulse tube diameter. For solids vertical distribution, the upwelling flow is important. The primary vertical flow occurs at the center of the vessel, with lesser upwells occurring between adjacent pulse tubes, particularly for the 12-tube designs. A useful parameter to consider is

$$
\phi_{\mathrm{PT}}=\mathrm{N}\left(\mathrm{D}_{\mathrm{PT}} / \mathrm{D}\right)^{2}
$$

where $\phi_{\mathrm{PT}}$ is the ratio of total pulse tube cross-sectional area to the vessel cross-sectional area and $\mathrm{D}_{\mathrm{PT}}$ is the pulse tube diameter. For the Waste Treatment Plant vessels, this ratio varies from 0.063 for vessel HOP-903/904 to 0.214 for vessel TCP-01. For the 12-tube array used in Phase 2 testing, the value is 0.2. If the upwelling flow is uniform and confined by the vessel diameter, the effect of an area reduction equivalent to this ratio would result in velocities increased by $\left(1-\phi_{\mathrm{PT}}\right)^{-1}$, corresponding to a velocity increase of about $25 \%$. However, the upwell flows are not uniform over the vessel diameter. The width of the upwell flows scales with nozzle diameter and is therefore much smaller than the vessel diameter. Hence, it is expected that actual increased upwell velocity associated with prototypic pulse tube outer diameters is much smaller than $\left(1-\phi_{\mathrm{PT}}\right)^{-1}$.

The potential magnitude of the displacement effect on solids vertical distribution associated with pulse tube diameter was estimated in Meyer et al. (2009), which suggests that cloud heights in vessels with prototypic operation could be increased by a factor of $\left(1-\phi_{\mathrm{PT}}\right)^{-1}$ due to the displacement effect of pulse tube outer diameter.

- Prototypic fill level: The results of Hicks, ${ }^{1}$ discussed in Section 2 of Meyer et al. (2009) demonstrate that $\mathrm{U}_{\mathrm{CS}}$ is insensitive to fill level when the solids loading is based on a reference volume and not the slurry volume. Similarly, cloud height is also insensitive to fill level as long as the cloud is below the fill level. It follows, therefore, that solids vertical distribution is also independent of fill level as long as the cloud is below the fill level. However, once the cloud reaches the fill level, the solids vertical distribution will depend on the fill level.

- Prototypic PJM refill: The vertical entrainment effect associated with the closed loop operation of the Phase 1 test apparatus was discussed in Section 7.6 of Meyer et al. (2009). It suggested that predicted cloud height for plant vessels will be lower than that predicted by the correlations, which were based on data from tests with entrainment. A modified settling velocity was introduced that was thought to be useful in quantifying this potential effect. The influence of artificial vertical entrainment on cloud height was recognized to be important, as evidenced by trends observable in the cloud height data. However, it was thought that there would be little effect, if any, on $U_{C S}$. The effect on $U_{C S}$ is reconsidered in Section 4.2.

$1 \quad$ Hicks MT and KJ Myers. 1993. "Cloud Height, Fillet Volume, and the Effect of Multiple Impellers in Solids Suspension.” MIXING XIV, Santa Barbara, Calif. Engineering Foundation, New York, and North American Mixing Forum. 


\subsection{Analysis of the Potential Effect of Prototypic PJM Refill on $U_{c s}$}

In analyzing the potential reasons for the discrepancy in Phase 1 and Phase 2 test results we have revisited the prototypic refill issue as a potential cause. The effects of enhanced vertical solids entrainment due to closed loop operation in Phase 1 can be illustrated in terms of a modified settling velocity. The direction of the effect is to make the settling velocity essentially smaller than if the jet operation were prototypic. A smaller settling velocity would result in a correspondingly smaller value of $\mathrm{U}_{\mathrm{CS}}$. Hence this effect potentially could explain the observed differences in Phase 1 and 2 test results.

The modified settling velocity was presented in Meyer et al. (2009) and is re-derived in Appendix D in more detail. The modified settling velocity $\left(\mathrm{U}_{\mathrm{TH}}{ }^{\prime}\right)$ is

$$
\mathrm{U}_{\mathrm{TH}}^{\prime}=\mathrm{U}_{\mathrm{TH}}-\frac{\phi_{\mathrm{J}} \mathrm{U}_{\mathrm{J}} \mathrm{DC}}{1-\phi_{\mathrm{PT}}}
$$

Equation (4.2) suggests that the effective settling velocity in the Phase 1 mixing systems is reduced by an amount that depends on the jet density $\left(\phi_{\mathrm{J}}\right)$, the pulse tube area ratio $\left(\phi_{\mathrm{PT}}\right)$, the duty cycle (DC), and the jet velocity (U).

In order to analyze the potential effect this may have on the test results, we apply the correlations taking Eq. (4.2) into consideration. Specifically, we express Eq. (4.2) as

$$
\mathrm{U}_{\mathrm{TH}}^{\prime \prime}=\mathrm{U}_{\mathrm{TH}}+\frac{\phi_{\mathrm{J}} \mathrm{U}_{\mathrm{J}} \mathrm{DC}}{1-\phi_{\mathrm{PT}}}
$$

where $\mathrm{U}_{\mathrm{TH}}^{\prime \prime}$ is substituted into the model in place of the settling velocity and then solved iteratively for $\mathrm{U}_{\mathrm{CS}}$. The resulting equation has the form

$$
\mathrm{U}_{\mathrm{CS}}=\left(\mathrm{U}_{\mathrm{TH}}+\phi_{\mathrm{J}} \mathrm{DC} \mathrm{U}_{\mathrm{CS}} /\left(1-\phi_{\mathrm{PT}}\right)\right)^{\alpha} \times \mathrm{f}
$$

where the multiplying term $\mathrm{f}$ accounts for all of the additional terms in the model.

It is seen from Eq. (4.4) that $U_{\mathrm{CS}}$ will be increased by inclusion of the modified settling velocity. The resulting increase is dependent on the value of $U_{C S}$ itself; the larger the value of $U_{C S}$, the larger the increase above what the model would have predicted without the additional term.

This approach was applied using the new physical model, Eq. (B.11) shown below, with modified settling velocity from Eq. (4.3) used in place of the hindered settling velocity, $\mathrm{U}_{\mathrm{TH}}$. The adjusted new physical model is shown explicitly in Eq. (4.5), and the results are shown in Table 4.1. The adjusted new physical model was bench marked with data taken during prototypic drive tests which are described in Appendix E.

$$
\mathrm{U}_{\mathrm{CS}}=2.302 \mathrm{U}_{\mathrm{TH}}\left(\frac{\mathrm{D}(\mathrm{s}-1) \mathrm{g}}{\mathrm{U}_{\mathrm{TH}}{ }^{2}}\right)^{0.261} \phi_{\mathrm{J}}{ }^{-0.511} \mathrm{DC}^{-0.261} \phi_{\mathrm{S}}{ }^{0.261} \phi_{\mathrm{p}}{ }^{-0.234} \mathrm{Ga}^{-0.176}
$$




$$
\mathrm{U}_{\mathrm{CS}}=2.302\left(\mathrm{U}_{\mathrm{TH}}+\phi_{\mathrm{J}} \mathrm{DC} \mathrm{U}_{\mathrm{CS}} /\left(1-\phi_{\mathrm{PT}}\right)\right)^{0.478}(\mathrm{D}(\mathrm{s}-1) \mathrm{g})^{0.261} \phi_{\mathrm{J}}^{-0.511} \mathrm{DC}^{-0.261} \phi_{\mathrm{S}}^{0.261} \phi_{\mathrm{p}}^{-0.234} \mathrm{Ga}^{-0.176}
$$

Table 4.1. Results of Using the Adjusted Settling Velocity U”, in the New Physical Model

\begin{tabular}{|c|c|c|c|c|c|}
\hline $\begin{array}{c}\text { Test } \\
\text { Sequence }\end{array}$ & $\begin{array}{c}\text { Settling } \\
\text { Velocity } \\
\mathrm{U}_{\mathrm{TH}} \\
(\mathrm{m} / \mathrm{s})\end{array}$ & $\begin{array}{c}\text { Adjusted } \\
\text { Settling Velocity } \\
\mathrm{U}_{\mathrm{TH}}^{\prime \prime}(\text { Eq. 4.3) } \\
(\mathrm{m} / \mathrm{s})\end{array}$ & $\begin{array}{c}\mathrm{U}_{\mathrm{CS}} \text { from } \\
\text { New Physical } \\
\text { Model (Eq. 4.4) } \\
(\mathrm{m} / \mathrm{s})\end{array}$ & $\begin{array}{c}\mathrm{U}_{\mathrm{CS}} \text { from Adjusted } \\
\text { New Physical } \\
\text { Model (Eq. 4.5) } \\
\text { (m/s) }\end{array}$ & $\begin{array}{c}\text { Estimated } \\
\text { Actual } U_{\mathrm{CS}} \\
(\mathrm{m} / \mathrm{s})\end{array}$ \\
\hline 1 & 1.57E-02 & $1.98 \mathrm{E}-02$ & $4.9-5.1$ & $5.6-5.7$ & $8.0-8.2$ \\
\hline 3 & $3.02 \mathrm{E}-03$ & 8.31 E-03 & $4.4-4.5$ & $7.2-7.4$ & $6.7-7.8$ \\
\hline 13FV1 & 3.17E-03 & $6.04 \mathrm{E}-03$ & $6.7-7.0$ & $9.2-9.4$ & $8.3-9.9$ \\
\hline
\end{tabular}

From the results in Table 4.1 we see that by using the adjusted settling velocity, the model predictions for $\mathrm{U}_{\mathrm{CS}}$ are improved. For Test Sequences 3 and 13FV1, the predicted values are essentially the same as the actual values, within the uncertainty of the estimated actual values. For Test Sequence 1, the predicted value of $U_{C S}$ is closer to the actual value but is still about $30 \%$ lower. A $30 \%$ variation is within the range of accuracy of the original correlation to the data ${ }^{1}$. However, it is not clear if this is, in fact, the correct explanation, or if it is something more fundamental to the data.

\subsection{Summary}

In this section we reviewed the key differences between the Phase 1 and Phase 2 test approaches. The effects of the majority of the non-prototypic features of Phase 1 testing on $\mathrm{U}_{\mathrm{CS}}$ are thought to be small. The effects of closed loop operation of the jets was previously known to affect cloud height but was thought to have only a negligible effect on $\mathrm{U}_{\mathrm{CS}}$. The effect of the absence of refill can be described in terms of an adjusted settling velocity. When the adjusted settling velocity is used in the correlations and applied to prototypic mixing systems, the models produce predictions of $U_{\mathrm{CS}}$ which are larger. When the adjusted new physical model (new physical model with the adjusted settling velocity) approach is applied to Phase 2 Test Sequences 3 and 13FV1, the resulting predictions of $U_{\mathrm{CS}}$ are within the uncertainty of the estimated actual values. The resulting prediction for Test Sequence 1 is $30 \%$ lower than the estimated actual value, within the variability of the original correlations. While not definitive, these results suggest that the absence of prototypic refill in Phase 1 caused values of $U_{\mathrm{CS}}$ to be reduced compared with prototypic drive systems. By accounting for this effect in terms of an adjusted settling velocity, the Phase 1 adjusted new physical model predicts values that are closer to the limited Phase 2 test results. The effect of non-prototypic refill, taken together with limitations with the Phase 1 models for 8-tube geometries, may be sufficient to explain the discrepancy between the Phase 1 and Phase 2 data. This assessment suggests that the adjusted new physical model for $U_{C S}$ with the adjusted settling velocity (Equation 4.5) can be applied with caution to predict $\mathrm{U}_{\mathrm{CS}}$ for prototypic PJM operation.

1 For example, the new physical model predicts values that are within $\pm 27 \%$ of the original data for about $95 \%$ of the test conditions. 


\subsection{Implications to Scale Up}

This section addresses the applicability of the Phase 1 scale-up laws to the Phase 2 results. Section 5.1 presents a summary of the scale-up behavior of the models for the data obtained in Phase 1 testing. Section 5.2 looks at the direct scale-up results for $\mathrm{U}_{\mathrm{CS}}$ and $\mathrm{H}_{\mathrm{C}}$ from a limited set of data where matched conditions were achieved at two different scales. Section 5.3 explores the effects of scale on vertical solids distribution. In Section 5.4, the applicability of applying the Phase 1 results to Phase 2 testing is addressed. The results are summarized in Section 5.5.

\subsection{Summary of Scale-Up Data from Phase 1 Correlations}

The effect of scale on a given mixing result can be expressed mathematically as

$$
\alpha_{x}=\frac{\partial \ln x}{\partial \ln D}
$$

where $\mathrm{x}$ is a mixing result such as $\mathrm{U}_{\mathrm{CS}}$ or $\mathrm{H}_{\mathrm{C}}$ and $\mathrm{D}$ is the vessel diameter. If the mixing result is expressed in terms of a power-law function then $\alpha_{\mathrm{x}}$ is equivalent to the exponent on scale. For example we can write

$$
\begin{aligned}
& \mathrm{U}_{\mathrm{CS}} \approx \mathrm{D}^{\alpha \mathrm{U}} \\
& \mathrm{H}_{\mathrm{C}} \approx \mathrm{D}^{\alpha} \mathrm{H}
\end{aligned}
$$

The Phase 1 M3 test program conducted tests at three different scales with a wide range of operational, geometric, and physical conditions. These data were correlated in various ways to obtain analytical expressions used for predicting $\mathrm{U}_{\mathrm{CS}}$ and $\mathrm{H}_{\mathrm{C}}$. Each of these expressions demonstrated a dependence on vessel scale - essentially the exponent on vessel diameter.

These scale-up exponents for the various correlations are shown in Table 5.1. Note that the scale-up exponents for $\mathrm{H}_{\mathrm{C}}$ are for cloud heights at or above the $\mathrm{U}_{\mathrm{CS}}$ condition.

Table 5.1. Scale-up Exponents from the Various Data Correlations of the Phase 1 M3 Data Set

\begin{tabular}{lcc}
\hline Correlation & $\mathrm{U}_{\mathrm{CS}}$ scale-up exponent & $\mathrm{H}_{\mathrm{C}}$ scale-up exponent \\
\hline New physical model & 0.26 & 0.143 \\
Physical model & 0.28 & 0 \\
Dimensional model & 0.25 & 0.53 \\
Generalized model & 0.4 & 0.53 \\
\hline
\end{tabular}

During the Phase 1 tests, measurements of the solids concentration in the cloud were also obtained at the critical suspension velocity. The concentration measurements are described in Appendix $\mathrm{C}$ of Meyer et al. (2009). To obtain a concentration profile, an ultrasonic probe was inserted into the vessel, most prevalently at the vessel vertical center line within the cloud and at a specified elevation. The 
ultrasonic signal attenuation was measured during the PJM cycle to document the attenuation throughout the cycle. Concentration was calculated from the measured attenuation. The data was analyzed to determine the minimum, average, and maximum concentration over the entire pulse and to determine the concentration at specific points during the cycle such as beginning of drive and end of drive. The concentration measurements were all performed at or very near to $\mathrm{U}_{\mathrm{CS}}$; therefore, no direct scale-up information was obtained.

\subsection{Phase 1 Direct Scale-Up Data}

The values shown in Table 5.1 represent best fits for the scale-up functionality over a wide range of test conditions. In order to look more carefully at the scale-up behavior, it is useful to examine select test cases where the only difference in two tests is the vessel scale - in other words, test cases in which all operational, geometric, and physical test conditions were identical at two or more scales. Specifically, it is most useful to consider matched test cases with the 15-in. and 70-in vessels exclusively, as these tests were conducted at those scales with identical elliptical dish bottoms. In this way, all other test condition variations other than scale are eliminated from the data comparison, and the effect of scale alone is isolated.

Table 5.2 shows the test conditions for the 14 matched test cases conducted in the 15- and 70-in. vessels with elliptical dish bottoms. Table 5.3 shows the values for $\mathrm{U}_{\mathrm{CS}}$ and $\mathrm{H}_{\mathrm{C}}$ together with the scale-up exponents for the individual test cases. Also shown in Table 5.3 is a scale-up exponent for relative cloud height $\mathrm{H}_{\mathrm{C}} / \mathrm{D}$ which is simply $1-\alpha_{\mathrm{H}}$.

Table 5.2. Matched Test Conditions in the 15-in. and 70-in Vessel

\begin{tabular}{lcccccccc}
\hline & $\begin{array}{c}\text { Number } \\
\text { of Pulse } \\
\text { Tubes }\end{array}$ & $\begin{array}{c}\text { Density } \\
\text { Ratio }\end{array}$ & $\begin{array}{c}\text { Solids } \\
\text { Diameter } \\
\text { N }\end{array}$ & $\begin{array}{c}\text { Terminal } \\
\text { Settling } \\
\text { Velocity }\end{array}$ & $\begin{array}{c}\text { Ratio of Solids } \\
\text { Volume to } \\
\text { Reference Volume }\end{array}$ & $\begin{array}{c}\text { Pulse } \\
\text { Volume } \\
\text { Fraction }\end{array}$ & $\begin{array}{c}\text { Duty } \\
\text { Cycle }\end{array}$ & $\begin{array}{c}\text { Jet } \\
\text { Density }\end{array}$ \\
Case ID & $(-)$ & $(-)$ & $(\mu \mathrm{m})$ & $(\mathrm{m} / \mathrm{s})$ & $\begin{array}{c}\phi_{\mathrm{S}} \\
(-)\end{array}$ & $\begin{array}{c}\phi_{\mathrm{p}} \\
(-)\end{array}$ & $\begin{array}{c}\text { DC } \\
(-)\end{array}$ & $\begin{array}{c}\phi_{\mathrm{J}} \\
(-)\end{array}$ \\
\hline E_4s1d1Zc_1 & 12 & 2.46 & 166.4 & 0.0156 & 0.00155 & 0.050 & 0.334 & 0.00092 \\
E_4s1d1Zd_1 & 12 & 2.46 & 166.4 & 0.0160 & 0.00155 & 0.050 & 0.185 & 0.00092 \\
E_4s1d2Rc_1 & 12 & 2.48 & 69.3 & 0.0035 & 0.01 & 0.050 & 0.333 & 0.00092 \\
E_4s1d2Xc_1 & 12 & 2.48 & 69.3 & 0.0038 & 0.015 & 0.050 & 0.335 & 0.00092 \\
E_4s1d2Xd_1 & 12 & 2.48 & 69.3 & 0.0039 & 0.015 & 0.050 & 0.185 & 0.00092 \\
E_4s1d2Yc_1 & 12 & 2.48 & 69.3 & 0.0036 & 0.005 & 0.050 & 0.332 & 0.00092 \\
E_4s1d2Zc_1 & 12 & 2.48 & 69.3 & 0.0035 & 0.00155 & 0.050 & 0.334 & 0.00092 \\
E_4s1d2Zd_1 & 12 & 2.48 & 69.3 & 0.0036 & 0.00155 & 0.050 & 0.182 & 0.00092 \\
E_4s2d2Yc_1 & 12 & 4.18 & 75.6 & 0.0089 & 0.005 & 0.050 & 0.335 & 0.00092 \\
E_4s2d2Zc_1 & 12 & 4.18 & 75.6 & 0.0089 & 0.00155 & 0.050 & 0.336 & 0.00092 \\
E8_6s1d2Vc_1 & 8 & 2.48 & 69.3 & 0.0040 & 0.0143 & 0.050 & 0.334 & 0.00139 \\
E8_6s1d2Vc_2 & 8 & 2.48 & 69.3 & 0.0039 & 0.0143 & 0.100 & 0.331 & 0.00139 \\
E8_6s1d2Zc_1 & 8 & 2.48 & 69.3 & 0.0039 & 0.00155 & 0.050 & 0.334 & 0.00139 \\
E8_6s1d2Zc_2 & 8 & 2.48 & 69.3 & 0.0039 & 0.00155 & 0.100 & 0.331 & 0.00139 \\
\hline
\end{tabular}


Table 5.3. Measured Values of $\mathrm{U}_{\mathrm{CS}}$ and $\mathrm{H}_{\mathrm{CS}}$ and Their Corresponding Scale-up Exponents

\begin{tabular}{|c|c|c|c|c|c|c|c|}
\hline Case ID & $\mathrm{U}_{\mathrm{CS}} 15$ & $\mathrm{U}_{\mathrm{CS}} 70$ & $\mathrm{H}_{\mathrm{CS}} 15$ & $\mathrm{H}_{\mathrm{CS}} 70$ & $\begin{array}{c}\text { alpha U } \\
\alpha_{U}\end{array}$ & $\begin{array}{c}\text { alpha } H \\
\alpha_{H}\end{array}$ & $\begin{array}{c}\text { alpha } C \\
\alpha_{C}=1-\alpha_{H}\end{array}$ \\
\hline E_4s1d1Zc_1 & 4.2 & 7.1 & 0.159 & 0.832 & 0.33 & 1.05 & -0.05 \\
\hline E_4s1d1Zd_1 & 4.5 & 7.1 & 0.171 & 0.775 & 0.29 & 0.96 & 0.04 \\
\hline E_4s1d2Rc_1 & 5.4 & 7.2 & 0.165 & 0.908 & 0.18 & 1.08 & -0.08 \\
\hline E_4s1d2Xc_1 & 5.8 & 8.5 & 0.165 & 1.054 & 0.24 & 1.17 & -0.17 \\
\hline E_4s1d2Xd_1 & 7.4 & 11.6 & 0.140 & 1.092 & 0.28 & 1.30 & -0.30 \\
\hline E_4s1d2Yc_1 & 4.3 & 6 & 0.133 & 0.699 & 0.21 & 1.05 & -0.05 \\
\hline E_4s1d2Zc_1 & 2.8 & 4.6 & 0.171 & 0.724 & 0.31 & 0.91 & 0.09 \\
\hline E_4s1d2Zd_1 & 3.4 & 5.4 & 0.175 & 0.673 & 0.29 & 0.85 & 0.15 \\
\hline E_4s2d2Yc_1 & 7.6 & 12.5 & 0.146 & 0.648 & 0.32 & 0.94 & 0.06 \\
\hline E_4s2d2Zc_1 & 5.2 & 8.4 & 0.171 & 0.724 & 0.30 & 0.91 & 0.09 \\
\hline E8_6s1d2Vc_1 & 4.8 & 6.8 & 0.248 & 1.816 & 0.22 & 1.26 & -0.26 \\
\hline E8_6s1d2Vc_2 & 4.4 & 6.4 & 0.254 & 1.638 & 0.24 & 1.18 & -0.18 \\
\hline E8_6s1d2Zc_1 & 2.6 & 4.4 & 0.229 & 2.235 & 0.33 & (1) & (1) \\
\hline E8_6s1d2Zc_2 & 2.8 & 4.3 & 0.413 & 2.210 & 0.27 & 1.06 & -0.06 \\
\hline \multirow{2}{*}{\multicolumn{4}{|c|}{$\begin{array}{l}\text { (1) Cloud height data demonstrated anomalous behavior } \\
\text { for this test case and is therefore not included }\end{array}$}} & Average & 0.27 & 1.06 & -0.06 \\
\hline & & & & Max & 0.33 & 1.30 & -0.30 \\
\hline & & & & Min & 0.18 & 0.86 & 0.15 \\
\hline & & & & St Dev & 0.05 & 0.14 & 0.14 \\
\hline
\end{tabular}

From Table 5.3 it is seen that the scale-up exponents $\left(\alpha_{U}\right)$ for $U_{\text {CS }}$ varied between 0.18 and 0.33 , with an average of 0.27 . Note that a value of $0.33(1 / 3)$ corresponds to constant power per unit volume. The variation in $\alpha_{U}$ is not a result of uncertainty, as the $U_{\text {CS }}$ measurements were quite accurate and repeatable. Rather, the variation indicates that simple power-law functionality is insufficient to accurately describe the behavior. Mathematically, this means the scale-up exponent is a function of other test variables. A sensitivity analysis indicates that $\alpha_{U}$ is most strongly dependant on the solids loading, $\phi_{\mathrm{S}}$. This can be seen in Figure 5.1 where $\alpha_{U}$ is plotted versus $\phi_{S}$ for the 14 matched test cases. Both 8-tube and 12-tube data are shown. While the data show some scatter, Figure 5.1 suggests that $\alpha_{U}$ generally decreases with increasing solids loading.

The scale-up exponents $\left(\alpha_{\mathrm{H}}\right)$ for $\mathrm{H}_{\mathrm{CS}}$ vary between 0.86 and 1.3 with an average of 1.06. Note that a value of 1.0 corresponds to constant relative cloud height $\mathrm{H}_{\mathrm{C}} / \mathrm{D}$. Note also that the scale-up exponent for $\mathrm{H}_{\mathrm{CS}}$ is significantly larger than that obtained for $\mathrm{H}_{\mathrm{C}}$ from the data correlation as shown in Table 5.1. This suggests that once the velocity is above $\mathrm{U}_{\mathrm{CS}}$, the cloud behavior scales differently than it does for the just-suspended condition. Although cloud height data is somewhat more variable than $\mathrm{U}_{\mathrm{CS}}$ data, the variation in $\alpha_{H}$ is due in part to non-power law behavior. A sensitivity analysis indicates that $\alpha_{H}$ is also most strongly dependant on the solids loading, $\phi_{\mathrm{S}}$. This can be seen in Figure 5.2 where $\alpha_{\mathrm{H}}$ is plotted versus $\phi_{\mathrm{S}}$ for the matched test cases. Both 8-tube and 12-tube data are shown. While the data show some scatter, Figure 5.2 suggests that $\alpha_{\mathrm{H}}$ generally increases with increasing solids loading. The same trend is observed in Figure 5.3 where the scale-up exponent for $\mathrm{H}_{\mathrm{C}} / \mathrm{D}$ is shown. For solids loadings below about 0.005 , the relative cloud height decreases with scale, while at higher solids loadings the relative cloud height increases with scale. 


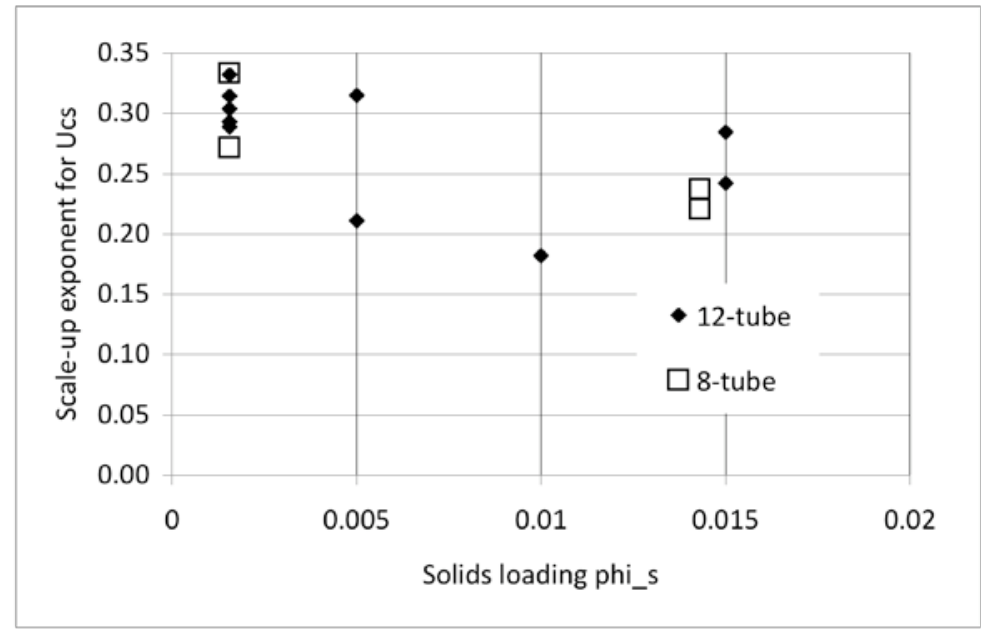

Figure 5.1. Demonstrating the Dependence of the Scale-up Exponent for $\mathrm{U}_{\mathrm{CS}}$ on Solids Loading

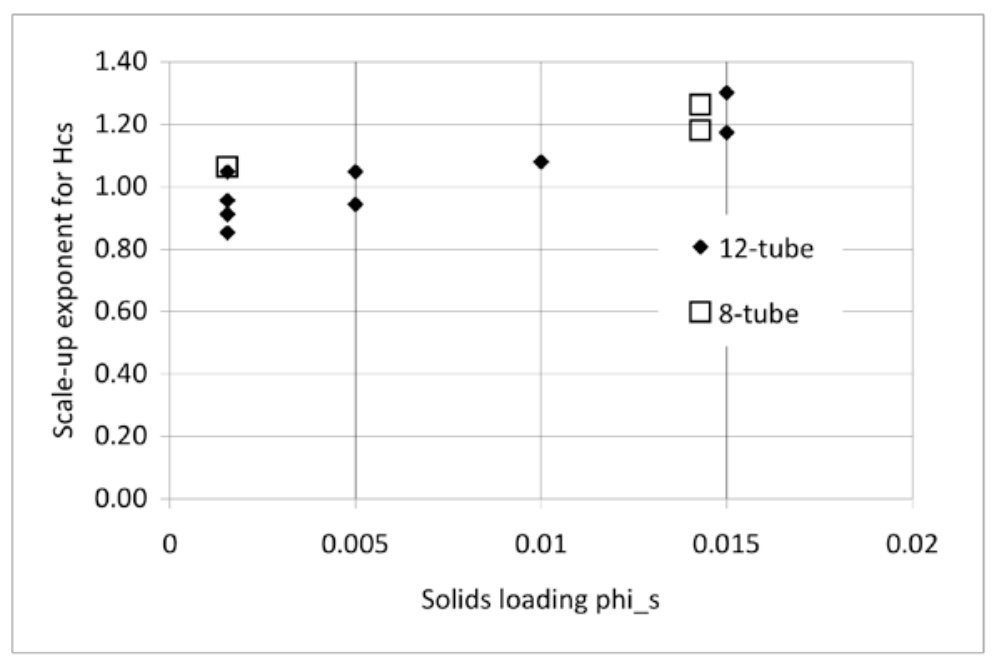

Figure 5.2. The Dependence of the Scale-up Exponent for $\mathrm{H}_{\mathrm{CS}}$ on Solids Loading

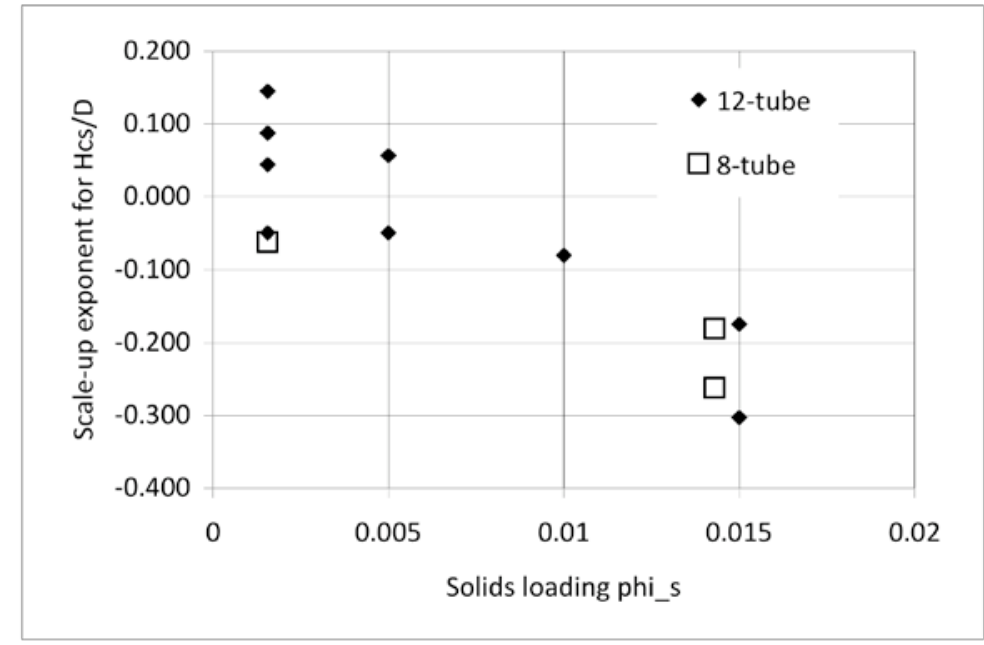

Figure 5.3. The Dependence of the Scale-up Exponent for $\mathrm{H}_{\mathrm{CS}} / \mathrm{D}$ on Solids Loading 


\subsection{Phase 1 Concentration Data Scale-Up}

Cloud height gives an indirect indication of the scale-up behavior for solids concentration. For a given concentration profile within the cloud, we expect concentrations within the cloud (e.g., the average or maximum) to be inversely proportional to the normalized cloud height according to

$$
\mathrm{C}=\phi_{\mathrm{S}}\left(\mathrm{H}_{\mathrm{C}} / \mathrm{D}\right)^{-1}
$$

So if we write a power-law scale-up expression for concentration in the form $C \sim D^{\alpha} C$ then we have the relation $\alpha_{\mathrm{C}}=1-\alpha_{\mathrm{H}}$. Hence the relative cloud height scale-up behavior in Figure 5.3 also indicates how concentration may scale. Specifically, at low solids loading in the vessel, the data suggest that concentration increases with scale, and at higher solids loading, the concentration may decrease with scale.

Measured concentration profiles during Phase 1 testing generally were taken at the just-suspended condition. Hence the velocity was different at the different scales so that direct scale-up information was not obtained. However, by considering the concentration profiles at $U_{\mathrm{CS}}$ at two different scales some information on scale-up behavior can be achieved.

Table 5.4 shows the specific test cases at $\mathrm{U}_{\mathrm{CS}}$ in the 15 -in. and 70 -in vessel where concentration profiles were obtained. The concentration profiles are shown in Figure 5.5. All of the data shown are taken at the center of the vessel $(r=0)$ and are averages over five complete drive cycles.

Table 5.4. Test Conditions at $\mathrm{U}_{\mathrm{CS}}$ in the 15-in. and 70-in Vessel Where Concentration Profiles were Obtained

\begin{tabular}{lcccccccc}
\hline & $\begin{array}{c}\text { Number } \\
\text { of Pulse } \\
\text { Tubes }\end{array}$ & $\begin{array}{c}\text { Density } \\
\text { Ratio }\end{array}$ & $\begin{array}{c}\text { Solids } \\
\text { Diameter } \\
\text { N }\end{array}$ & $\begin{array}{c}\text { Terminal } \\
\text { Settling } \\
\text { Velocity }\end{array}$ & $\begin{array}{c}\text { Ratio of Solids } \\
\text { Volume to } \\
\text { Reference Volume }\end{array}$ & $\begin{array}{c}\text { Pulse } \\
\text { Volume }\end{array}$ & $\begin{array}{c}\text { Duty } \\
\text { Fraction } \\
\text { Cycle }\end{array}$ & $\begin{array}{c}\text { Jet } \\
\text { Density }\end{array}$ \\
Case ID & $(-)$ & $(-)$ & $(\mu \mathrm{m})$ & $(\mathrm{m} / \mathrm{s})$ & $(-)$ & $\begin{array}{c}\phi_{\mathrm{p}} \\
(-)\end{array}$ & $\begin{array}{c}\text { DC } \\
(-)\end{array}$ & $\begin{array}{c}\phi_{\mathrm{J}} \\
(-)\end{array}$ \\
\hline E_4s1d1Zc_1 & 12 & 2.46 & 166.4 & 0.0156 & 0.00155 & 0.050 & 0.334 & 0.00092 \\
E_4s1d2Xc_1 & 12 & 2.48 & 69.3 & 0.0038 & 0.015 & 0.050 & 0.335 & 0.00092 \\
E_4s1d2Yc_1 & 12 & 2.48 & 69.3 & 0.0036 & 0.005 & 0.050 & 0.332 & 0.00092 \\
E_4s1d2Zc_1 & 12 & 2.48 & 69.3 & 0.0035 & 0.00155 & 0.050 & 0.334 & 0.00092 \\
E_4s2d2Yc_1 & 12 & 4.18 & 75.6 & 0.0089 & 0.005 & 0.050 & 0.335 & 0.00092 \\
E_4s2d2Zc_1 & 12 & 4.18 & 75.6 & 0.0089 & 0.00155 & 0.050 & 0.336 & 0.00092 \\
E8_6s1d2Vc_1 & 8 & 2.48 & 69.3 & 0.0040 & 0.0143 & 0.050 & 0.334 & 0.00139 \\
\hline
\end{tabular}




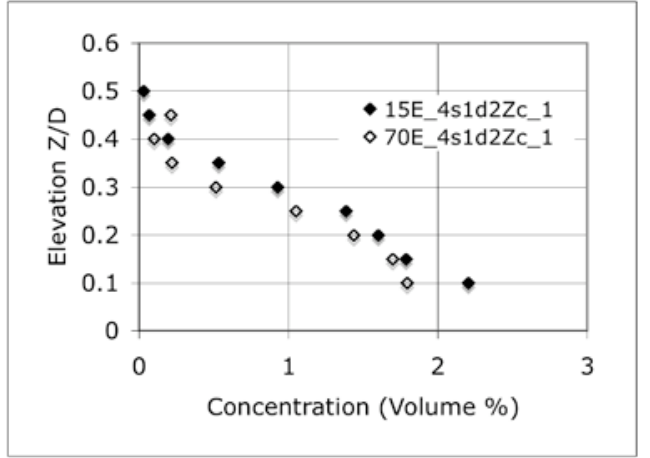

(a)

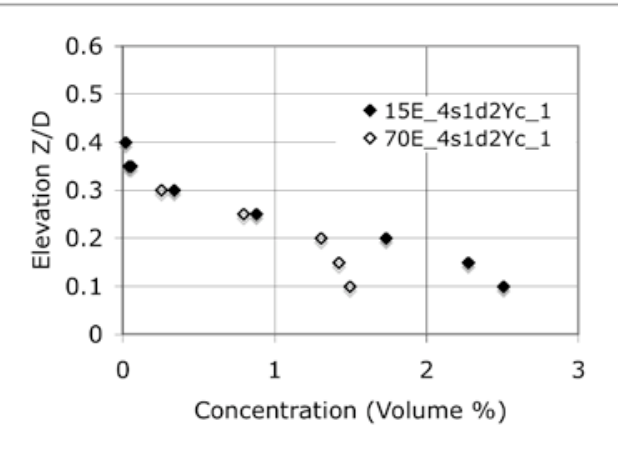

(b)

(a) Solids fraction $\left(\phi_{\mathrm{S}}=0.00155[\mathrm{Z}]\right)$ using a 4 in. full-scale nozzle with duty cycle (DC $=0.33$ [c]) and pulse volume fraction $\left(\phi_{\mathrm{p}}=0.05\right.$ [_1]). Simulant is $\operatorname{sid} 2\left(\rho_{\mathrm{s}}=2.48 \mathrm{~g} / \mathrm{cm}^{3}, \mathrm{~d}_{50}=69 \mu \mathrm{m}\right)$, 12 pulse tubes. Information in square brackets [] refers to label on plot.

(b) Solids fraction ( $\left.\phi_{\mathrm{S}}=0.005[\mathrm{Y}]\right)$ using a $4 \mathrm{in}$. full-scale nozzle with duty cycle (DC $=0.33$ [c]) and pulse volume fraction $\left(\phi_{\mathrm{p}}=0.05\right.$ [_1]). Simulant is $\operatorname{sid} 2\left(\rho_{\mathrm{s}}=2.48 \mathrm{~g} / \mathrm{cm}^{3}, \mathrm{~d}_{50}=69 \mu \mathrm{m}\right)$, 12 pulse tubes. Information in square brackets [] refers to label on plot.

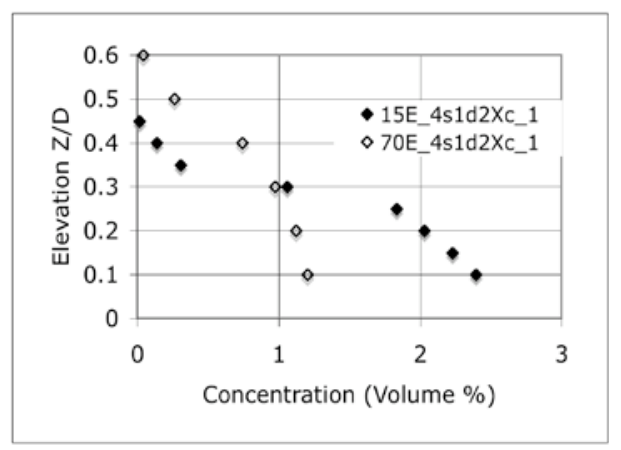

(c)

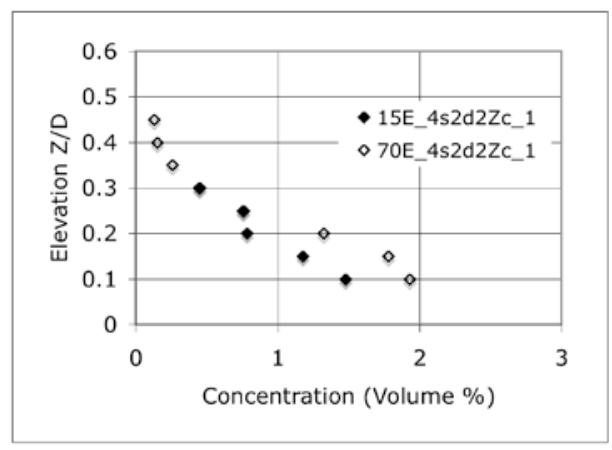

(d)

(c) Solids fraction $\left(\phi_{\mathrm{S}}=0.015[\mathrm{X}]\right)$ using a 4 in. full-scale nozzle with duty cycle $(\mathrm{DC}=0.33[\mathrm{c}])$ and pulse volume fraction $\left(\phi_{\mathrm{p}}=0.05\right.$ [1]). Simulant is $\mathrm{s} 1 \mathrm{~d} 2\left(\rho_{\mathrm{s}}=2.48 \mathrm{~g} / \mathrm{cm}^{3}, \mathrm{~d}_{50}=69 \mu \mathrm{m}\right)$, 12 pulse tubes. Information in square brackets [] refers to label on plot.

(d) Solids fraction $\left(\phi_{\mathrm{S}}=0.00155\right.$ [Z]) using a 4 in. full-scale nozzle with duty cycle (DC $=0.33$ [c]) and pulse volume fraction $\left(\phi_{\mathrm{p}}=0.05\right.$ [_1]). Simulant is s2d2 $\left(\rho_{\mathrm{s}}=4.18 \mathrm{~g} / \mathrm{cm}^{3}, \mathrm{~d}_{50}=76 \mu \mathrm{m}\right)$, 12 pulse tubes. Information in square brackets [] refers to label on plot. 


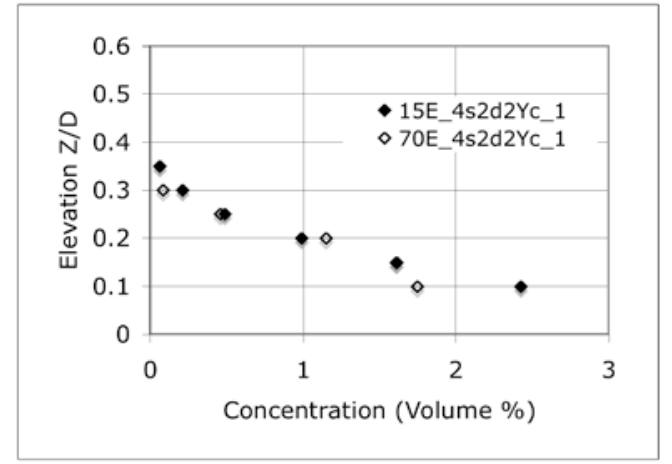

(e)

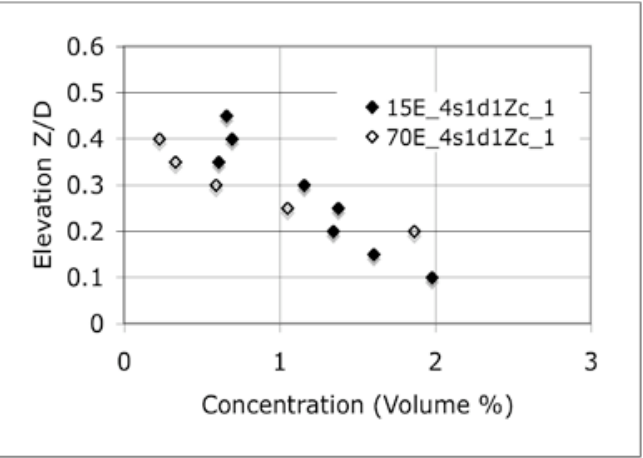

(f)

(e) Solids fraction $\left(\phi_{\mathrm{S}}=0.005[\mathrm{Y}]\right)$ using a 4 in. full-scale nozzle with duty cycle (DC $=0.33$ [c]) and pulse volume fraction $\left(\phi_{\mathrm{p}}=0.05\right.$ [_1]). Simulant is s2d2 $\left(\rho_{\mathrm{s}}=4.18 \mathrm{~g} / \mathrm{cm}^{3}, \mathrm{~d}_{50}=76 \mu \mathrm{m}\right)$, 12 pulse tubes. Information in square brackets [] refers to label on plot.

(f) Solids fraction ( $\phi_{\mathrm{S}}=0.00155$ [Z]) using a 4 in. full-scale nozzle with duty cycle (DC $=0.33$ [c]) and pulse volume fraction $\left(\phi_{\mathrm{p}}=0.05\right.$ [1] $)$. Simulant is s1d1 $\left(\rho_{\mathrm{s}}=2.46 \mathrm{~g} / \mathrm{cm}^{3}, \mathrm{~d}_{50}=166 \mu \mathrm{m}\right)$, 12 pulse tubes. Information in square brackets [] refers to label on plot.

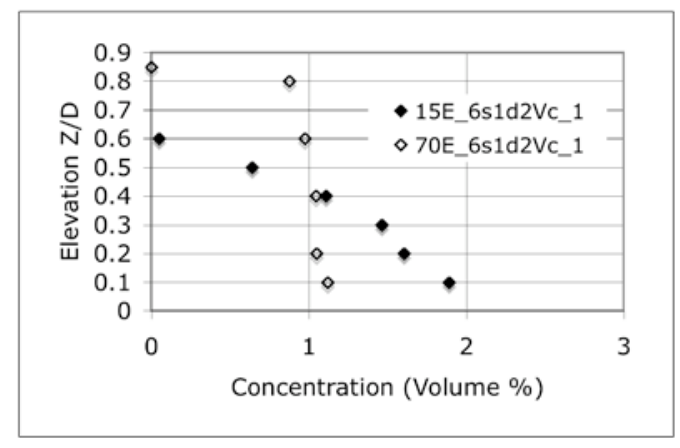

(g)

(g) Solids fraction $\left(\phi_{\mathrm{S}}=0.0143\right.$ [Z]) using a 4 in. full-scale nozzle with duty cycle (DC $=0.33$ [c]) and pulse volume fraction $\left(\phi_{\mathrm{p}}=0.05\right.$ [1] $)$. Simulant is $\mathrm{s} 1 \mathrm{~d} 1\left(\rho_{\mathrm{s}}=2.46 \mathrm{~g} / \mathrm{cm}^{3}, \mathrm{~d}_{50}=166 \mu \mathrm{m}\right)$, 8 pulse tubes. Information in square brackets [] refers to label on plot.

Figure 5.4. Centerline Concentration Profiles at $U_{\mathrm{CS}}$ for Matched Test Cases in the 15- and 70-in. Vessel

From the data shown in Figure 5.4 a number of observations can be made concerning how solids vertical distribution at the $\mathrm{U}_{\mathrm{CS}}$ conditions may be affected by scale:

- There appears to be no consistent general trend from the data shown in Figure 5.4. In some cases the maximum concentration in the 70-in vessel is larger than in the 15-in. vessel [(d), (e), (f)], while in other cases the opposite is true [(a), (b), (c), (g)].

- There is some evidence that at higher solids loadings the maximum concentration in the 15-in. vessel is higher than in the 70-in. vessel [(b), (c), (e)]. 
- The effect of solids density can be seen comparing (a) $\mathrm{s}=2.54$ with (d) $\mathrm{s}=4$.3. At lower solids density the profiles are similar at both scales. With the higher density, the maximum concentration in the 70-in. vessel is larger than in the 15-in. vessel.

- The effect of particle size can be seen by comparing (a) $d_{50}=69 \mu \mathrm{m}$ with (f) $d_{50}=166 \mu \mathrm{m}$. At the smaller particle size, profiles are similar at both scales. With the larger particle size, the maximum concentration in the 70-in. vessel is larger than in the 15-in. vessel.

Hence in general it appears that there is no consistent general trend on how solids vertical distribution (in particular maximum solids concentration) scales with respect to $\mathrm{U}_{\mathrm{CS}}$ scaling. In some cases, a scale law larger than the $U_{C S}$ scale-law would be necessary to assure similar concentration profiles with those observed at smaller scale. While in other cases, the observed distribution at small scale would be at least as good as that at larger scale when the $\mathrm{U}_{\mathrm{CS}}$ scale-law is used.

\subsection{Scale-up Behavior with Prototypic PJM Operation}

This section addresses whether the scale-up behavior observed in Phase 1 testing is applicable to Phase 2 tests performed with prototypic drive systems.

In Section 4 we showed that the absence of prototypic refill in Phase 1 caused values of $U_{C S}$ to be reduced compared with prototypic drive systems. By accounting for this effect in terms of an adjusted settling velocity, the Phase 1 adjusted new physical model does a better job of predicting the limited Phase 2 test results [The analysis presented here assesses the implications of how the adjusted settling velocity correction may affect scale up.] This result suggests that the scale-up behavior with prototypic drive systems may indeed be different than found in the Phase 1 work.

In the Phase 1 testing, measured values of $U_{\mathrm{CS}}$ increased with scale with an average scale-up exponent $\alpha_{U}=0.26$ (see Table 5.3). Since $U_{C S}$ increases with scale, it follows that the modified settling velocity (Eq. 4.2) decreases with scale. This suggests that at larger scales in Phase 1 testing, the effective settling velocity was reduced. Hence the value of the scale-up exponent $\alpha_{U}$, was less than what it would have been had prototypic refill been in operation.

Applying Eq. (5.1) to the adjusted new physical model with modified settling velocity results in

$$
\alpha_{\mathrm{U}}=\frac{\partial \ln \mathrm{U}_{\mathrm{CS}}}{\mathrm{d} \ln \mathrm{D}}=0.26 \frac{\left(1-\phi_{\mathrm{PT}}+\phi_{\mathrm{J}} \mathrm{DC} \mathrm{U}_{\mathrm{CS}} / \mathrm{U}_{\mathrm{TH}}\right)}{\left(1-\phi_{\mathrm{PT}}+0.48 \phi_{\mathrm{J}} \mathrm{DC} \mathrm{U}_{\mathrm{CS}} / \mathrm{U}_{\mathrm{TH}}\right)}
$$

Equation (5.5) is shown plotted in Figure 5.5 for conditions corresponding to Test Sequence 3 (8-tube) and Test Sequence 13FV1 (12-tube). The results show that at low velocity the scale-up exponent approaches the value of 0.26 . As the velocity is increased, the scale-up exponent increases.

In Figure 5.6 the scale-up behavior for the two cases is shown. The "new" physical model with modified settling velocity, see Eq. (4.5), is plotted versus vessel size, ranging from test scale to full scale. The power law fit of the curve shows and average scale-up exponent of 0.40 for Test Sequence 3 and 0.36 for Test Sequence 13FV1. Also shown on the plot are the observed values of $U_{\mathrm{CS}}$ for the two test sequences. 


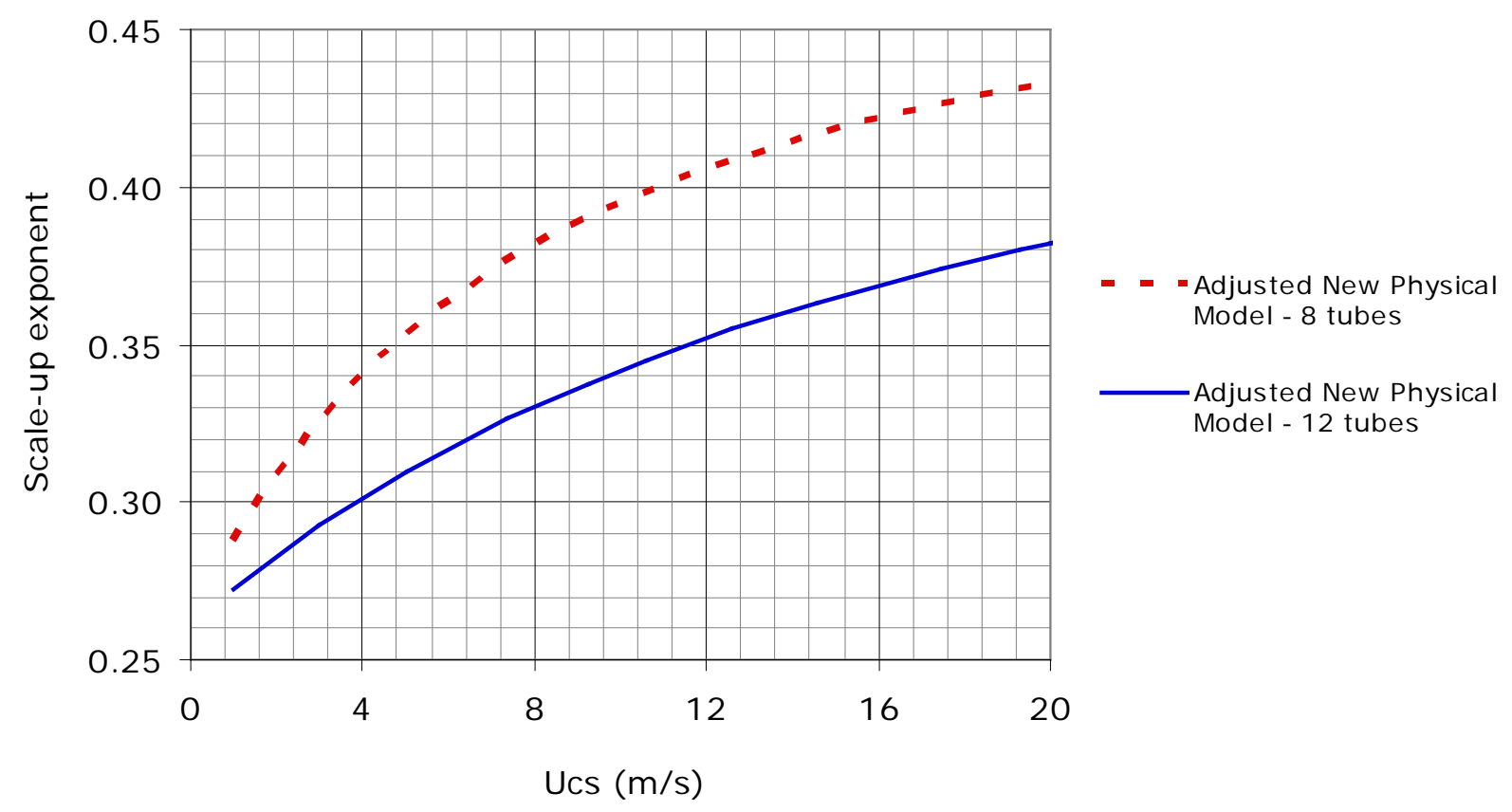

Figure 5.5. Scale-up Exponent Dependence on $\mathrm{U}_{\mathrm{CS}}$ for the New Physical Model with Modified Settling Velocity for Conditions Corresponding to Test Sequence 3 (8 tube) and Test Sequence 13FV1 (12 tube)

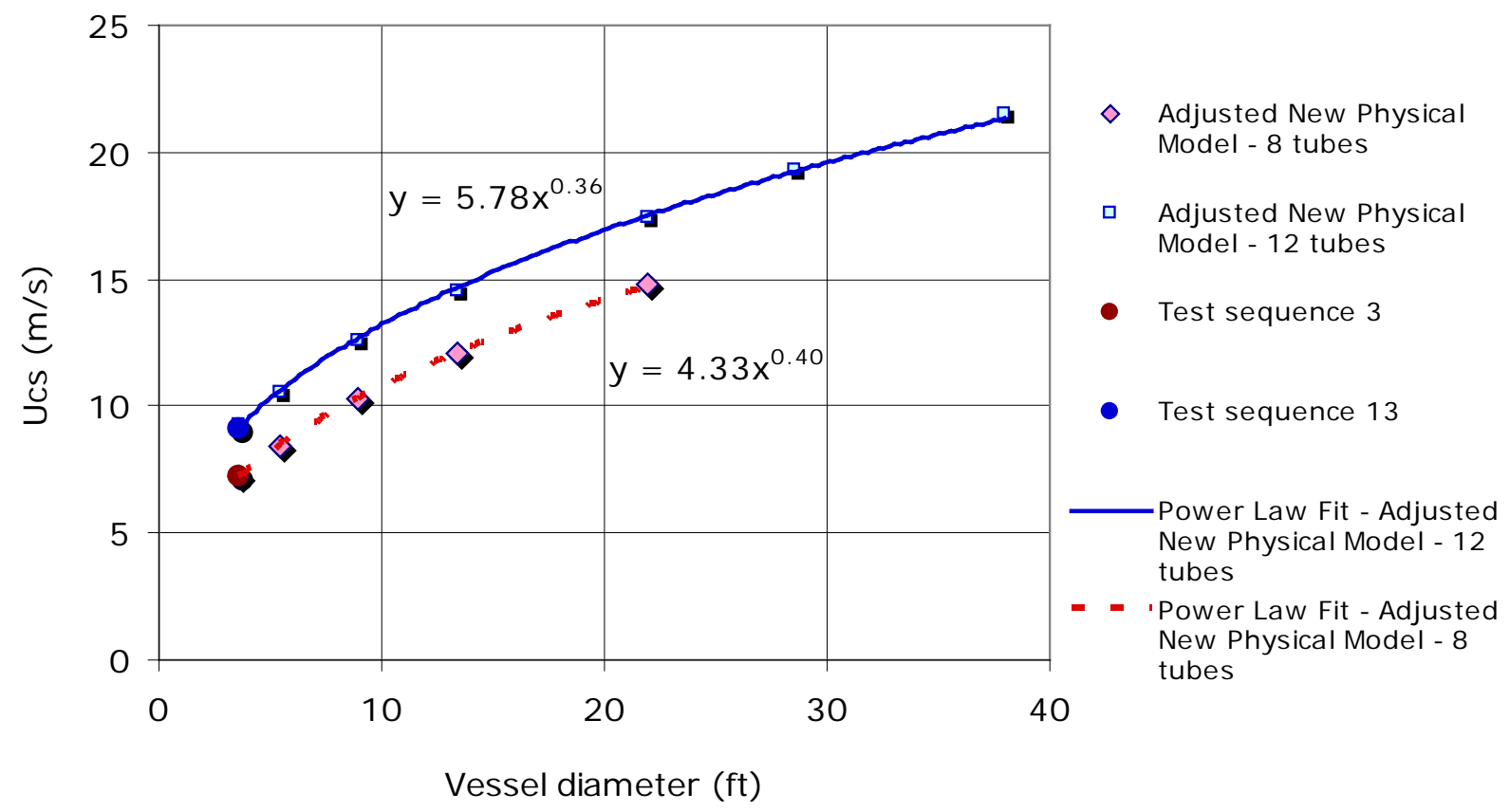

Figure 5.6. Predicted $U_{C S}$ Versus Vessel Scale for the New Physical Model with Modified Settling Velocity for Conditions Corresponding to Test Sequence 3 (8 tube) and Test Sequence 13FV1 (12 tube) 


\subsection{Summary}

The correlations for $\mathrm{U}_{\mathrm{CS}}$ from Phase 1 testing demonstrate scale-up exponents ranging from 0.25 (dimensional model) to 0.4 (generalized model). When direct scale up between only matched test cases is considered, the average scale-up exponent is found to be 0.27 with a standard deviation of 0.05 . The variation in these exponents is not experimental uncertainty rather it demonstrates that the scale-up behavior depends on other test variables. The most prominent of these is solids loading. At low solids loading, the scale-up exponent appears to approach a value of 0.33 , while at higher solids loadings it is reduced. The scale up of cloud height (at $U_{\mathrm{CS}}$ ) shows a similar trend. At low solids loading relative cloud height $\left(\mathrm{H}_{\mathrm{C}} / \mathrm{D}\right)$ gets smaller with scale, while at higher solids loadings $\mathrm{H}_{\mathrm{C}} / \mathrm{D}$ increases with scale. Cloud height gives an indirect indication of the scale-up behavior for solids concentration. For a given concentration profile within the cloud, we expect concentrations within the cloud (e.g. the average or maximum) to be inversely proportional to the normalized cloud. Hence, the cloud height behavior suggests that at low solids loadings maximum concentration would increase with scale, while at larger solids loadings it would decrease with scale.

Limited data of the effect of scale on solids vertical distribution was analyzed. In general it appears that there is no consistent trend on how solids vertical distribution (in particular maximum solids concentration) scales with respect to $U_{C S}$ scaling. In some cases, a scale law larger than the $U_{C S}$ scale law would be necessary to assure similar concentration profiles with those observed at smaller scale.

The applicability of the Phase 1 scale-up behavior to Phase 2 prototypic testing was analyzed. The effects of non-prototypic refill caused measured values of $U_{C s}$ to be somewhat reduced at larger scales. Hence the scale-up exponents are believed to be smaller than they would have been had there been prototypic refill. By using the "new" physical model with modified settling velocity, an estimate of the scale-up behavior for the Phase 2 testing was obtained. This suggests that a scale-up exponent of 0.40 for 8-tube tests and 0.36 for 12-tube tests might be expected. While these larger scale-up exponents are indicated by this analysis, experimental verification would be necessary to establish the actual scale-up exponents for prototypic PJM operation. 


\subsection{Conclusions}

There were two primary goals of this work. The first goal was to analyze the apparent discrepancy between measured values of $\mathrm{U}_{\mathrm{CS}}$ from Phase 1 and Phase 2 testing in order to quantify the magnitude of the difference, and if possible, to identify the cause of the difference. The second goal was to address the applicability of applying the Phase 1 scale-up laws to Phase 2 test results.

Three Phase 2 test sequences were selected for analysis and comparison to Phase 1 test results; the Phase 2 test sequences were selected on the basis of the similarity of the controlling parameters (geometric, simulant, and operational) to parameters used in Phase 1 tests. We looked for major sources of discrepancy in the following: 1) the controlling parameters needed for predicting $U_{C s}$ at center, 2) the actual nozzle velocities achieved in Phase 2 tests, and 3 ) the visual determination of $U_{\mathrm{CS}}$ at center as reported in test observations. Two major sources of discrepancy that contributed to the reporting of elevated Phase 2 values for $U_{\mathrm{CS}}$ at center are:

- The nominal nozzle velocity tends to be higher than the nozzle velocity actually achieved in the test, particularly at the higher test velocities.

- The Phase 2 test observers' reporting of center clearing by the end of the pulse was at higher velocities than would have been reported for $\mathrm{U}_{\mathrm{CS}}$ at center in the Phase 1 tests.

Compounding these differences was a difference in the definition of the critical suspension velocity: $\mathrm{U}_{\mathrm{CS}}$ as used in Phase 2 documentation refers to the condition when by the end of the drive no solids remain on any portion of the tank head out to the wall, while the Phase 1 tests required the tank bottom center to be clear of stationary solids by the end of the drive, here called " $\mathrm{U}_{\mathrm{CS}}$ at center."

Even with the sources of discrepancy determined above, we established that values of $\mathrm{U}_{\mathrm{CS}}$ for the Phase 2 test sequences were still higher than would be expected from Phase 1 testing (by about 35\% for the 12-tube geometry and $65 \%$ for the 8-tube geometry). We considered whether this could be explainable in terms of the range of variability of the Phase 1 correlations (e.g., how well the correlations predict the data from which they were derived). In doing so we introduced a new physical model which was developed from the Phase 1 data set to better account for 8-tube test data. We also made some direct data comparisons where the Phase 2 data points were compared directly with closely matched Phase 1 data points. We established that the difference in Phase 1 and Phase 2 values for $\mathrm{U}_{\mathrm{CS}}$ are not explainable solely in terms of data correlation limitations. Hence we concluded some differences exist that are fundamental to the actual test data.

In an effort to resolve the remaining discrepancy in $U_{\mathrm{CS}}$ values, we reviewed the key differences between the Phase 1 and Phase 2 test approaches. The effects of the majority of the non-prototypic features of Phase 1 testing on $U_{C S}$ are thought to be small. Closed loop operation of the jets was previously known to affect cloud height but was thought to have only a negligible effect on $\mathrm{U}_{\mathrm{CS}}$. This effect, associated with the absence of PJM refill, can be described in terms of an adjusted settling velocity. When the adjusted settling velocity is used with the new physical model to provide the adjusted new physical model, it predicts values of $\mathrm{U}_{\mathrm{CS}}$ for Phase 2 tests that are very close to the measured values for two of the three cases considered. The prediction for the third case is still lower by about $30 \%$, an amount that is just within the variability of the original correlation. While not definitive, these results suggest that the absence of prototypic refill in Phase 1 caused values of $U_{C s}$ to be reduced compared with 
prototypic drive systems. By accounting for this effect in terms of an adjusted settling velocity, the Phase 1 adjusted new physical model does a better job of predicting the limited Phase 2 test results. This effect of non-prototypic refill, taken together with limitations with the Phase 1 models for 8-tube geometries, appears sufficient to explain the discrepancy between the Phase 1 and Phase 2 data.

In addressing the applicability of using the Phase 1 scale-up laws for Phase 2 testing, we first reviewed and analyzed the Phase 1 scale-up data. The correlations for $\mathrm{U}_{\mathrm{CS}}$ from Phase 1 testing demonstrate scale-up exponents ranging from 0.25 (dimensional model) to 0.4 (generalized model). When direct scale up between only matched test cases is considered, the average scale-up exponent is found to be 0.27 with a standard deviation of 0.05 . The variation in these exponents is not experimental uncertainty; rather, it demonstrates that the scale-up behavior depends on other test variables. The most prominent of these is solids loading. At low solids loading, the scale-up exponent appears to approach a value of 0.33 , while at higher solids loadings, it is reduced. The scale up of cloud height (at $\mathrm{U}_{\mathrm{CS}}$ ) shows a similar trend. At low solids loading relative cloud height, $\mathrm{H}_{\mathrm{C}} / \mathrm{D}$ gets smaller with scale, while at higher solids loadings $\mathrm{H}_{\mathrm{C}} / \mathrm{D}$ increases with scale. Cloud height gives an indirect indication of the scale-up behavior for solids concentration. For a given concentration profile within the cloud, we expect concentrations within the cloud (e.g., the average or maximum) to be inversely proportional to the normalized cloud height. Hence, the cloud height behavior suggests at low solids loadings maximum concentration would increase with scale, while at larger solids loadings it would decrease with scale. These results are limited to cloud height behavior of mono-disperse particles when the jets are operated at the just-suspended velocity.

Limited data on the effect of scale on solids vertical distribution was analyzed. In general it appears that there is no consistent trend on how solids vertical distribution (in particular maximum solids concentration) scales with respect to $U_{C S}$ scaling. In some cases, a scale-up exponent larger than the $U_{C S}$ scale-up exponent would be necessary to assure similar concentration profiles with those observed at smaller scale.

The applicability of the Phase 1 scale-up behavior to Phase 2 prototypic testing was analyzed. The effects of non-prototypic refill caused measured values of $U_{C S}$ to be somewhat reduced at larger scales. Hence, the scale-up exponents are believed to be smaller than they would have been had there been prototypic refill. By using the adjusted new physical model (developed from the new physical model with adjusted settling velocity), an expression for the scale-up exponent for tests conducted with prototypic PJM refill was obtained. Evaluating this expression for the test conditions corresponding to the Phase 2 test sequences considered suggests that a scale-up exponent of 0.40 for 8 -tube tests and 0.36 for 12 -tube tests might be expected. These larger scale-up exponents suggest the Phase 1 scale laws may not bound actual scale-up behavior for tests with prototypic PJM refill. However, experimental verification is required to establish with certainty if indeed the Phase 2 tests scale differently than Phase 1. 


\subsection{References}

Bathija PR. 1982. “Jet Mixing Design and Applications.” Chemical Engineering 89(25):89-94.

Kurath DE, BD Hanson, MJ Minette, DL Baldwin, BM Rapko, LA Mahoney, PP Schonewill, RC Daniel, PW Eslinger, JL Huckaby, JM Billing, PS Sundar, GB Josephson, JJ Toth, ST Yokuda, EBK Baer, SM Barnes, EC Golovich, SD Rassat, CF Brown, JGH Geeting, GJ Sevigny, AJ Casella, JR Bontha, RL Aaberg, PM Aker, CE Guzman-Leong, ML Kimura, SK Sundaram, RP Pires, BE Wells, and OP Bredt. 2009. Pretreatment Engineering Platform Phase 1 Final Test Report. PNNL-18894, WTP-RPT-197 Rev 0, Pacific Northwest National Laboratory, Richland, Washington.

Meyer, PA, JA Bamberger, CW Enderlin, JA Fort, BE Wells, SK Sundaram, PA Scott, MJ Minette, GL Smith, CA Burns, MS Greenwood, GP Morgan, EBK Baer, SF Snyder, M White, GF Piepel, BG Amidan, and A Heredia-Langner. 2009. Pulse Jet Mixing Tests With Noncohesive Solids.

PNNL-18098, WTP-RPT-182 Rev. 0, Pacific Northwest National Laboratory, Richland, Washington.

Olsen J. 2008. Determination of Mixing Requirements for Pulse-Jet-Mixed Vessels in the Waste Treatment Plant. 24590-WTP-ES-PT-08-002, Rev. 0, Bechtel National Incorporated, Richland, Washington.

Smith GL. January 2007. Scaled Testing to Determine the Adequacy of the WTP Pulse Jet Mixer Designs. 24590-PTF-TSP-RT-06-007, Bechtel National Inc., Richland Washington.

Wells BE, MA Knight, EC Buck, SK Cooley, RC Daniel, LA Mahoney, PA Meyer, AP Poloski, JM Tingey, WS Callaway III, GA Cooke, ME Johnson, MG Thien, DJ Washenfelder, JJ Davis, MN Hall, GL Smith, SL Thomson, and Y Onishi. 2007. Estimate of Hanford Waste Insoluble Solid Particle Size and Density Distribution. PNWD-3824, WTP-RPT-153 Rev. 0, Battelle - Pacific Northwest Division, Richland, Washington. 



\section{Appendix A}

\section{Peak-Average Nozzle Velocities for Phase 2 Test Sequences}





\section{Appendix A}

\section{Peak-Average Nozzle Velocities for Phase 2 Test Sequences}

Plots shown in this Appendix present PJM nozzle velocity versus cycle time for each of the test sequences analyzed for Section 2.0, and Figure captions show the Phase 1 equivalent values from Tables in Section 2.0. Test Sequences $1 \mathrm{~A}$ and $1 \mathrm{~B}$ are shown in Figures A.1 and A.2. Test Sequences $3 \mathrm{D}$ and $3 \mathrm{E}$ are shown in Figures A.3 and A.4. Test Sequences 13VF1A and 13VF1B are shown in Figures A.5 and A.6. Each plot shows the comparison of nozzle velocities calculated from three sources of DAS data: PJM pressure, PJM level (from capacitance probes) and tank level from radar. ${ }^{1}$ The velocity curves have been calculated from ten-cycle averages of level and pressure data for each test sequence and starting time shown on the plots below. It should be noted that the peak portion of each velocity curve is manually selected. While this allows the user to avoid non-physical anomalies, such as the velocity spikes seen in the 8-tube tests, failing to capture the full peak drive time introduces a degree of bias in the peak average calculation as the velocity tends to drop over the drive.

Nozzle velocity from PJM pressure data is calculated using the Bernoulli equation with flow loss; separate coefficients are used for forward flow loss during the drive and backward flow loss during PJM refill. In an attempt to calculate a bounding nozzle velocity during the drive, zero forward flow loss was assumed, while a rough parameter fit was used to find reasonable reverse flow loss coefficients for each array. Since no head space or room pressure was taken for pressure differences between the PJMs and the open tank, standard atmospheric pressure was assumed (this is expected to be slightly high). The very good agreement seen in velocities from the three data sources during in the peak plateau regions is therefore somewhat surprising.

Due to the use of smaller diameter nozzles in the 12-tube PJM array, the radar signal noise is amplified by roughly a factor of two compared to that seen in the 8-tube array. However, the difference in geometry factors does not fully explain the increased noise seen in Test Sequence 13FV1A compared to 13FV1B (where the noise amplitude is mostly well within $\pm 2 \mathrm{~m} / \mathrm{s}$ ). Fortunately, in these cases tank radar data is not being used as the data source for pulse volume fraction and peak-average nozzle velocity. Rather, these two plots serve to illustrate some of the pitfalls associated with the use of electronically acquired level data.

The effects of internal signal averaging within the radar probes used for tank level data are evident in all of the comparison plots. It appears as a time delay in the velocity curves and a broadening of the peak. However, only Test Sequence $13 \mathrm{FV} 1 \mathrm{~B}$, at $13 \mathrm{~m} / \mathrm{s}$, shows the peak average velocity obtained from radar level measurements dropping related to averaging over a short drive time.

1 WTP-RPT-208 was written in parallel with development of the M3 Test Platform Data Study by Energy Solutions. In the M3 Test Platform Data Study, WTP recommends that the use of radar-based PJM jet velocity derivation should not be used for data analysis for several reasons (signal delay, large tolerance band width, and other issues). The use of both pressure transmitter data and the Drexelbrook level probe data to derive the profile are correct. 


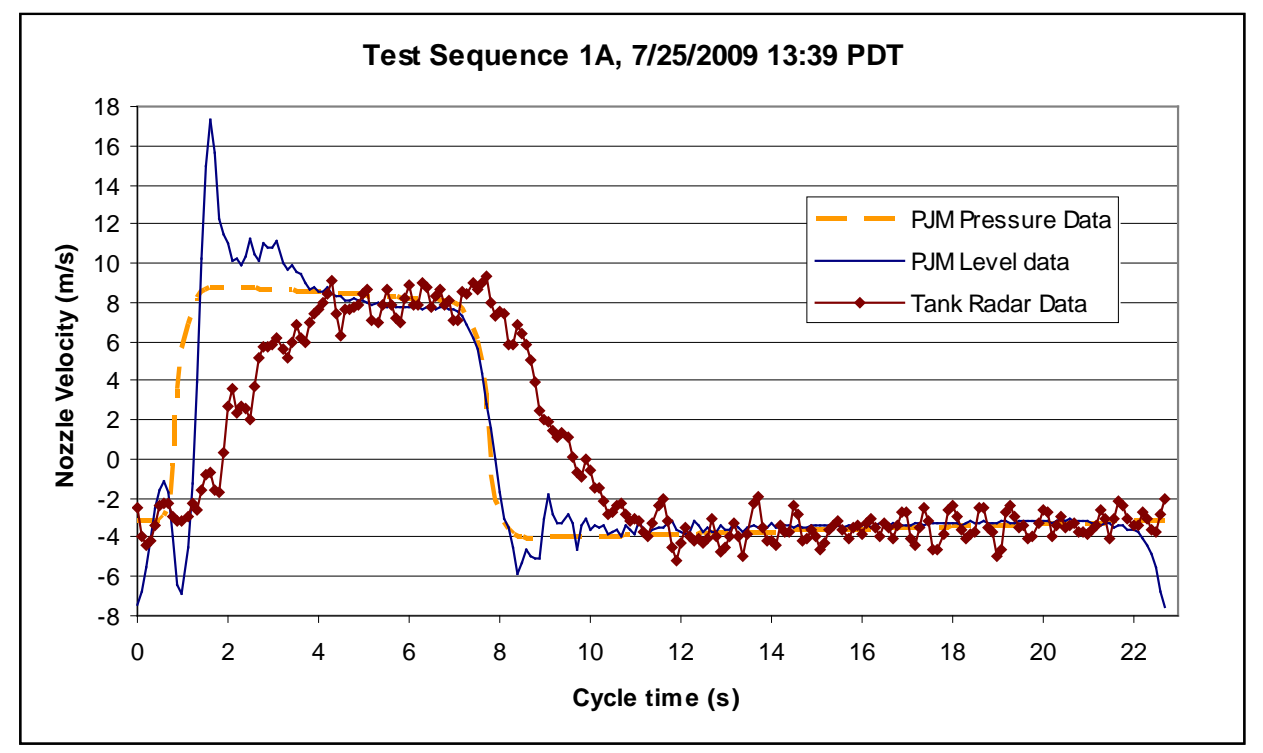

Figure A.1. Nozzle Exit Velocity (U) Averaged Over Ten Cycles for Test Sequence 1A with Target Exit Velocity $=8 \mathrm{~m} / \mathrm{s}$ and an 8-Tube Array. Estimated test conditions are simulant p1d7 $\left(\rho_{\mathrm{s}}=2.45 \mathrm{~g} / \mathrm{cm}^{3}, \mathrm{~d}_{50}=178 \mu \mathrm{m}\right)$, solids fraction $\left(\phi_{\mathrm{s}}=0.0072\right)$ using a $\mathrm{d}=0.655 \mathrm{in}$. diameter nozzle with duty cycle $(\mathrm{DC}=0.31)$ and pulse volume fraction $\left(\phi_{\mathrm{p}}=0.081\right)$.

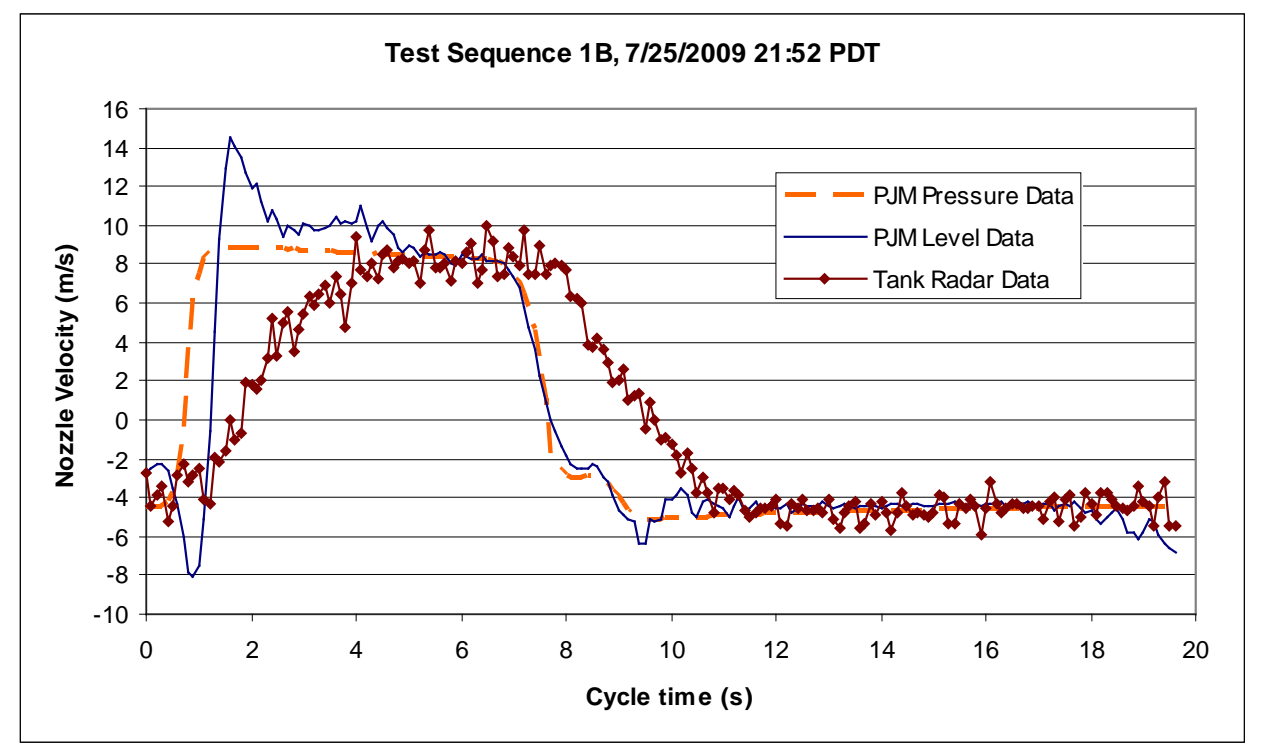

Figure A.2. Nozzle Exit Velocity (U) Averaged Over Ten Cycles for Test Sequence 1B with Target Exit Velocity $=9 \mathrm{~m} / \mathrm{s}$ and an 8-Tube Array. Estimated test conditions are simulant p1d7 $\left(\rho_{\mathrm{s}}=2.45 \mathrm{~g} / \mathrm{cm}^{3}, \mathrm{~d}_{50}=178 \mu \mathrm{m}\right)$, solids fraction $\left(\phi_{\mathrm{s}}=0.0072\right)$ using a $\mathrm{d}=0.655 \mathrm{in}$. diameter nozzle with duty cycle $(\mathrm{DC}=0.35)$ and pulse volume fraction $\left(\phi_{\mathrm{p}}=0.080\right)$. 


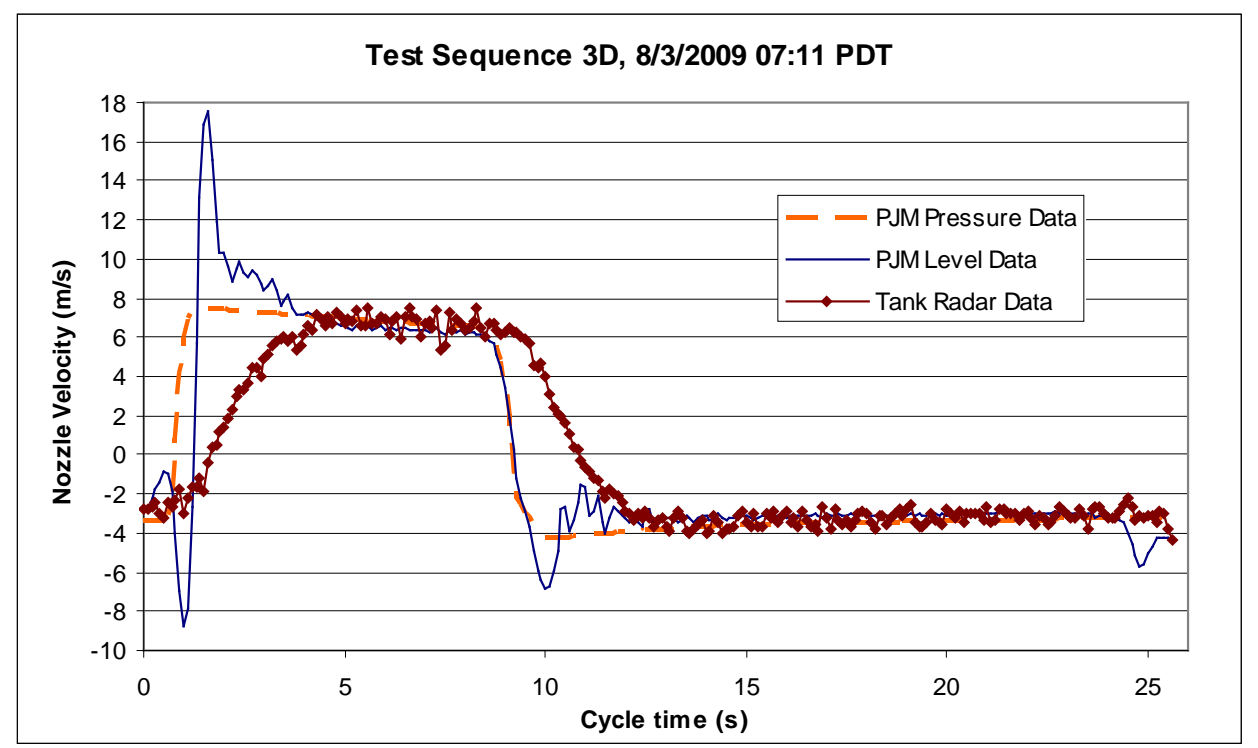

Figure A.3. Nozzle Exit Velocity (U) Averaged Over Ten Cycles for Test Sequence 3D with Target Exit Velocity $=7 \mathrm{~m} / \mathrm{s}$ and an 8-Tube Array. Estimated test conditions are simulant s1d2 $\left(\rho_{\mathrm{s}}=2.48 \mathrm{~g} / \mathrm{cm}^{3}, d_{50}=69 \mu \mathrm{m}\right)$, solids fraction $\left(\phi_{\mathrm{S}}=0.0138\right)$ using a $\mathrm{d}=0.655 \mathrm{in}$. diameter nozzle with duty cycle $(\mathrm{DC}=0.33)$ and pulse volume fraction $\left(\phi_{\mathrm{p}}=0.083\right)$.

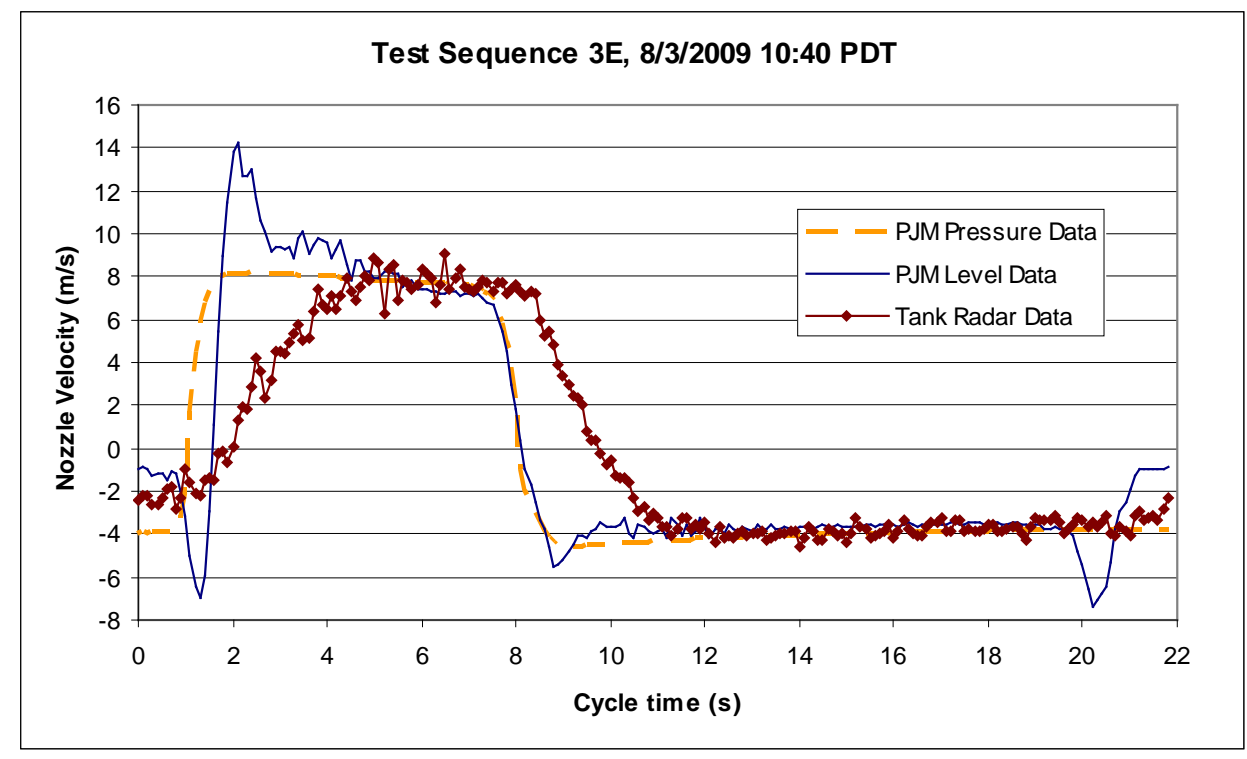

Figure A.4. Nozzle Exit Velocity (U) Averaged Over Ten Cycles for Test Sequence 3E with Target Exit Velocity $=8 \mathrm{~m} / \mathrm{s}$ and an 8-Tube Array. Estimated test conditions are simulant s1d2 $\left(\rho_{\mathrm{s}}=2.48 \mathrm{~g} / \mathrm{cm}^{3}, d_{50}=69 \mu \mathrm{m}\right)$, solids fraction $\left(\phi_{\mathrm{S}}=0.0138\right)$ using a $\mathrm{d}=0.655 \mathrm{in}$. diameter nozzle with duty cycle $(\mathrm{DC}=0.33)$ and pulse volume fraction $\left(\phi_{\mathrm{p}}=0.077\right)$. 


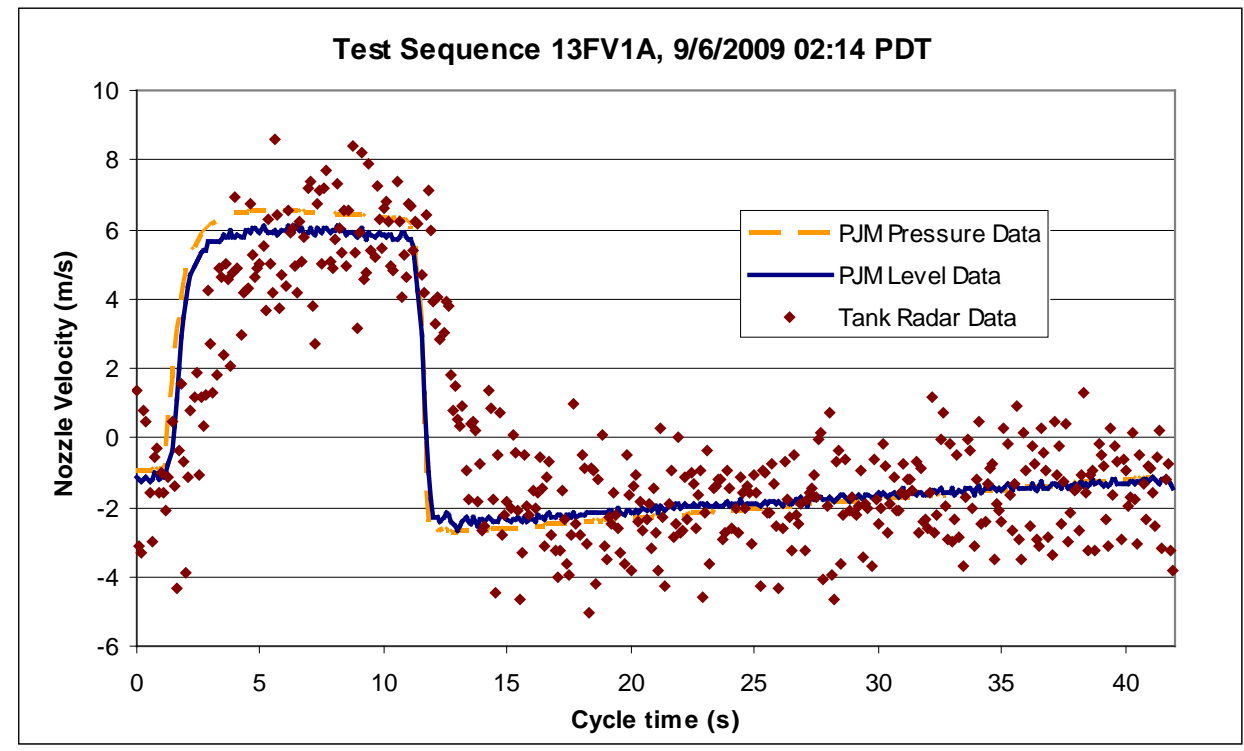

Figure A.5. Nozzle Exit Velocity (U) Averaged Over Ten Cycles for Test Sequence 13V1A with Target Exit Velocity $=6 \mathrm{~m} / \mathrm{s}$ and a 12-Tube Array. Estimated test conditions are simulant s1d2 $\left(\rho_{\mathrm{s}}=2.48 \mathrm{~g} / \mathrm{cm}^{3}, d_{50}=69 \mu \mathrm{m}\right)$, solids fraction $\left(\phi_{\mathrm{s}}=0.0086\right)$ using a $\mathrm{d}=0.379 \mathrm{in}$. diameter nozzle with duty cycle $(\mathrm{DC}=0.25)$ and pulse volume fraction $\left(\phi_{\mathrm{p}}=0.047\right)$.

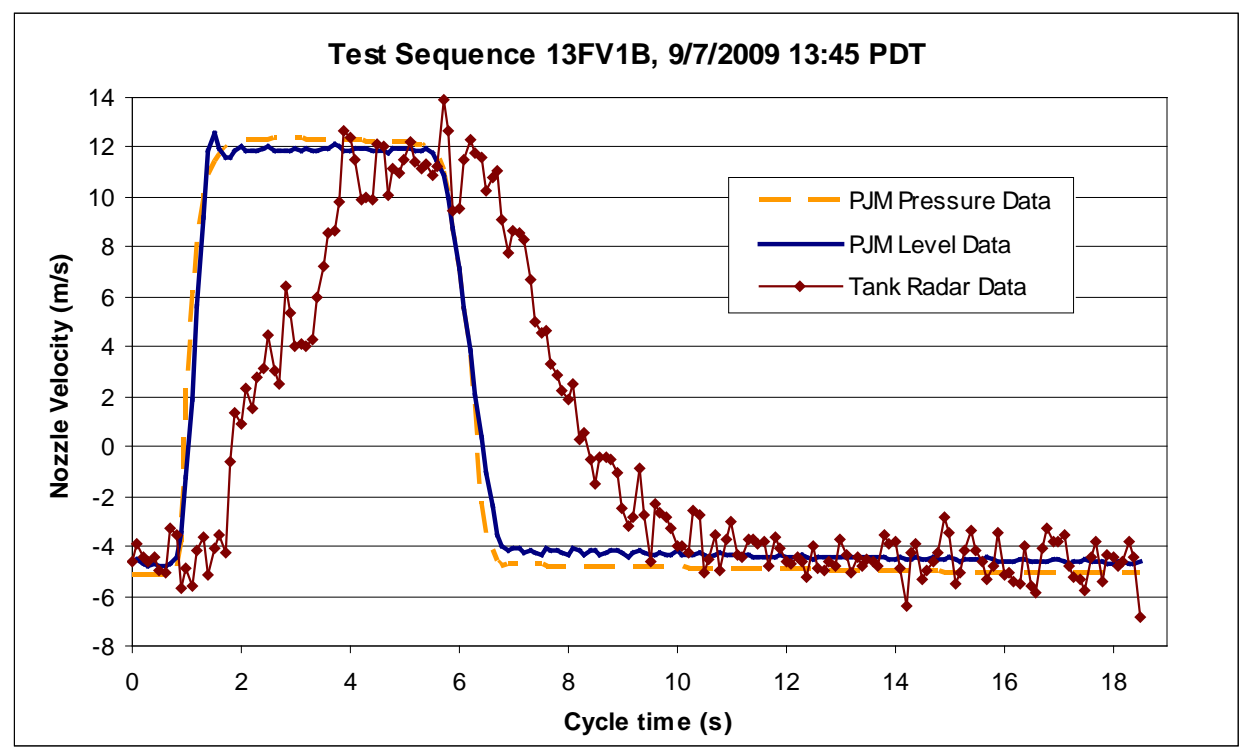

Figure A.6. Nozzle Exit Velocity (U) Averaged Over Ten Cycles for Test Sequence 13V1B with Target Exit Velocity $=13 \mathrm{~m} / \mathrm{s}$ and a 12-Tube Array. Estimated test conditions are simulant s1d2 $\left(\rho_{\mathrm{s}}=2.48 \mathrm{~g} / \mathrm{cm}^{3}, \mathrm{~d}_{50}=69 \mu \mathrm{m}\right)$, solids fraction $\left(\phi_{\mathrm{S}}=0.0086\right)$ using a $\mathrm{d}=0.379 \mathrm{in}$. diameter nozzle with duty cycle $(\mathrm{DC}=0.29)$ and pulse volume fraction $\left(\phi_{\mathrm{p}}=0.048\right)$. 
Appendix B

Correlations from Pulse Jet Mixing Tests with Noncohesive Solids 



\section{Appendix B}

\section{Correlations from Pulse Jet Mixing Tests with Noncohesive Solids}

The main correlations from the "Pulse Jet Mixing Tests with Noncohesive Solids” Report (Meyer et al. 2009) are summarized in Sections B.1 through B.4, and details of the models are described in Section 7 and Appendices D, E and F of Meyer et al. (2009). Correlations for a "new" physical model (Fort et al. 2010) are summarized in Section B.5. The model parameters are summarized in Table B.1.

Table B.1. Model and Response Variables

\begin{tabular}{|c|c|}
\hline Variable & Definition \\
\hline $\mathrm{D}$ & tank diameter (m) \\
\hline $\mathrm{d}$ & jet nozzle diameter (m) \\
\hline$d_{s}$ & solids particle diameter $=\mathrm{d}_{50}=$ median particle diameter $(\mathrm{m})$ \\
\hline DC & duty cycle (nondimensional) \\
\hline $\mathrm{Ga}$ & Galileo number $=\mathrm{Ga}=(\mathrm{s}-1) \mathrm{g} \mathrm{d}_{\mathrm{s}}{ }^{3} / v^{2} ; v=$ kinematic viscosity \\
\hline HS & head shape $(\mathrm{E}=$ elliptical, $\mathrm{FD}=$ flange and dish, $\mathrm{S}=$ spherical) \\
\hline $\mathrm{N}_{\mathrm{I}}$ & number of operating pulse jets on inner ring \\
\hline $\mathrm{N}_{J}$ & $\mathrm{~N}_{\mathrm{J}}=\mathrm{N}_{\mathrm{O}}+\mathrm{N}_{\mathrm{I}}=$ number of operating pulse jets (number) \\
\hline $\mathrm{N}_{\mathrm{O}}$ & number of operating pulse jets on outer ring \\
\hline s & density ratio of solids to liquid (nondimensional) \\
\hline $\mathrm{U}$ & discharge velocity (m/s) \\
\hline $\mathrm{U}_{\mathrm{T}}$ & unhindered terminal settling velocity $(\mathrm{m} / \mathrm{s})$ \\
\hline $\mathrm{U}_{\mathrm{TH}}$ & hindered terminal settling velocity $(\mathrm{m} / \mathrm{s})$ \\
\hline$\phi_{\mathrm{J}}$ & $\mathrm{phi}_{\mathrm{J}}=$ jet density $=\mathrm{N}_{\mathrm{J}}(\mathrm{d} / \mathrm{D})^{2}$ (nondimensional) \\
\hline$\phi_{\mathrm{p}}$ & phi $_{\mathrm{p}}=$ pulse volume fraction $=\mathrm{N}_{\mathrm{J}} \mathrm{V}_{\mathrm{P}} / \mathrm{V}_{\mathrm{REF}}=\mathrm{N}_{\mathrm{J}} \mathrm{V}_{\mathrm{P}} /\left(\pi \mathrm{D}^{3} / 4\right)$ (nondimensional) \\
\hline$\phi_{\mathrm{S}}$ & phi $_{\mathrm{S}}=$ solids fraction $=\mathrm{V}_{\mathrm{S}} / \mathrm{V}_{\mathrm{REF}}=\mathrm{V}_{\mathrm{S}} /\left(\pi \mathrm{D}^{3} / 4\right)$ (nondimensional) \\
\hline \multicolumn{2}{|l|}{ Response } \\
\hline $\mathrm{C}_{0}$ & $\begin{array}{l}\text { average solids concentration at the vessel bottom at elevation } 0 \text { (volume percent } \\
\text { solids) }\end{array}$ \\
\hline $\mathrm{C}(\mathrm{Z})$ & $\begin{array}{l}\text { solids vertical distribution, concentration as a function of elevation (volume } \\
\text { percent solids) }\end{array}$ \\
\hline $\mathrm{H}_{\mathrm{C}}$ & cloud height (m) \\
\hline $\mathrm{U}_{\mathrm{CS}}$ & critical suspension velocity, all solids suspended at the end of the pulse $(\mathrm{m} / \mathrm{s})$ \\
\hline
\end{tabular}




\section{B.1 Summary of Physical Models}

This section summarizes the physical models for $\mathrm{U}_{\mathrm{CS}}, \mathrm{H}_{\mathrm{C}}, \mathrm{C}_{0}$, and $\mathrm{C}(\mathrm{Z})$ described in Sections 7.3.2, 7.3.3 and 7.3.4 of Meyer et al. (2009).

\section{B.1.1 U U Physical Model}

The physical model for $\mathrm{U}_{\mathrm{CS}}$ is listed as Eq. (7.48) in Section 7.3.4 (Meyer et al. 2009). ${ }^{1}$

$$
\mathrm{U}_{\mathrm{CS}}=2.220 \mathrm{U}_{\mathrm{TH}}\left(\frac{\mathrm{D}(\mathrm{s}-1) \mathrm{g}}{\mathrm{U}_{\mathrm{TH}}{ }^{2}}\right)^{0.284} \phi_{\mathrm{J}}{ }^{-0.487} \mathrm{DC}^{-0.284} \phi_{\mathrm{S}}{ }^{0.284} \phi_{\mathrm{p}}{ }^{-0.198} \mathrm{Ga}^{-0.142}
$$

\section{B.1.2 $\mathrm{H}_{\mathrm{C}}$ Physical Model}

The physical model for $\mathrm{H}_{\mathrm{C}}$ is listed as Eq. (7.49) in Section 7.3.4 (Meyer et al. 2009).

$$
\mathrm{H}_{\mathrm{C}}=\frac{\mathrm{DC} \cdot \mathrm{U}_{\mathrm{TH}}^{2} \phi_{\mathrm{p}}^{0.698} \phi_{\mathrm{J}}^{1.714}}{(\mathrm{~s}-1) \mathrm{g} \phi_{\mathrm{S}}} \cdot \exp \left[8.847\left(\frac{\mathrm{U}}{\mathrm{U}_{\mathrm{TH}}}\right)^{0.131}\right]
$$

\section{B.1.3 Solids Concentration on Vessel Floor Model}

The model for solids concentration on the vessel floor is listed as Eq. (7.50) in Section 7.3.4 (Meyer et al. 2009).

$$
\mathrm{C}_{0}=\frac{2 \mathrm{D}(\mathrm{s}-1) \mathrm{g} \phi_{\mathrm{S}}{ }^{2}}{\mathrm{DC} \cdot \mathrm{U}_{\mathrm{TH}}{ }^{2} \phi_{\mathrm{p}}{ }^{0.698} \phi_{\mathrm{J}}{ }^{1.714}} \cdot \frac{1}{\exp \left[8.847\left(\frac{\mathrm{U}}{\mathrm{U}_{\mathrm{TH}}}\right)^{0.131}\right]}
$$

\section{B.1.4 Solids Concentration as a Function of Elevation}

The model for the solids concentration at height $\mathrm{Z}(\mathrm{m})$ assuming a linear profile is listed as Eq. (7.51) in Section 7.3.4 (Meyer et al. 2009).

$1 \quad$ Note the $\phi_{\mathrm{P}}$ and $\phi_{\mathrm{S}}$ are based on vessel reference volumes as defined in Table B.1. 


$$
\begin{aligned}
\mathrm{C}(\mathrm{Z}) & =2 \phi_{\mathrm{S}}\left\{\frac{\mathrm{DC} \cdot \mathrm{U}_{\mathrm{TH}}{ }^{2} \phi_{\mathrm{p}}^{0.698} \phi_{\mathrm{J}}^{1.714}}{\mathrm{D}(\mathrm{s}-1) \mathrm{g} \phi_{\mathrm{S}}} \cdot \exp \left[8.847\left(\frac{\mathrm{U}}{\mathrm{U}_{\mathrm{TH}}}\right)^{0.131}\right]\right\}^{-1} \\
& \bullet\left[1-\frac{\mathrm{Z}}{\frac{\mathrm{DC} \cdot \mathrm{U}_{\mathrm{TH}}{ }^{2} \phi_{\mathrm{p}}{ }^{0.698} \phi_{\mathrm{J}}{ }^{1.714}}{(\mathrm{~s}-1) \mathrm{g} \phi_{\mathrm{S}}} \cdot \exp \left[8.847\left(\frac{\mathrm{U}}{\mathrm{U}_{\mathrm{TH}}}\right)^{0.131}\right]}\right]
\end{aligned}
$$

\section{B.2 Summary of Generalized Models}

This section summarizes the generalized models for $\mathrm{U}_{\mathrm{CS}}$ and $\mathrm{H}_{\mathrm{C}}$ described in Appendix $\mathrm{F}$ Sections F.2.4.3 and F3.4.3, respectively of Meyer et al. (2009).

\section{B.2.1 $U_{c s}$ Generalized Models}

The generalized model forms for $\mathrm{U}_{\mathrm{CS}}$ are listed as Eq. (F.9a) and Eq. (F.9b) in Section F.2.4.1 of Appendix F (Meyer et al. 2009). The resulting $U_{C S}$ generalized models for the full data set, listed in Eq. (F.13a) and Eq. (F.13b) in Section F.2.4.1 of Appendix F (Meyer et al. 2009), ${ }^{1}$ are

$$
\mathrm{U}_{\mathrm{CS}}=0.273 \mathrm{U}_{\mathrm{T}}\left(\frac{\mathrm{D}(\mathrm{s}-1) \mathrm{g}}{\mathrm{U}_{\mathrm{T}}^{2}}\right)^{0.397}\left(\frac{\mathrm{d}}{\mathrm{D}}\right)^{-0.991}(\mathrm{~s}-1)^{0.086} \mathrm{DC}^{-0.205} \phi_{\mathrm{S}}^{0.243} \phi_{\mathrm{p}}^{-0.221} \mathrm{~N}_{\mathrm{J}}^{-0.511}
$$

and

$$
\begin{aligned}
\ln \left(\mathrm{U}_{\mathrm{CS}}\right)= & -1.297+\ln \left(\mathrm{U}_{\mathrm{T}}\right)+0.397 \ln \left(\frac{\mathrm{D}(\mathrm{s}-1) \mathrm{g}}{\mathrm{U}_{\mathrm{T}}^{2}}\right)-0.991 \ln \left(\frac{\mathrm{d}}{\mathrm{D}}\right)+0.086 \ln (\mathrm{s}-1) \\
& -0.205 \ln (\mathrm{DC})+0.243 \ln \left(\phi_{\mathrm{S}}\right)-0.221 \ln \left(\phi_{\mathrm{p}}\right)-0.511 \ln \left(\mathrm{N}_{\mathrm{J}}\right)
\end{aligned}
$$

\section{B.2.2 $\quad H_{C}$ Generalized Models}

The generalized model forms for $\mathrm{H}_{\mathrm{C}}$ are listed as Eq. (F.22a) and Eq. (F.22b) in Section F3.4.1 of Appendix $\mathrm{F}$ (Meyer et al. 2009). The resulting $\mathrm{H}_{\mathrm{C}}$ generalized models for the full data set, listed in Eq. (F.26a) and (F.26b) in Section F3.4.3 of Appendix F (Meyer et al. 2009), ${ }^{1}$ are

$$
\begin{aligned}
\mathrm{H}_{\mathrm{C}} & =3.040 \mathrm{D}\left(\frac{\mathrm{U}^{2}}{\mathrm{D}(\mathrm{s}-1) \mathrm{g}}\right)^{0.473}\left(\frac{\mathrm{d}}{\mathrm{D}}\right)^{1.693}(\mathrm{~s}-1)^{-0.356}\left(\frac{\mathrm{U}_{\mathrm{T}}}{\mathrm{U}}\right)^{-0.410} \mathrm{DC}^{0.364} \\
& \times \phi_{\mathrm{S}}^{-0.616}\left(1-\phi_{\mathrm{s}}\right)^{-17.206} \phi_{\mathrm{p}}^{0.213} \mathrm{~N}_{\mathrm{J}}^{0.320}
\end{aligned}
$$

1 Note the $\phi_{\mathrm{p}}$ and $\phi_{\mathrm{S}}$ are based on vessel reference volumes as defined in Table B.1. 
and

$$
\begin{aligned}
& \ln \left(\mathrm{H}_{\mathrm{C}}\right)=1.112+\ln (\mathrm{D})+0.473 \ln \left(\frac{\mathrm{U}^{2}}{\mathrm{D}(\mathrm{s}-1) \mathrm{g}}\right)+1.693 \ln \left(\frac{\mathrm{d}}{\mathrm{D}}\right)-0.356 \ln (\mathrm{s}-1)-0.410 \ln \left(\frac{\mathrm{U}_{\mathrm{T}}}{\mathrm{U}}\right) \\
& +0.364 \ln (\mathrm{DC})-0.616 \ln \left(\phi_{\mathrm{S}}\right)-17.206 \ln \left(1-\phi_{\mathrm{S}}\right)+0.213 \ln \left(\phi_{\mathrm{p}}\right)+0.320 \ln \left(\mathrm{N}_{\mathrm{J}}\right)
\end{aligned}
$$

\section{B.3 Summary of Dimensional Models without Interaction Terms}

This section summarizes the dimensional models for $\mathrm{U}_{\mathrm{CS}}$ and $\mathrm{H}_{\mathrm{C}}$ without interaction terms from Appendix F Sections F.2.4.2 and F3.4.2, respectively of Meyer et al. (2009).

The dimensional models for $\mathrm{U}_{\mathrm{CS}}$ and $\mathrm{H}_{\mathrm{C}}$ were developed as follows. The nondimensional variables on both sides of the $\mathrm{U}_{\mathrm{CS}}$ and $\mathrm{H}_{\mathrm{C}}$ nondimensional models of Section B.1 were expressed in terms of their separate component test variables. These model forms were next rewritten with only the response variable $\left(\mathrm{U}_{\mathrm{CS}}\right.$ or $\left.\mathrm{H}_{\mathrm{C}}\right)$ on the left side of the model and the predictor variables on the right. Then the terms for each test variable were collected, and each collected term was assigned a coefficient to be estimated from the data using multiple regression (MR). By assigning a separate coefficient for each predictor variable, we obtained a generalized form of the physical model on which it was based. The results from fitting the resulting model forms to the experimental data are listed here and described in Meyer et al. (2009) Appendix F.

\section{B.3.1 $U_{c s}$ Dimensional Model without Interaction Terms}

The $\mathrm{U}_{\mathrm{CS}}$ dimensional models without interaction terms for the full data set, listed in Eq. (F.11a) and Eq. (F.11b) in Appendix F Section F.2.4.2 of (Meyer et al. 2009) ${ }^{1}$ are

$$
\begin{aligned}
\mathrm{U}_{\mathrm{CS}} & =0.309(\mathrm{D})^{1.321}(\mathrm{~s}-1)^{0.471}\left(\phi_{\mathrm{S}}\right)^{0.222}\left(\mathrm{U}_{\mathrm{T}}\right)^{0.148}(\mathrm{DC})^{-0.247}\left(\phi_{\mathrm{p}}\right)^{-0.211} \\
& \times\left(\mathrm{N}_{\mathrm{J}}\right)^{-0.525}(\mathrm{~d})^{-1.072}
\end{aligned}
$$

and

$$
\begin{aligned}
\ln \left(\mathrm{U}_{\mathrm{CS}}\right) & =-1.173+1.321 \ln (\mathrm{D})+0.471 \ln (\mathrm{s}-1)+0.222 \ln \left(\phi_{\mathrm{S}}\right)+0.148 \ln \left(\mathrm{U}_{\mathrm{T}}\right) \\
& -0.247 \ln (\mathrm{DC})-0.211 \ln \left(\phi_{\mathrm{p}}\right)-0.525 \ln \left(\mathrm{N}_{\mathrm{J}}\right)-1.072 \ln (\mathrm{d})
\end{aligned}
$$

\section{B.3.2 $\mathrm{H}_{\mathrm{C}}$ Dimensional Model without Interaction Terms}

The $\mathrm{H}_{\mathrm{C}}$ dimensional models without interaction terms for the full data set, listed in Eq. (F.24a) and Eq. (F.24b) in Appendix F Section F.3.4.2 of (Meyer et al. 2009) ${ }^{1}$ are

$$
\begin{aligned}
\mathrm{H}_{\mathrm{C}} & =1.079(\mathrm{D})^{-1.191}(\mathrm{~s}-1)^{-0.836}\left(\phi_{\mathrm{S}}\right)^{-0.623}\left(1-\phi_{\mathrm{S}}\right)^{-17.502}\left(\mathrm{U}_{\mathrm{T}}\right)^{-0.412}(\mathrm{DC})^{0.371} \\
& \times\left(\phi_{\mathrm{p}}\right)^{0.218}\left(\mathrm{~N}_{\mathrm{J}}\right)^{0.330}(\mathrm{~d})^{1.722}(\mathrm{U})^{1.378}
\end{aligned}
$$

1 Note the $\phi_{\mathrm{p}}$ and $\phi_{\mathrm{S}}$ are based on vessel reference volumes as defined in Table B.1. 
and

$$
\begin{aligned}
\ln \left(\mathrm{H}_{\mathrm{C}}\right)= & 0.076-1.191 \ln (\mathrm{D})-0.836 \ln (\mathrm{s}-1)-0.623 \ln \left(\phi_{\mathrm{S}}\right)-17.502 \ln \left(1-\phi_{\mathrm{S}}\right) \\
& -0.412 \ln \left(\mathrm{U}_{\mathrm{T}}\right)+0.371 \ln (\mathrm{DC})+0.218 \ln \left(\phi_{\mathrm{p}}\right)+0.330 \ln \left(\mathrm{N}_{\mathrm{J}}\right)+1.722 \ln (\mathrm{d}) \\
& +1.378 \ln (\mathrm{U}) .
\end{aligned}
$$

\section{B.4 Summary of Dimensional Models with Two Variable Interaction Terms}

This section summarizes the dimensional models for $\mathrm{U}_{\mathrm{CS}}$ and $\mathrm{H}_{\mathrm{C}}$ with interaction terms in Appendix F Sections F.2.5 and F3.5, respectively from Meyer et al. (2009).

The term interaction is used in the following way: two variables interact if the effect on the response variable (e.g., $\mathrm{U}_{\mathrm{CS}}$ or $\mathrm{H}_{\mathrm{C}}$ ) of one variable depends on the value of the second variable. The method used to add interactions to the $\mathrm{U}_{\mathrm{CS}}$ and $\mathrm{H}_{\mathrm{C}}$ dimensional model forms and the results of fitting these model forms to the full and trimmed data sets are discussed in Meyer et al. (2009) Sections F.2.5 and F.3.5 of Appendix F. Adding interaction terms moderately improved the interpolative prediction performance of the dimensional models without interaction terms. However, extrapolative use of models with interaction terms can yield significantly inaccurate predictions. Hence, it is recommended the dimensional models with interaction terms be limited to interpolative use within the region of conditions covered during experimental testing (see Section F.5 of Appendix F).

\section{B.4.1 $\mathrm{U}_{\mathrm{cs}}$ Dimensional Model with Interaction Terms}

The $\mathrm{U}_{\mathrm{CS}}$ dimensional models with interaction terms for the full data set, listed in Eq. (F.15a) and Eq. (F.15b) in Appendix F Section F.2.5 of Meyer et al. (2009) ${ }^{1}$ are

$$
\begin{aligned}
\mathrm{U}_{\mathrm{CS}} & =0.652(\mathrm{D})^{1.186}(\mathrm{~s}-1)^{0.421}\left(\phi_{\mathrm{S}}\right)^{0.264}\left(\mathrm{U}_{\mathrm{T}}\right)^{0.082+0.276(\mathrm{DC})+0.897\left(\phi_{\mathrm{S}}\right)} \\
& \times(\mathrm{DC})^{0.366-0.170(\mathrm{D})}\left(\phi_{\mathrm{p}}\right)^{-0.210}\left(\mathrm{~N}_{\mathrm{J}}\right)^{-0.545}(\mathrm{~d})^{-1.116}
\end{aligned}
$$

and

$$
\begin{aligned}
\ln \left(\mathrm{U}_{\mathrm{CS}}\right) & =-0.428+1.186 \ln (\mathrm{D})+0.421 \ln (\mathrm{s}-1)+0.264 \ln \left(\phi_{\mathrm{S}}\right) \\
& +\left[0.082+0.276(\mathrm{DC})+0.897\left(\phi_{\mathrm{S}}\right)\right] \ln \left(\mathrm{U}_{\mathrm{T}}\right)+[0.366-0.170(\mathrm{D})] \ln (\mathrm{DC}) \\
& -0.210 \ln \left(\phi_{\mathrm{p}}\right)-0.545 \ln \left(\mathrm{N}_{\mathrm{J}}\right)-1.116 \ln (\mathrm{d}),
\end{aligned}
$$

1 Note the $\phi_{\mathrm{p}}$ and $\phi_{\mathrm{S}}$ are based on vessel reference volumes as defined in Table B.1. 


\section{B.4.2 $\mathrm{H}_{\mathrm{C}}$ Dimensional Model with Interaction Terms}

The $\mathrm{H}_{\mathrm{C}}$ dimensional models with interaction terms for the full data set, listed in Eq. (F.28a) and Eq. (F.28b) in Appendix F Section F.3.5 of Meyer et al. (2009) ${ }^{1}$ are

$$
\begin{aligned}
\mathrm{H}_{\mathrm{C}} & =0.627(\mathrm{D})^{-0.820}(\mathrm{~s}-1)^{-0.833}\left(\phi_{\mathrm{S}}\right)^{-0.880+0.153(\mathrm{D})}\left(1-\phi_{\mathrm{S}}\right)^{-59.975}\left(\mathrm{U}_{\mathrm{T}}\right)^{-0.505} \\
& \times(\mathrm{DC})^{0.434}\left(\phi_{\mathrm{p}}\right)^{0.292}\left(\mathrm{~N}_{\mathrm{J}}\right)^{0.497}(\mathrm{~d})^{1.979}(\mathrm{U})^{1.731-16.176\left(\phi_{\mathrm{S}}\right)}
\end{aligned}
$$

and

$$
\begin{aligned}
\ln \left(\mathrm{H}_{\mathrm{C}}\right) & =-0.467-0.820 \ln (\mathrm{D})-0.833 \ln (\mathrm{s}-1)+[-0.880+0.153(\mathrm{D})] \ln \left(\phi_{\mathrm{S}}\right) \\
& -59.975 \ln \left(1-\phi_{\mathrm{S}}\right)-0.505 \ln \left(\mathrm{U}_{\mathrm{T}}\right)+0.434 \ln (\mathrm{DC})+0.292 \ln \left(\phi_{\mathrm{p}}\right) \\
& +0.497 \ln \left(\mathrm{N}_{\mathrm{J}}\right)+1.979 \ln (\mathrm{d})+\left[1.731-16.176\left(\phi_{\mathrm{S}}\right)\right] \ln (\mathrm{U}),
\end{aligned}
$$

\section{B.5 Summary of New Physical Model}

This section summarizes the new physical model for $\mathrm{U}_{\mathrm{CS}}, \mathrm{H}_{\mathrm{C}}, \mathrm{C}_{0}$, and $\mathrm{C}(\mathrm{Z})$ from Fort et al. (2010) which are developed in Appendix C.

\section{B.5.1 $U_{c s}$ New Physical Model}

The development of the $\mathrm{U}_{\mathrm{CS}}$ new physical model is described in Appendix C Section C.2.1. Combining equations C.1, C.2, and C.3 yields ${ }^{1}$

$$
\mathrm{U}_{\mathrm{CS}}=2.302 \mathrm{U}_{\mathrm{TH}}\left(\frac{\mathrm{D}(\mathrm{s}-1) \mathrm{g}}{\mathrm{U}_{\mathrm{TH}}{ }^{2}}\right)^{0.261} \phi_{\mathrm{J}}{ }^{-0.511} \mathrm{DC}^{-0.261} \phi_{\mathrm{S}}{ }^{0.261} \phi_{\mathrm{p}}{ }^{-0.234} \mathrm{Ga}^{-0.176}
$$

\section{B.5.2 $\mathrm{H}_{\mathrm{C}}$ New Physical Model}

The development of the $\mathrm{H}_{\mathrm{C}}$ new physical model is described in Appendix C Section C.2.2. Combining equations C. 4 and C. 5 yields ${ }^{1}$

$$
\mathrm{H}_{\mathrm{C}}=\frac{\mathrm{DC} \cdot \mathrm{U}_{\mathrm{TH}}^{2} \phi_{\mathrm{p}}^{0.539} \phi_{\mathrm{J}}^{1.662} \mathrm{~N}^{-0.658} \mathrm{Re}_{\mathrm{J}}^{0.143}}{(\mathrm{~s}-1) \mathrm{g} \phi_{\mathrm{S}}} \cdot \exp \left[8.223\left(\frac{\mathrm{U}}{\mathrm{U}_{\mathrm{TH}}}\right)^{0.1364}\right\rfloor
$$

$1 \quad$ Note the $\phi_{\mathrm{p}}$ and $\phi_{\mathrm{S}}$ are based on vessel reference volumes as defined in Table B.1. 


\section{B.5.3 New Solids Concentration on Vessel Floor Model}

The model for solids concentration on the vessel floor is obtained by substituting Eq. (B.12) into Eq. (7.46) of Meyer et al. (2009) $\left[\mathrm{C}_{0}=\mathrm{k} \phi_{\mathrm{S}}\left(\mathrm{H}_{\mathrm{C}} / \mathrm{D}\right)^{-1}\right.$ where $\mathrm{C}_{0}$ is in volume percent ] with $\mathrm{k}=2$, which yields ${ }^{1}$

$$
\mathrm{C}_{0}=2 \phi_{\mathrm{S}} \frac{\mathrm{D}}{\mathrm{H}_{\mathrm{C}}}=\frac{2 \mathrm{D}(\mathrm{s}-1) \mathrm{g} \phi_{\mathrm{S}}{ }^{2}}{\mathrm{DC} \cdot \mathrm{U}_{\mathrm{TH}}{ }^{2} \phi_{\mathrm{p}}^{0.539} \phi_{\mathrm{J}}^{1.662} \mathrm{~N}^{-0.658} \mathrm{Re}_{\mathrm{J}}^{0.143}} \cdot \frac{1}{\exp \left[8.223\left(\frac{\mathrm{U}}{\mathrm{U}_{\mathrm{TH}}}\right)^{0.1364}\right]}
$$

where $\operatorname{Re}_{\mathrm{J}}=\mathrm{Ud} / \mathrm{v}$.

\section{B.5.4 New Solids Concentration as a Function of Elevation}

The model for the solids concentration at height $\mathrm{Z}(\mathrm{m})$ assuming a linear profile is obtained by substituting Eq. (B.12) into Eq. (7.47) of Meyer et al. (2009)

$\left[\mathrm{C}(\mathrm{Z})=\mathrm{C}_{0}\left(1-\mathrm{Z} / \mathrm{H}_{\mathrm{C}}\right)=\mathrm{k} \phi_{\mathrm{S}}\left(\mathrm{H}_{\mathrm{C}} / \mathrm{D}\right)^{-1}\left[1-\mathrm{Z} / \mathrm{H}_{\mathrm{C}}\right]\right.$ with $\mathrm{k}=2$, which gives

$$
\begin{aligned}
& \mathrm{C}(\mathrm{Z})=\mathrm{C}_{0}\left(1-\frac{\mathrm{Z}}{\mathrm{H}_{\mathrm{C}}}\right)=2 \phi_{\mathrm{S}}\left\{\frac{\mathrm{DC} \cdot \mathrm{U}_{\mathrm{TH}}^{2} \phi_{\mathrm{p}}^{0.539} \phi_{\mathrm{J}}^{1.662} \mathrm{Re}_{\mathrm{J}}^{0.143}}{\mathrm{D}(\mathrm{s}-1) \mathrm{g} \phi_{\mathrm{S}}} \cdot \exp \left[8.223\left(\frac{\mathrm{U}}{\mathrm{U}_{\mathrm{TH}}}\right)^{0.1364}\right]\right\}^{-1} \\
& \left\{1-\frac{\mathrm{Z}}{\frac{\mathrm{DC} \cdot \mathrm{U}_{\mathrm{TH}}{ }^{2} \phi_{\mathrm{p}}^{0.539} \phi_{\mathrm{J}}^{1.662} \mathrm{Re}_{\mathrm{J}}^{0.143}}{(\mathrm{~s}-1) \mathrm{g} \phi_{\mathrm{S}}} \cdot \exp \left[8.223\left(\frac{\mathrm{U}}{\mathrm{U}_{\mathrm{TH}}}\right)^{0.1364}\right]}\right]
\end{aligned}
$$

\section{B.6 Adjusted New Physical Model}

The development of the $U_{C s}$ adjusted new physical model is described in Section 4.2. Incorporating an adjusted settling velocity which accounts for the effects of non-prototypic refill during the Phase 1 tests yields ${ }^{1}$

$$
\mathrm{U}_{\mathrm{CS}}=2.302\left(\mathrm{U}_{\mathrm{TH}}+\phi_{\mathrm{J}} \mathrm{DC} \mathrm{U}_{\mathrm{CS}} /\left(1-\phi_{\mathrm{PT}}\right)\right)^{0.478}(\mathrm{D}(\mathrm{s}-1) \mathrm{g})^{0.261} \phi_{\mathrm{J}}^{-0.511} \mathrm{DC}^{-0.261} \phi_{\mathrm{S}}^{0.261} \phi_{\mathrm{p}}^{-0.234} \mathrm{Ga}^{-0.176}
$$

This adjustment principle could be applied to all the correlations that incorporate settling velocity.

1 Note the $\phi_{\mathrm{p}}$ and $\phi_{\mathrm{S}}$ are based on vessel reference volumes as defined in Table B.1. 


\section{B.7 References}

Fort, JA, PA Meyer, JA Bamberger, CW Enderlin, PA Scott, MJ Minette, PA Gauglitz. 2010. "Scaled Testing to Evaluate Pulse Jet Mixer Performance in Waste Treatment Plant Mixing Vessels.” In Waste Management 2010 WM2010 Conference, March 7-10, 2010, Phoenix, Arizona.

Meyer, PA, JA Bamberger, CW Enderlin, JA Fort, BE Wells, SK Sundaram, PA Scott, MJ Minette, GL Smith, CA Burns, MS Greenwood, GP Morgan, EBK Baer, SF Snyder, M White, GF Piepel, BG Amidan, A Heredia-Langner. 2009. Pulse Jet Mixing Tests With Noncohesive Solids. PNNL-18098, WTP-RPT-182 Rev. 0, Pacific Northwest National Laboratory, Richland, Washington. 
Appendix C

New Physical Model 



\section{Appendix C}

\section{New Physical Model}

Since release of the original draft of RPT-WTP-182 [Rev A], a number of observations have been made, both by authors and reviewers, regarding the data and method of analysis. Many of these observations are significant, and their correction and/or implementation would result in more accurate models and predictions. Although schedule and priorities did not allow their implementation in the final report (Meyer et al. 2009), an initial attempt was made after the report release to address a number of the high priority items. These activities and findings are summarized in this appendix.

\section{C.1 Improvements Addressed}

The issues addressed in this analysis are essentially those listed in Section 10.3 of Meyer et al. (2009) and are restated and elaborated upon here:

- Adding a tube number term to the physical model - The physical model was originally developed using a data set that excluded the Fall 2007 test data. The Fall 2007 data set included a substantial number of tests with 4 and 8 jets. When the additional data were included, the cloud height model was found to under predict much of the 4- and 8-tube results. It was determined that the fit of cloud height $\left(\mathrm{H}_{\mathrm{C}}\right)$ model to the complete data set was significantly improved by simply introducing into the $\mathrm{H}_{\mathrm{C}}$ physical model the number of operating tubes as an unconstrained correlating parameter in the model. While this change to the $\mathrm{H}_{\mathrm{C}}$ physical model is small, the ramifications to the benchmarking and model application are likely to be significant.

- Benchmarking approach - The initial benchmarking of the models against previous test data from a large-scale prototypic testing was somewhat qualitative. Consequently, the selection of $U_{95}$ as the settling velocity that best characterizes mixing when the model is applied to slurries with a broad particle size and density distribution (PSDD) lacked a rigorous basis. A better approach was to systematically determine the best-fit value of $U_{T}$ for each benchmark case. This was briefly explored for two meaningful cases: a favorably conservative bound, and a best estimate. The favorably conservative bound assumed that the maximum concentration measured in each of the benchmark test cases was the value at the floor of the test tank. The best-estimate method involved estimating the concentration at the floor by applying mass conservation together with the measured concentration profile. An initial attempt at this (as described in Section 10.3 of Meyer et al. 2009) resulted in estimates for settling velocity of approximately $\overline{\mathrm{U}}_{40}$ for the favorably conservative bound and approximately $\overline{\mathrm{U}}_{60}$ for the best estimate. When these values are translated to the Hanford PSDD, they correspond to approximately $\mathrm{U}_{94}$ and $\mathrm{U}_{96}$, respectively. It turns out that the $\mathrm{U}_{95}$ value recommended in Meyer et al. (2009) is bounded by these more systematically determined values, and a more rigorous treatment of the benchmarking data would provide a clear technical basis for this choice. In this process, consideration should be given to selection of benchmarks where operating conditions are within the range of M3 experiments and WTP vessel applications. 
- Vessel evaluation methodology - There are two improvements to the vessel evaluations that will be significant. First, based on the benchmarking approach mentioned above, the settling velocity values of $\mathrm{U}_{95}$ and $\overline{\mathrm{U}}_{90}$ can be replaced with the systematically determined values (approximately $\overline{\mathrm{U}}_{40}$ and $\bar{U}_{60}$, and approximately $\mathrm{U}_{94}$ and $\mathrm{U}_{96}$, respectively). This results in a much tighter range of predicted performance in the plant vessels. The second improvement relates to the concentration performance metric.

The approach used to predict the concentration on the floor of a prototypic vessel involved a series of assumptions that result in a potentially large uncertainty in this parameter. First, it was assumed that the solids vertical distributions are linear. While this is indeed correct to first order for the average of all data, it is clear that in many cases the data were not well represented by a linear fit. Second, it was assumed that the value of concentration on the floor could be linearly extrapolated from the profiles. As part of this extrapolation process, a 1.5x correction was also applied to floor concentration in all applications to conservatively account for experimental observations where measured concentration exceeded that given by a linear extrapolation. However, since increasing concentration profiles were not observed in all cases, this additional correction factor was difficult to justify. Third and finally, there are assumptions inherent in the method used to translate concentration profiles from predicted high clouds that exceeded actual fill levels into concentration profiles within the finite fill level (note that this did not impact benchmark cases and WTP vessel applications where cloud heights were below fill height). In the absence of actual measurements of concentration near the floor of vessels, the above-mentioned assumptions result in an unquantifiable uncertainty for the calculated concentration at the floor of the vessel. In light of this uncertainty, an alternative performance metric that is more closely and directly tied to the actual test data is needed. The alternative metric recommended in the peer review ${ }^{1}$ was the jet velocity required to achieve a solids cloud that reaches a specific value of $\mathrm{H}_{\mathrm{C}} / \mathrm{H}_{\mathrm{F}}\left(\mathrm{H}_{\mathrm{F}}\right.$ is the fill height) which was within the range of values measured during M3 testing. This would exclude excessively low cloud heights that were predicted for some of the WTP vessels, as well as "well-mixed" cases where predicted cloud heights exceed actual fill. The jet velocity required to achieve a cloud height that just reaches the fill level in the prototypic vessel is consistent with this recommendation. The magnitude of this velocity relative to the design velocity is an important indicator of a given design's ability to vertically distribute solids. Floor concentrations can still be inferred from this approach by assuming uniform or linear concentration profiles.

\section{C.2 New Physical Model}

The new physical model was generated using the full data set from Meyer et al. (2009), but without the Fall 2007 data points recently identified as having low return line inlet height (RLIH). For this analysis these points were removed from the dataset used in the correlations. The models were developed using data that met the criteria:

- $\mathrm{DC}<0.7$

- $\mathrm{U} / \mathrm{U}_{\mathrm{CS}}=1$ (for the $\mathrm{U}_{\mathrm{CS}}$ model) or $\mathrm{U} / \mathrm{U}_{\mathrm{CS}} \geq 1$ (for the $\mathrm{HC}$ model)

- ratio of the return line height to the tank diameter $\geq$ unity.

1 Banerjee, S, G Wallis and C Crowe, letter to PA Scott, "Peer review of M3 test report, WTP-RPT-182 Draft A experimental,” April 24, 2009. 
The updated models described here are new versions of the physical model that was described in Meyer et al. (2009). New features in each model are summarized in the following subsections.

\section{C.2.1 U $U_{\text {cs }}$ Model}

Other than constraints imposed on the fit coefficients and the use of the modified dataset, the $\mathrm{U}_{\mathrm{CS}}$ model is unchanged. Coefficients and exponents are different than in Meyer et al. (2009), but the equation form is the same. Specifically, the exponents on pulse volume fraction $\left(\phi_{\mathrm{p}}\right)$ and jet density $\left(\phi_{\mathrm{J}}\right)$ were allowed to vary unconstrained from those in the $\mathrm{H}_{\mathrm{C}}$ model. In the previously reported models, these exponents were the same in both. The exponent on Galileo number (Ga) was allowed to vary in an effort to improve the fit. It was previously set to 0.5, which was a value cited in Meyer et al. (2009) as being consistent with power required to maintain solids suspension. The optimized coefficient is sufficiently close to not disallow this argument. In contrast to the new $\mathrm{H}_{\mathrm{C}}$ model, number of tubes was not included as an independent parameter for $\mathrm{U}_{\mathrm{CS}}$. Finally, the "hindered" settling $\left(\mathrm{U}_{\mathrm{TH}}\right)$ exponent is now set equal to 6 and the maximum concentration is corrected from 0.5 to 0.6 to agree with measured values, where in Eq. (C.2) $\phi_{\text {Smax }}$ is the solids fraction corresponding to maximum packing, and $\mathrm{p}$ is an empirical constant.

The result is

where $^{1}$

$$
\frac{\mathrm{U}_{\mathrm{CS}}}{\mathrm{U}_{\mathrm{TH}}}=2.302\left(\mathrm{D}^{*} / \mathrm{Ga}^{0.673}\right)^{0.261}
$$

$$
\mathrm{U}_{\mathrm{TH}}=\mathrm{U}_{\mathrm{T}}\left(1-\frac{\phi_{\mathrm{S}}}{\phi_{\mathrm{S} \max }}\right)^{\mathrm{P}}=\mathrm{U}_{\mathrm{T}}\left(1-\frac{\phi_{\mathrm{S}}}{0.6}\right)^{6}
$$

and

$$
\mathrm{D}^{*}=\frac{\mathrm{D}(\mathrm{s}-1) \mathrm{g} \phi_{\mathrm{S}}}{\mathrm{DC} \mathrm{U}_{\mathrm{TH}}^{2} \phi_{\mathrm{p}}^{0.898} \phi_{\mathrm{J}}^{1.958}}
$$

Correlation results for $\mathrm{U}_{\mathrm{CS}}$ are shown in Figure C.1. A comparison of model predictions with measured $\mathrm{U}_{\mathrm{CS}}$ is shown in Figure C.2.

1 Note the $\phi_{\mathrm{P}}$ and $\phi_{\mathrm{S}}$ are based on vessel reference volumes as defined in Table B.1. 


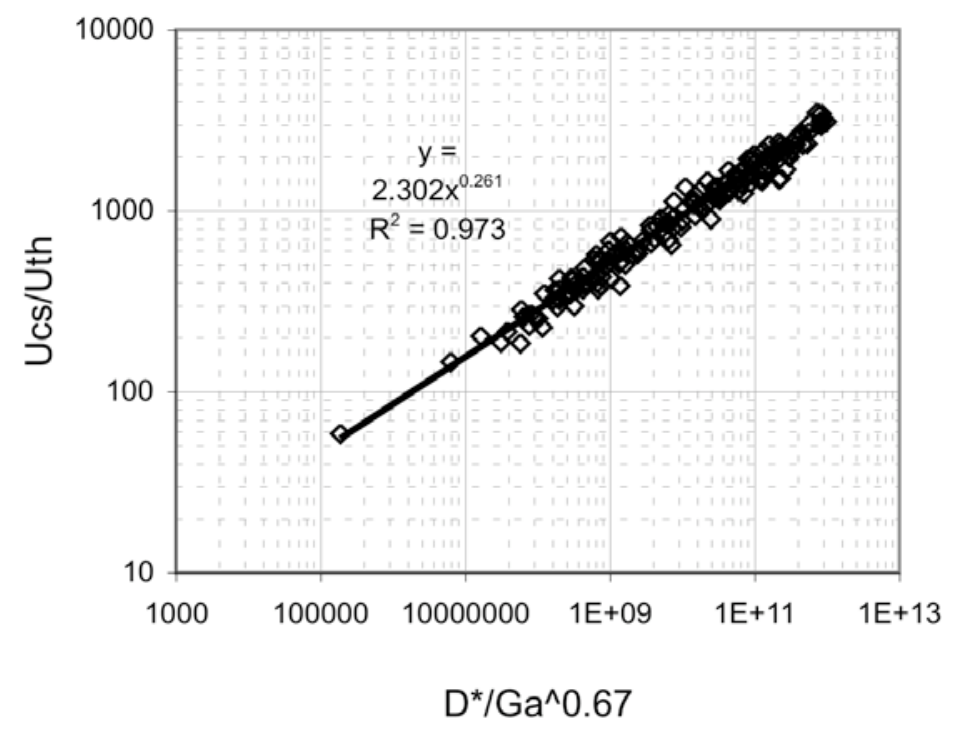

Figure C.1. Data correlation for $\mathrm{U}_{\mathrm{CS}}$

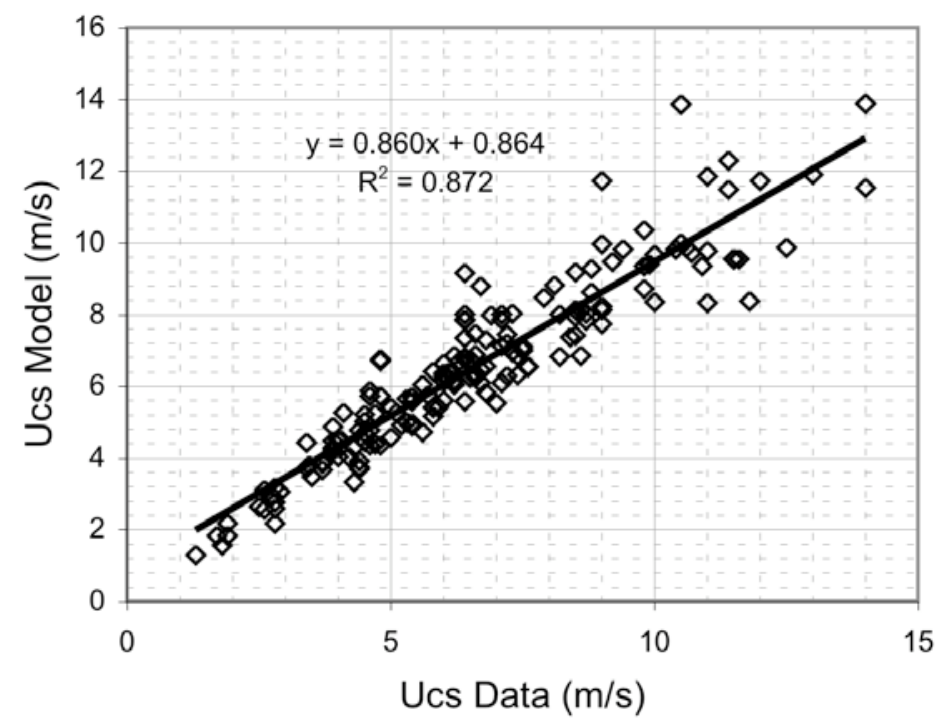

Figure C.2. Comparison of predicted and measured $\mathrm{U}_{\mathrm{CS}}$

\section{C.2.2 $\quad \mathrm{H}_{\mathrm{C}}$ Model}

For this model, the number of operating PJMs, N, is included as an independent parameter. As observed previously, many of the cloud height data points showing poor agreement with the model were for 8- and 4-tube tests. This pointed to insufficient functionality for $\mathrm{N}$, which the current model is intended to correct. As in the $\mathrm{U}_{\mathrm{CS}}$ model, the $\phi_{\mathrm{p}}$ and $\phi_{\mathrm{J}}$ exponents are allowed to vary independently. The exponent on Ga was allowed to vary, but was found to be very small $(<0.05)$; hence, it was set to zero (not varied) in the final model. The same "hindered" settling expression is used in both $\mathrm{U}_{\mathrm{CS}}$ and $\mathrm{H}_{\mathrm{C}}$ models. Finally, a jet Reynolds number term, $\mathrm{Re}_{\mathrm{J}}$, is added (based on nozzle diameter, not vessel diameter) to account for geometrical scale. 
The result is

$$
\ln \left[\mathrm{H}_{\mathrm{C}}^{*} \operatorname{Re}_{\mathrm{J}}^{-0.143}\right]=8.223\left(\mathrm{U} / \mathrm{U}_{\mathrm{TH}}\right)^{0.1364}
$$

where $^{1}$

$$
\mathrm{H}_{\mathrm{C}}^{*}=\frac{\mathrm{H}_{\mathrm{C}}}{\mathrm{D}} \mathrm{D}^{*}=\frac{\mathrm{H}_{\mathrm{C}}(\mathrm{s}-1) \mathrm{g} \phi_{\mathrm{S}} \mathrm{N}^{0.658}}{\mathrm{DC} \mathrm{U}_{\mathrm{TH}}^{2} \phi_{\mathrm{p}}^{0.898} \phi_{\mathrm{J}}^{1.662}}
$$

and

$$
\operatorname{Re}_{\mathrm{J}}=\frac{\mathrm{Ud}}{v}
$$

Note the inclusion of $\mathrm{Re}_{\mathrm{J}}$ results in $\mathrm{H}_{\mathrm{C}} \sim \mathrm{d}^{0.14}$. For geometric similarity $\mathrm{d}$ varies as $\mathrm{D}$ for a given test, hence this can be interpreted as a scale exponent of 0.14 .

Correlation results for $\mathrm{H}_{\mathrm{C}}$ are shown first in Figure C.3, then for $\ln \left(\mathrm{H}_{\mathrm{C}}\right)$ in Figure C.4. Model prediction versus measured $\mathrm{H}_{\mathrm{C}}$ is shown in Figure C.5. This comparison is substantially better than was observed with the previous physical model (see for comparison Figure 7.21 in Meyer et al. 2009).

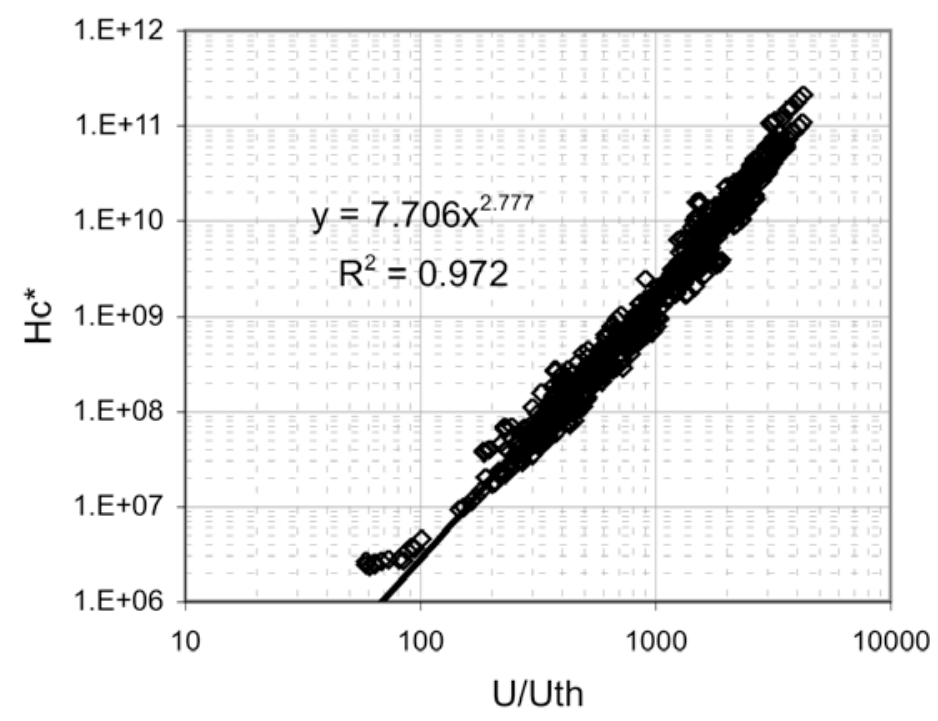

Figure C.3. Correlation for $\mathrm{H}_{\mathrm{C}}$ *

1 Note the $\phi_{\mathrm{p}}$ and $\phi_{\mathrm{S}}$ are based on vessel reference volumes as defined in Table B.1. 


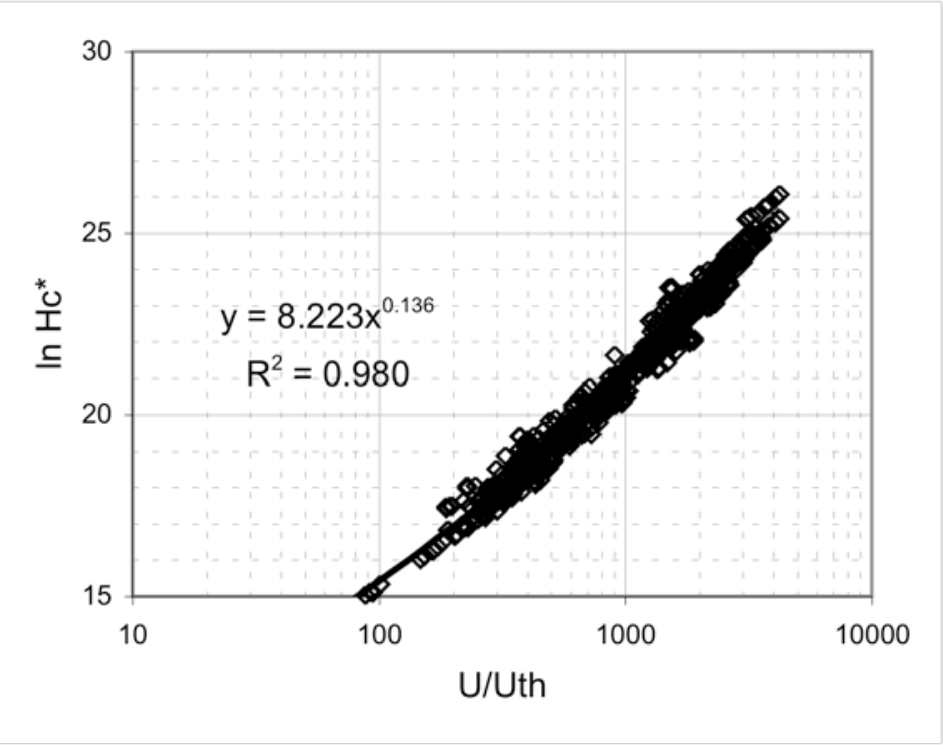

Figure C.4. Correlation for $\ln \left(\mathrm{H}_{\mathrm{C}}{ }^{*}\right)$

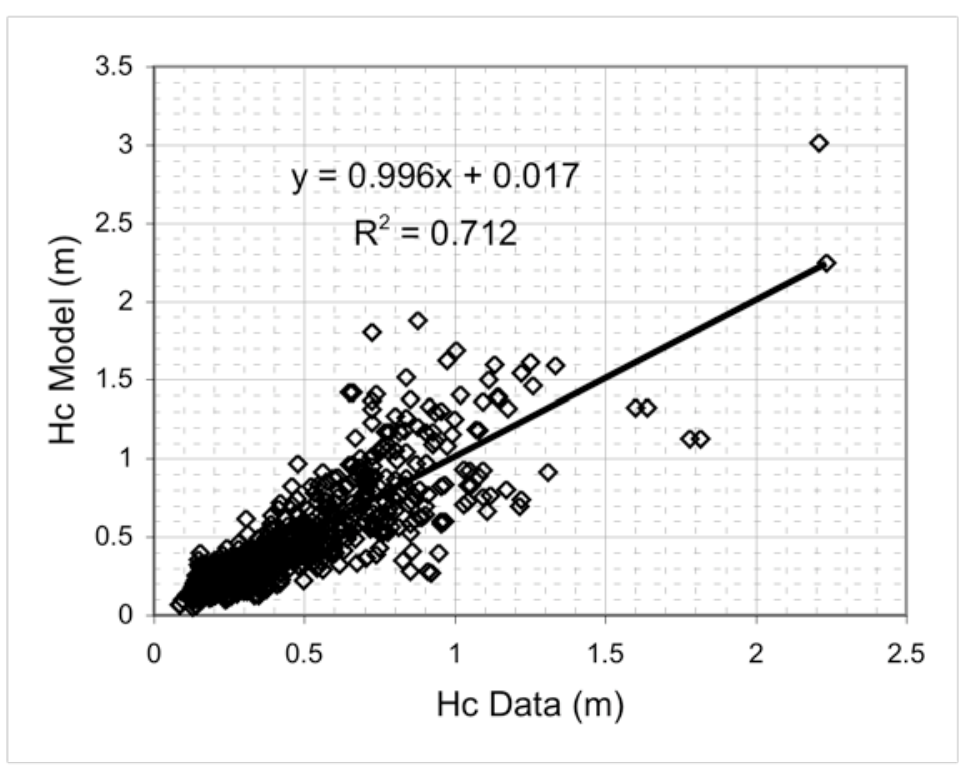

Figure C.5. Comparison of predicted and measured $\mathrm{H}_{\mathrm{C}}{ }^{*}$

A second $\mathrm{H}_{\mathrm{C}}$ correlation was generated with dish correction for the 34-inch test vessel. However, its use is not recommended because it cancels the Reynolds number scale-up behavior and this treatment is not adequately detailed. A more accurate treatment would include the impingement angles for inner and outer PJM nozzle rings, and this level of detail was not feasible in the current analysis.

The final model is in spreadsheet: 081111 167674KB 0811PM MSSDS DATA MODEL 081117 RLH Issue EM.xls. 


\section{C.3 Benchmarks}

The new models were used to update the individual benchmark files for each experiment. These files are

336_35micronGlass_Rating Tool5.6_post_rev0.xls

336_75micronGlass_Rating Tool5.6_post_rev0.xls

336_FiltrationSim_Rating Tool5.6_post_rev0.xls

Also, a single worksheet version was made including all benchmarks. This worksheet gives summary detail, but has all of the same calculations from the previous individual worksheets; therefore, this single worksheet version is much more easily modified and checked. The single worksheet version is RatingTool5.6_final EM Benchmark 090515_4.xls. As a first level check it was verified that the same results were produced by both methods.

The first change required in the benchmarks was to more consistently represent the experiment in the model inputs with the representation of operational parameters from the M3 experiments upon which the model is based. Specifically, adjustments were required to the PJM duty cycle and drive velocity used for the benchmarks. Figure C.6 illustrates a typical drive cycle and definition of duty cycle used in the M3 experiments. The target drive velocity is also shown in this figure, and it clearly represents the average of the maximum drive velocity. In PJM calculations, we have typically averaged over the time that the drive pressure is on. This includes the ramp-up portion of the drive profile in the average velocity calculation, which decreases the computed average over what was used in the M3 tests (Figure C.6). The duty cycle typically used for PJMs is equal to the time that drive pressure is applied divided by total cycle time. In Figure C.6, it can be seen that the duty cycle used for M3 experiments includes the ramp down time as well. Thus looking at the benchmark experiments with the perspective of using definitions consistent with the M3 experiments, we found that benchmark drive velocities and duty cycles should be increased. The drive velocity for the filtration simulant benchmarks is left unchanged since we do not have any measured drive function for that experiment. The $8 \mathrm{~m} / \mathrm{s}$ value used in that case was a rough estimate based on later experience at the recorded (4 bar) drive pressure. The updated drive velocities and duty cycles for each benchmark are shown with other input values in Tables C.1 through C.3. 


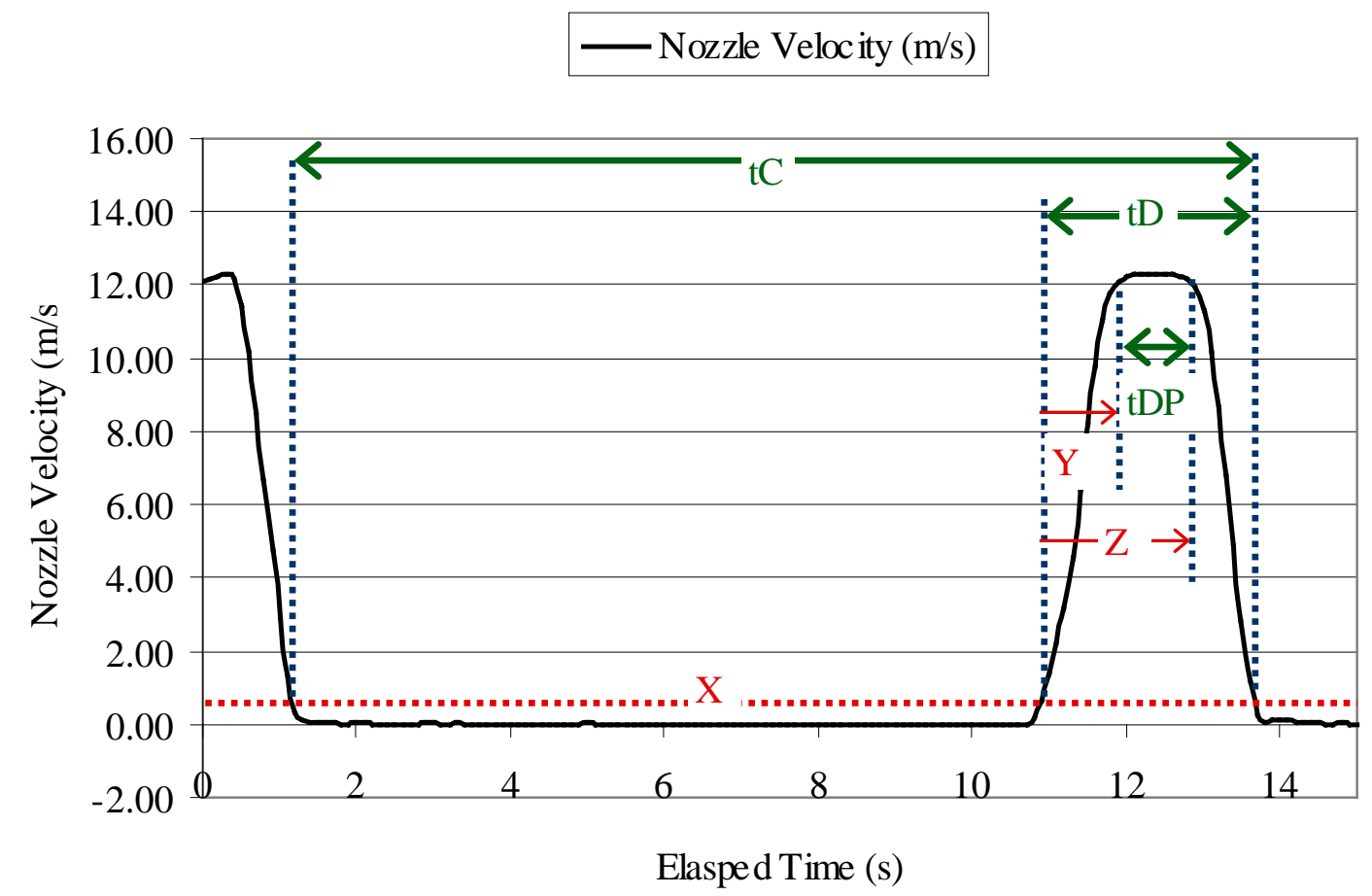

Figure C.6. Drive Profile Characterization in M3 Experiments. X, the setpoint, is a threshold velocity for distinguishing assumed zero flow condition and measured flow. A pulse or discharge pulse is that portion of the cycle for which the velocity is greater than $X . t_{D}$ is the discharge or pulse time, and $t_{\mathrm{DP}}$ is the time over which $\mathrm{U}_{\mathrm{PA}}$ is calculated or observed. (Figure 2.2 in [Enderlin, 2008] ${ }^{(1)}$

Table C.1. Updated Model Inputs for Tests with AZ-101/102 Filtration Simulant [Bontha et al. (2000)]

\begin{tabular}{cccccrrrr}
\hline Case \# & \% Max Drive & wt\% Solids & $\phi_{\mathrm{S}}$ & $\mathrm{DC}^{(\mathrm{a})}$ & $\phi_{\mathrm{p}}$ & $\phi_{\mathrm{J}}$ & $\mathrm{H} / \mathrm{D}$ & $\mathrm{U}(\mathrm{m} / \mathrm{s})$ \\
\hline 1 & $100 \%$ & 17.6 & 0.044 & 0.33 & 0.077 & 0.0027 & 0.82 & 8 \\
2 & $50 \%$ & 17.6 & 0.044 & 0.167 & 0.077 & 0.0027 & 0.82 & 8 \\
3 & $10 \%$ & 17.6 & 0.044 & 0.033 & 0.077 & 0.0027 & 0.82 & 8 \\
4 & $100 \%$ & 28.3 & 0.082 & 0.33 & 0.077 & 0.0027 & 0.86 & 8 \\
5 & $50 \%$ & 28.3 & 0.082 & 0.167 & 0.077 & 0.0027 & 0.86 & 8 \\
6 & $10 \%$ & 28.3 & 0.082 & 0.033 & 0.077 & 0.0027 & 0.86 & 8 \\
\hline
\end{tabular}

Table C.2. Updated Model Inputs for Tests with 75- $\mu \mathrm{m}$ Glass Beads [Bontha et al. (2003a)]

\begin{tabular}{ccccccccc}
\hline Case \# & Case & wt\% Solids & $\phi_{\mathrm{S}}$ & DC & $\phi_{\mathrm{p}}$ & $\phi_{\mathrm{J}}$ & H/D & $\mathrm{U}(\mathrm{m} / \mathrm{s})$ \\
\hline 7 & 4 PJMs & 10 & 0.042 & 0.20 & 0.056 & 0.0027 & 0.99 & 7.2 \\
\hline
\end{tabular}

1 Enderlin. 2008. 15-in Test Tank Instructions for Obtaining $U_{C S}$ Measurements. TI-RPP-WTP-636, Pacific Northwest National Laboratory, Richland, Washington. 
Table C.3. Updated Model Inputs for Tests with 35- $\mu \mathrm{m}$ Glass Beads [Bontha et al. (2003b)]

\begin{tabular}{ccccccccc}
\hline Case \# & Case & wt\% Solids & $\phi_{\mathrm{S}}$ & DC & $\phi_{\mathrm{p}}$ & $\phi_{\mathrm{J}}$ & $\mathrm{H} / \mathrm{D}$ & $\mathrm{U}(\mathrm{m} / \mathrm{s})$ \\
\hline 8 & 4 PJMs & 20 & 0.085 & 0.31 & 0.070 & 0.0027 & 0.93 & 9.7 \\
9 & 2 PJMs & 20 & 0.085 & 0.30 & 0.036 & 0.0014 & 0.93 & 9.3 \\
\hline
\end{tabular}

Also as described previously, a systematic approach was used to determine two representative settling velocities for each benchmark. One value, the favorably conservative bound, produced a concentration at the floor that matched that of the lowermost concentration measurement from the experiment. The second, best estimate, matched the floor concentration that would account for the total mass in the system.

The favorably conservative bound is unambiguous and is obtained directly from the experimental data. Its accuracy is that of the measurement and its representativeness of what was on the tank floor is partly a function of the distance the measurement above the floor and also a function of the measurements discernment of lateral distribution. Benchmark experiments differed in measurement position minimum heights and in measurements off of centerline.

The best estimate condition must be calculated using the measured concentration data. A simple stepwise integration was used, beginning at the floor, with concentration held fixed between measurement elevations. The accuracy of the floor concentration in this case was subject to this integration and the ability of the limited measurement locations to resolve the actual concentration profile. Several cases produced best estimate conditions that were not plausible, most often being far smaller than the favorably conservative bound.

For convenience in the plotted and tabular results, we will use $\mathrm{w}_{0}$ min to refer to the favorably conservative bound and $\mathrm{w}_{0}$ max to refer to the best estimate condition. The $\mathrm{w}_{0} \min$ and $\mathrm{w}_{0} \max$ concentrations calculated for each benchmark experiment are summarized in Table C.4 and details are given in file 090417 BM Mass Balance.xls. The italicized values in Table C.4 are implausible since floor concentrations will likely always be higher than the measured value at lowest elevation.

Table C.4. Favorably Conservative Bound $\left(\mathrm{w}_{0} \mathrm{~min}\right)$ and Best Estimate ( $\left.\mathrm{w}_{0} \max \right)$ Floor Concentrations for Benchmarks (FS = filtration simulant)

\begin{tabular}{|c|c|c|c|c|c|c|c|c|c|}
\hline $\begin{array}{c}\text { mass } \\
\text { fraction at } \\
\text { floor }\end{array}$ & $\begin{array}{l}\text { FS } \\
\# 3\end{array}$ & $\begin{array}{l}\text { FS } \\
\# 6\end{array}$ & $\begin{array}{l}\text { FS } \\
\# 14\end{array}$ & $\begin{array}{l}\text { FS } \\
\# 19\end{array}$ & $\begin{array}{l}\text { FS } \\
\# 20\end{array}$ & $\begin{array}{c}\text { FS } \\
\# 28\end{array}$ & $\begin{array}{c}\text { Glass } 75 \\
\mu \mathrm{m}\end{array}$ & $\begin{array}{c}\text { Glass } 35 \\
\mu \mathrm{m} 2 \\
\mathrm{PJM}\end{array}$ & $\begin{array}{c}\text { Glass } 35 \\
\mu \mathrm{m} 4 \\
\mathrm{PJM}\end{array}$ \\
\hline $\mathrm{w}_{0} \min$ & 0.178 & 0.200 & 0.259 & 0.270 & 0.306 & 0.367 & 0.284 & 0.357 & 0.220 \\
\hline $\mathrm{w}_{0} \max$ & 0.209 & 0.239 & 0.422 & 0.412 & 0.288 & 0.553 & 0.252 & 0.234 & 0.074 \\
\hline
\end{tabular}

The linear concentration profile model is used unchanged from the previous analysis. Sample benchmark results for one case are shown plotted in Figure C.7 illustrating the concentration profile with value at the floor matching the target values. This sample is also significant as it is the result for the $75-\mu \mathrm{m}$ glass benchmark. Figure C.8 compares the settling velocity distribution for the $75-\mu \mathrm{m}$ glass with the 35- $\mu \mathrm{m}$ glass and filtration simulants, the M3 simulants and the Case 3 Hanford PSDD. The 75- $\mu \mathrm{m}$ glass simulant has a narrow size distribution that is more typical of the M3 simulants, and so we would 
expect it to be more closely represented by the volume average settling velocity, Ubar. As the dashed line profile shows in Figure C.7, Ubar is a reasonably good fit to the concentration profile. The maximum floor concentration is not available (this benchmark is one of those highlighted in Table C.4) so no conclusion can be made about how the model using Ubar matches that parameter.

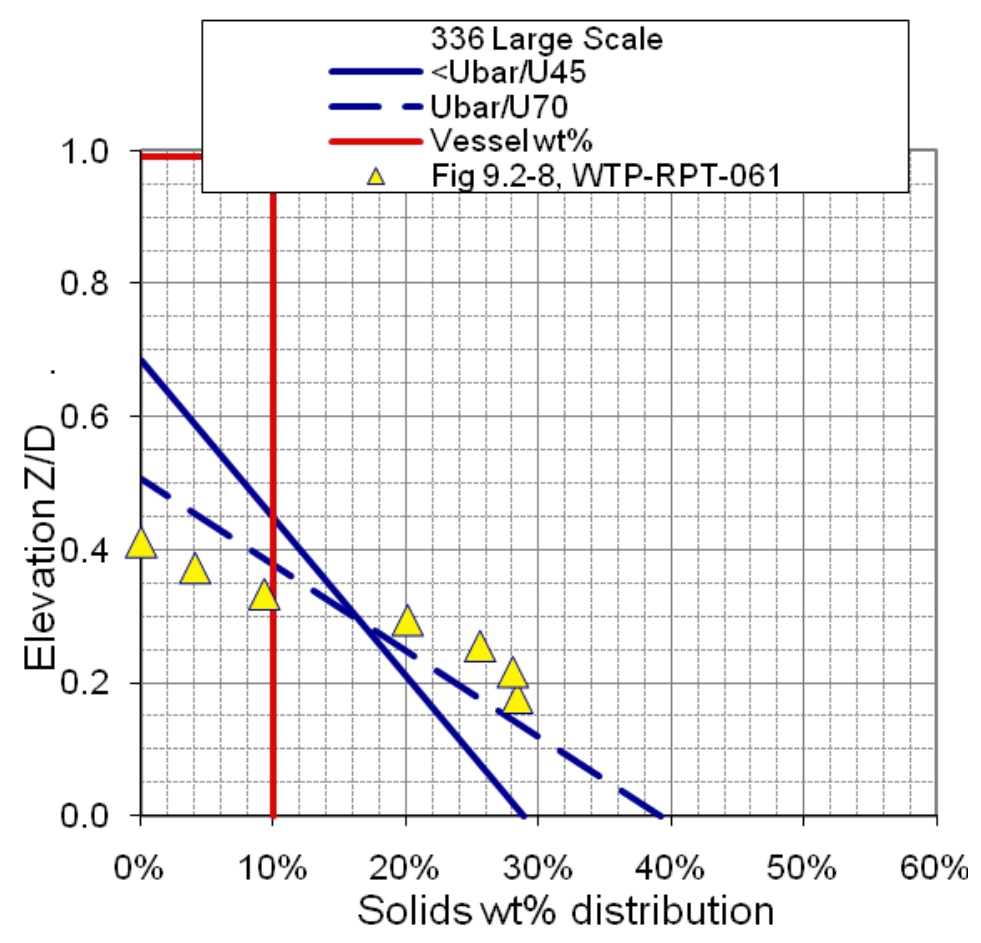

Figure C.7. Sample Benchmark Results Illustrating Concentration Profile and Values at Floor Matching Min and Max Targets

Settling velocities $\mathrm{U}_{\mathrm{Tmin}}$ and $\mathrm{U}_{\mathrm{Tmax}}$ used to match the $\mathrm{w}_{0} \mathrm{~min}$ and $\mathrm{w}_{0} \mathrm{max}$ floor concentration targets for individual benchmarks are listed in Table C.5. These values were then used with the respective PSDs or PSDDs for the experiment to determine percentiles and cumulative percentile (Ubar n) settling velocities. ${ }^{1}$ For the Filtration Simulant (FS) benchmark the PSDD has been updated to use the measured PSDs of each component. These measured PSDs were provided in support of settling velocity tests for this simulant in Bontha et al. (2003a) [WTP-RPT-061]. The updated Filtration Simulant PSDD is on sheet 'Approach 1' in 090122 AZ101102 PSDD Settling Velocity.xls. PSDs for the two glass simulant benchmarks are unchanged. The percentiles are shown along with the settling velocities in Table C.5. The settling velocities obtained for the physically implausible points are again shown italicized in this table.

$1 \quad$ Here Ubar $\mathrm{n}$ is used to refer to a Ubar value at a specific cumulative percentile beginning at the maximum settling velocity (Ubar 100). In this case Ubar 0 is the volume average settling velocity for the entire PSDD and is just referred to as Ubar. 


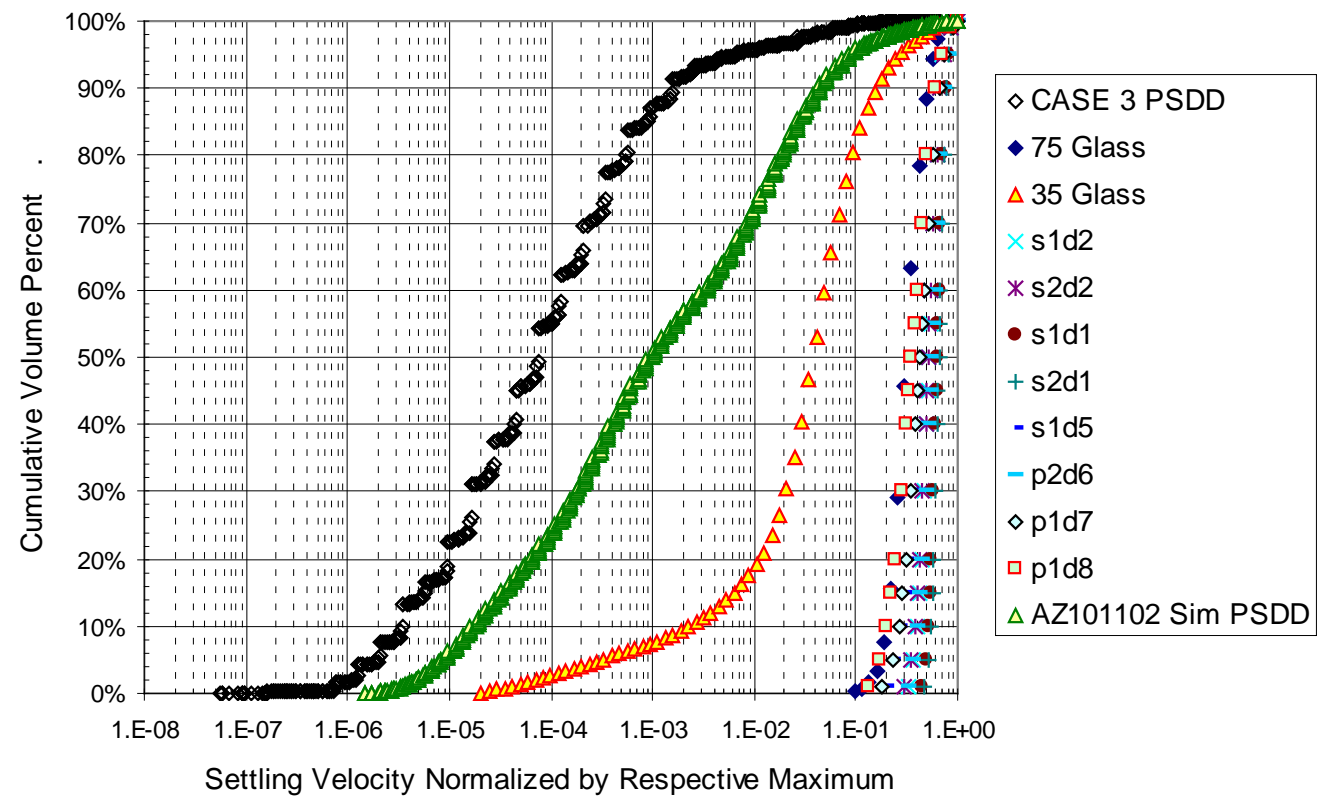

Figure C.8. Comparison of Settling Velocity Distributions Between Hanford Case 3 PSDD and M3 and Benchmark Experiment Simulants

Table C.5. Settling Velocities Required to Match Benchmark Concentration Targets

\begin{tabular}{|c|c|c|c|c|c|c|c|c|c|}
\hline $\begin{array}{c}\text { Velocity } \\
(\mathrm{mm} / \mathrm{s})\end{array}$ & $\begin{array}{l}\text { FS } \\
\# 3 \\
\end{array}$ & $\begin{array}{l}\text { FS } \\
\# 6 \\
\end{array}$ & $\begin{array}{c}\text { FS } \\
\# 14 \\
\end{array}$ & $\begin{array}{c}\text { FS } \\
\# 19 \\
\end{array}$ & $\begin{array}{l}\text { FS } \\
\# 20 \\
\end{array}$ & $\begin{array}{c}\text { FS } \\
\# 28 \\
\end{array}$ & $\begin{array}{c}\text { Glass } 75 \\
\mu \mathrm{m}\end{array}$ & $\begin{array}{c}\text { Glass } 35 \\
\mu \mathrm{m} 2 \\
\text { PJM } \\
\end{array}$ & $\begin{array}{c}\text { Glass } 35 \\
\mu \mathrm{m} 4 \\
\text { PJM }\end{array}$ \\
\hline $\mathbf{U}_{\mathrm{T}} \mathbf{m i n}$ & 1.1 & 1.5 & 0.92 & 1.7 & 1.4 & 0.94 & 3.6 & 4.2 & 3.8 \\
\hline Percentile & 0.86 & 0.89 & 0.83 & 0.91 & 0.89 & 0.83 & 0.39 & 0.92 & 0.91 \\
\hline Ubar n & 0.30 & 0.47 & 0.13 & 0.54 & 0.45 & 0.15 & 0 & 0.75 & 0.70 \\
\hline $\mathbf{U}_{\mathrm{T}} \max$ & 2.5 & 2.0 & 1.2 & 3.3 & 2.8 & 1.2 & 4.7 & 4.7 & 4.5 \\
\hline Percentile & 0.93 & 0.92 & 0.87 & 0.95 & 0.94 & 0.87 & 0.66 & 0.93 & 0.93 \\
\hline Ubar $\mathrm{n}$ & 0.69 & 0.60 & 0.34 & 0.78 & 0.73 & 0.34 & 0.01 & 0.79 & 0.78 \\
\hline
\end{tabular}

As a final step in the benchmarking exercise, average percentiles are computed to determine settling velocities, $\mathrm{U}_{\mathrm{T} 1}=\operatorname{avg}\left(\mathrm{U}_{\mathrm{T}} \mathrm{min}\right)$ and $\mathrm{U}_{\mathrm{T} 2}=\operatorname{avg}\left(\mathrm{U}_{\mathrm{T}} \max \right)$, that will be used in the WTP vessel applications. In computing these averages we consider several possible cases. The $75 \mu \mathrm{m}$ glass benchmark data is excluded from all cases since it is more typical of a monodisperse simulant, and our goal in the averaging process is to determine the settling velocity percentile that represents behavior of a broad spectrum polydisperse PSDD slurry in the WTP vessels (see Figure C.8). The cases considered are: 1) all filtration simulant and $35 \mu \mathrm{m}$ glass simulant benchmarks, 2) all benchmarks except the low duty cycle filtration simulant cases (FS \#14 and \#28), and 3) all benchmarks except the low duty cycle and italicized points in Table C.5. The low duty cycle cases are excluded because they are far out of range of the M3 experiments and WTP vessel applications. The italicized points in Table C.5 are excluded because we have no clear basis for $\mathrm{w}_{0}$ max, and the values are physically implausible as mentioned previously. For each case, a simple average results in the pair of settling velocities in Table C.6. Note that average percentiles are not included in this table, only cumulative percentiles (Ubar $n$ ) since these are the most 
appropriate values for representing different PSDDs in this application. Of the three cases shown, the most appropriate is the third, which gives Ubar53 for the average conservative bound and Ubar69 for the best estimate. As in Meyer et al. (2009), the WTP vessel applications use the Case 3 Hanford PSDD with liquid density of 1.1 Sp.G. and viscosity of $1.5 \mathrm{cP}$. For these conditions Ubar53 is $2.2 \mathrm{~mm} / \mathrm{s}$ and Ubar69 is $3.3 \mathrm{~mm} / \mathrm{s}$. The minimum falls between U94 and U95 and the maximum between U95 and U96. So as in the initial estimate described in Section 10.3 of Meyer et al. (2009), the conservative bound and best estimate settling velocities bracket the U95 settling velocity (U95 is $2.5 \mathrm{~mm} / \mathrm{s}$ ). WTP vessel applications are presented in the next section for Ubar53 and Ubar69.

Table C.6. Average Cumulative Percentile Settling Velocities

\begin{tabular}{cccc}
\hline & $\begin{array}{c}\text { All Benchmarks } \\
\text { (except 75 } \mu \text { glass) }\end{array}$ & $\begin{array}{c}\text { Excluding Low } \\
\text { DC FS Cases }\end{array}$ & $\begin{array}{c}\text { Excluding Low DC FS and Italicized } \\
\text { Points in Table C.5 }\end{array}$ \\
\hline $\mathrm{U}_{\mathrm{T} 1}=$ avg Ubar n min & 0.40 & 0.53 & 0.53 \\
$\mathrm{U}_{\mathrm{T} 2}=$ avg Ubar n max & 0.63 & 0.73 & 0.69 \\
\hline
\end{tabular}

\section{C.4 WTP Vessel Applications}

As in the benchmark calculations, the new models have been implemented in a single worksheet for calculations. As a verification test in this process the original report cases were repeated and checked to produce the same results (see RatingTool5.4.3_final EM 090513 r1.xls). The updated file with the new models is RatingTool5.6_final EM 090526.xls.

Geometry and operational data are unchanged from the cases used in the report (Meyer et al. 2009, Tables 9.2 and 9.4). Only the Hanford PSDD cases are included in this analysis. By using the same settling velocities from the report (U95 and Ubar90), a relative change can be observed between the original and new models. This comparison is shown for $\mathrm{U}_{\mathrm{CS}}$ and $\mathrm{H}_{\mathrm{C}}$ in Figures C.9 and C.10, respectively. It can be seen that both $\mathrm{U} / \mathrm{U}_{\mathrm{CS}}$ and $\mathrm{H}_{\mathrm{C}} / \mathrm{H}_{\mathrm{F}}$ for the new model are slightly increased for the same input settling velocity; thus, $\mathrm{U}_{\mathrm{CS}}$ is reduced in the new model and $\mathrm{H}_{\mathrm{C}}$ is increased. All results for this comparison and for subsequent results are for the maximum vessel fill level.

Results of the model applications for the selected min and max average percentile settling velocities $\left(\mathrm{U}_{\mathrm{T} 1}=\right.$ Ubar53 and $\mathrm{U}_{\mathrm{T} 2}=$ Ubar69) are shown in Figure C.11. The ratio of design velocity to the critical suspension velocity, $\mathrm{U} / \mathrm{U}_{\mathrm{CS}}$ is shown in Figure C.11a. Where this value is shown to be greater than one, the design nozzle discharge velocity is adequate to suspend the solids off the vessel floor, for the particle settling velocities indicated and the vessel design conditions (solids loading, PJM mixing parameters and vessel fill level). Values shown less than one indicate that the design velocity is inadequate to move all of the solids from the vessel floor. The ratio of cloud height to fill height, $\mathrm{H}_{\mathrm{C}} / \mathrm{H}_{\mathrm{F}}$, is shown in Figure C.11b. In this case, values of one represent a design where particulate suspension levels would just reach the vessel fill level. Since concentration increases from a minimum at the top of the cloud to maximum at the bottom of the vessel, $\mathrm{H}_{\mathrm{C}} / \mathrm{H}_{\mathrm{F}}=1$ still implies a majority of the solids in the bottom half of the vessel. Therefore $\mathrm{H}_{\mathrm{C}} / \mathrm{H}_{\mathrm{F}}=1$ represents a minimum requirement for the vessel. Values well above this are reasonably well-mixed, and values well below this are inadequate, again given these particulate settling velocities and vessel design parameters. Note that very small and very large values $\left(1>\mathrm{H}_{\mathrm{C}} / \mathrm{H}_{\mathrm{F}}>10\right)$ reflect limits of the model assumptions are not physically meaningful, except that they represent a mixing system that is either far underpowered (for very small values) or a system that has excess mixing capacity 
for these conditions. Finally, the pump suction metric, $0.2 / \mathrm{C}_{0}$, is shown in Figure C.11c. This represents the predicted solids weight fraction at the vessel floor relative to the 20 weight percent pump suction maximum. The ratio is formed such that values greater than one indicate an adequate design and lesser values indicate an inadequate design. Again, extreme values represent limits of the model (for example, solids weight fraction is limited by maximum packing, and in no physical case can $0.2 / \mathrm{C}_{0}$ exceed a value of 5), but as in the cloud height metric (Fig. C.11b) indicate a mixing system design that is either far underpowered (for very small values) or a system that has excess mixing capacity for these conditions. A direct comparison with the original report values (Meyer et al. 2009) can be made by comparing Figure C.9a and Figure C.11a for $\mathrm{U}_{\mathrm{CS}}$ and by comparing Figure C.10a with Figure C.11b for cloud height.

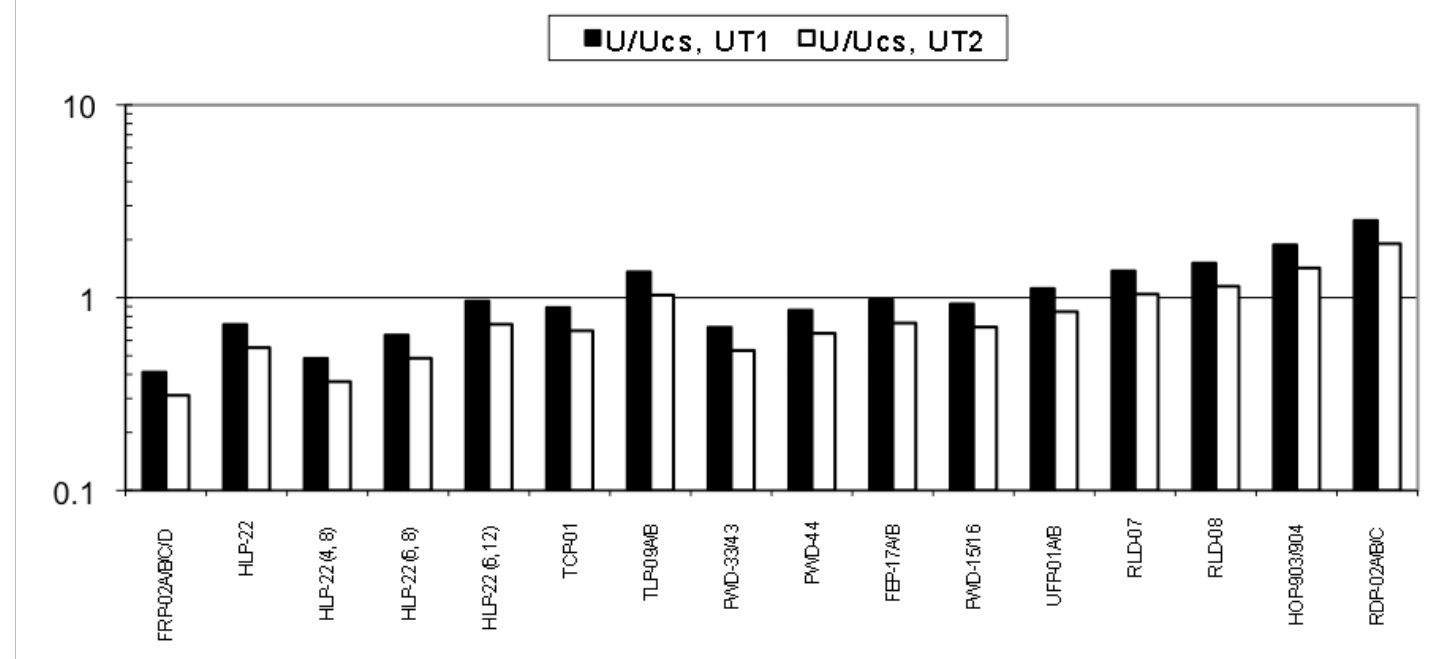

a. Physical model from Meyer et al. (2009) $\left(\mathrm{U}_{\mathrm{T} 1}=\mathrm{U}_{95}, \mathrm{U}_{\mathrm{T} 2}=\mathrm{U}_{\mathrm{bar} 90}\right)$

-U/Ucs, UT1 aU/Ucs, UT2

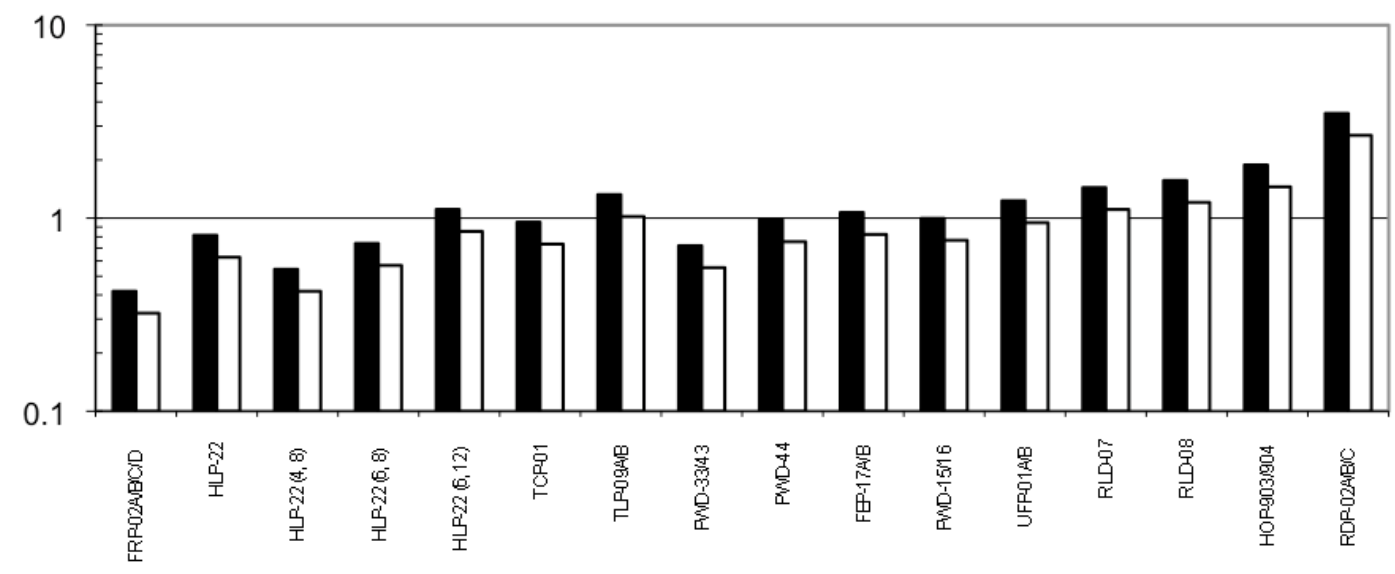

b. New physical model (UT1=U95, UT2=Ubar90)

Figure C.9. Difference in $\mathrm{U} / \mathrm{U}_{\mathrm{CS}}$ Between Report and New Physical Model for Same Settling Velocities (U95 and Ubar90) 


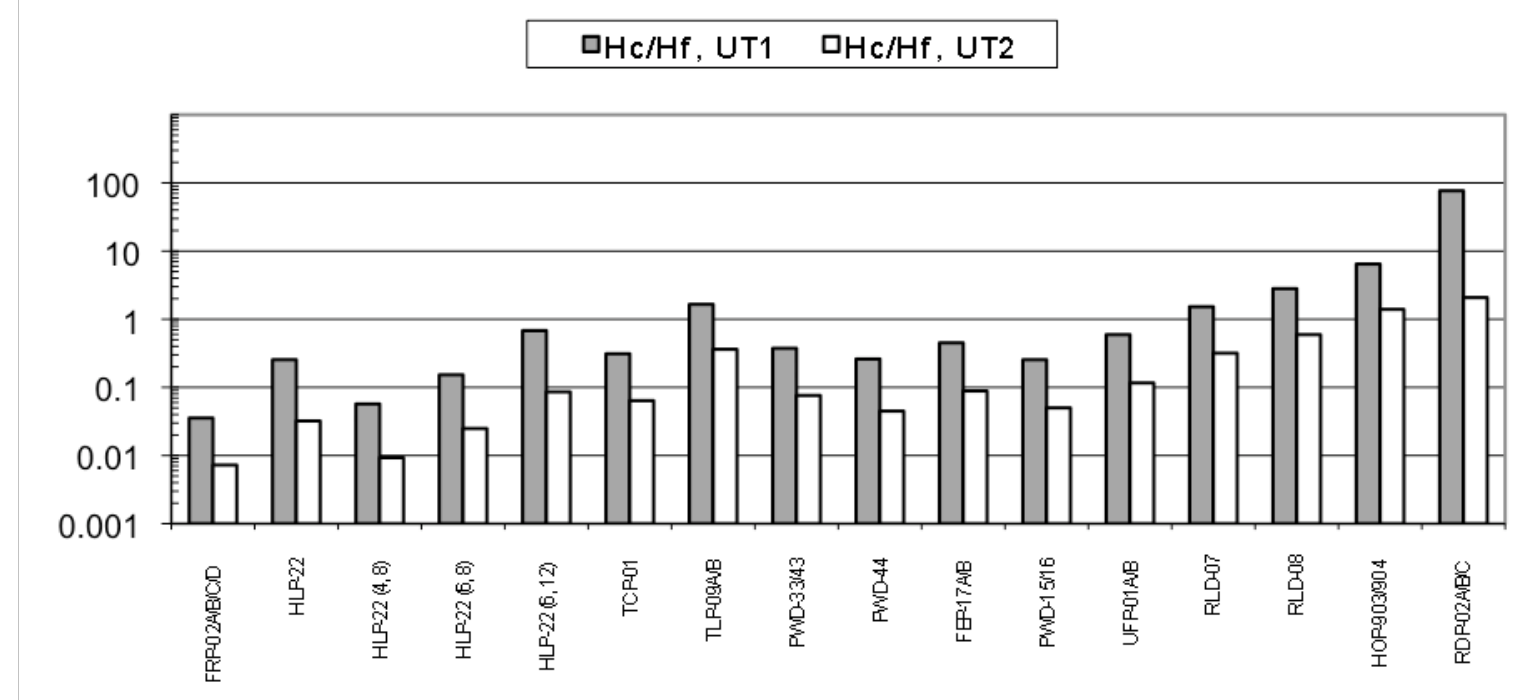

a. Physical model from Meyer et al. (2009) $\left(\mathrm{U}_{\mathrm{T} 1}=\mathrm{U}_{95}, \mathrm{U}_{\mathrm{T} 2}=\mathrm{U}_{\mathrm{bar} 90}\right)$

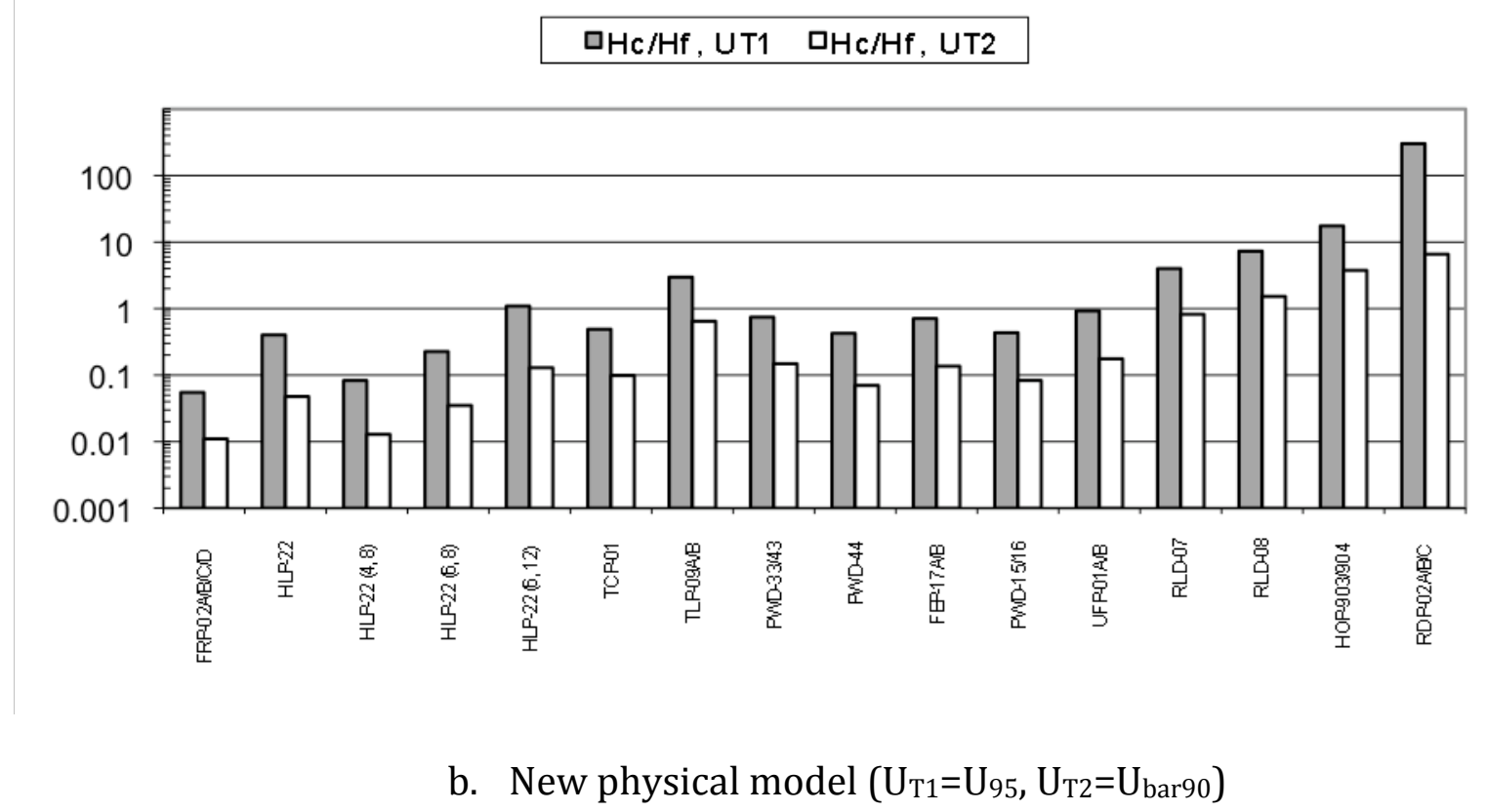

Figure C.10. Difference in $\mathrm{H}_{\mathrm{C}} / \mathrm{H}_{\mathrm{F}}$ Between Report and New Physical Model for Same Settling Velocities (U95 and Ubar90) 


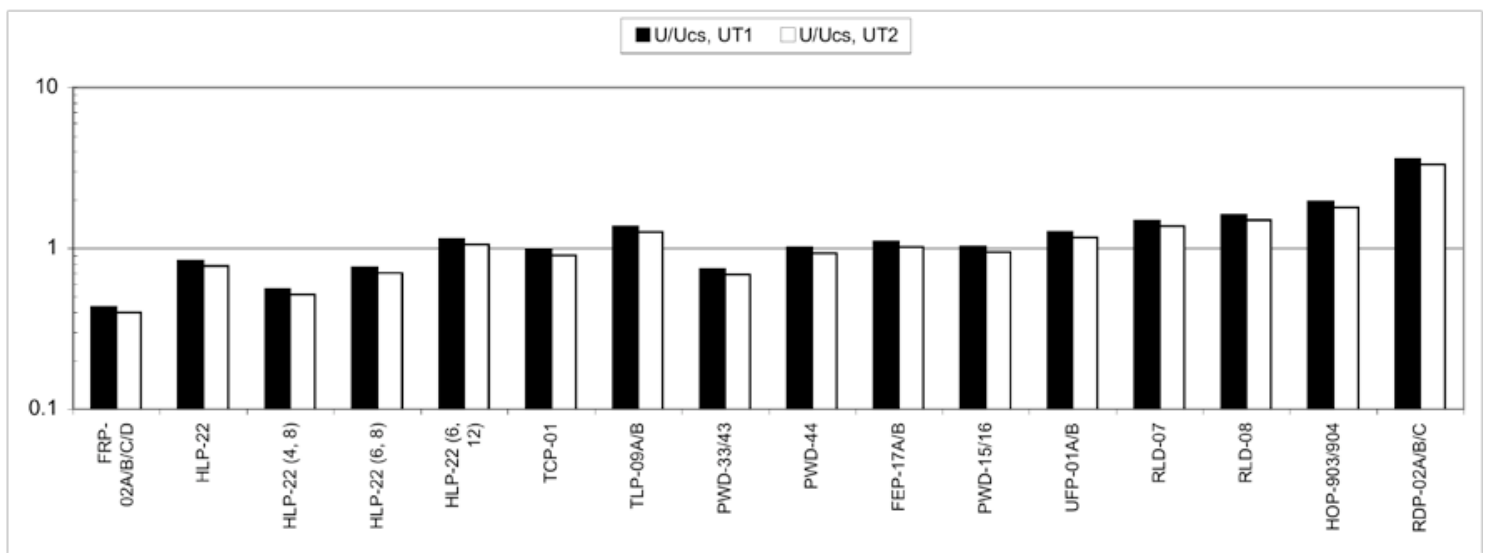

a. Critical suspension velocity metric $\left(\mathrm{U}_{\mathrm{T} 1}=\mathrm{U}_{\mathrm{bar} 53}, \mathrm{U}_{\mathrm{T} 2}=\mathrm{U}_{\mathrm{bar} 69}\right)$

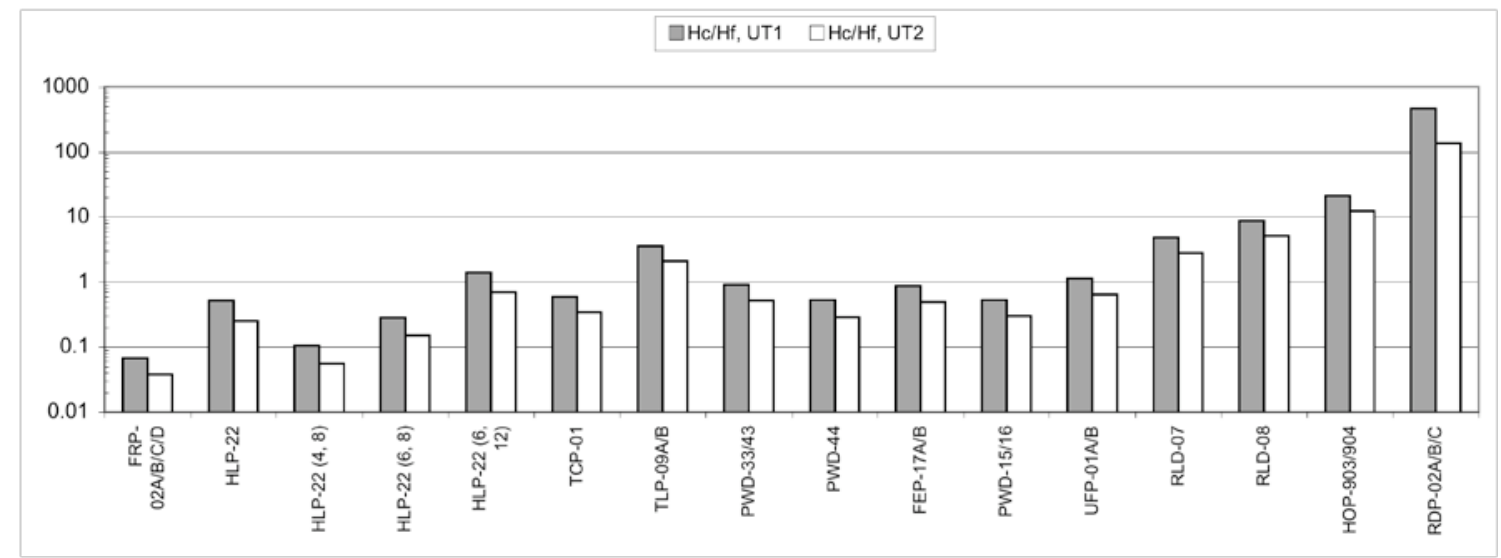

b. Cloud height $\left(\mathrm{U}_{\mathrm{T} 1}=\mathrm{U}_{\mathrm{bar} 53}, \mathrm{U}_{\mathrm{T} 2}=\mathrm{U}_{\mathrm{bar} 69}\right)$

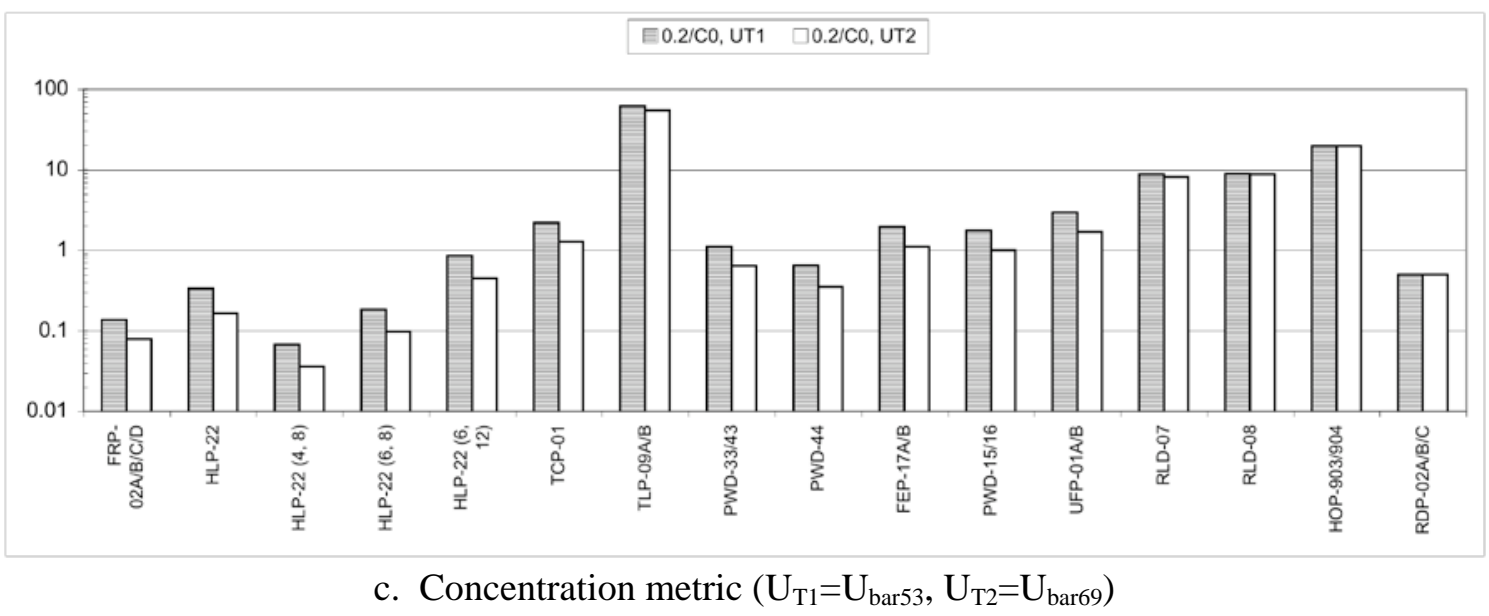

Figure C.11. Results for New Model with Min and Max Average Settling Velocities $(\mathrm{UT} 1=\mathrm{Ubar} 53=2.2 \mathrm{~mm} / \mathrm{s} ; \mathrm{UT2}=\mathrm{Ubar} 69=3.3 \mathrm{~mm} / \mathrm{s}$ ) 
Finally, a set of alternate performance metrics were computed with details included in file RatingTool5.6_final EM 090528 alt metrics_PM.xls. These are alternatives to the concentration metric which, as discussed previously, require a series of assumptions associated with an unquantifiable uncertainty. Figure C.12 shows the jet velocity required in order for the cloud to reach the fill level. While this does not represent a well-mixed condition, it is a useful metric for comparison. It is the most accurate prediction of solids suspension possible from the test data, as there is no assumption required regarding the effect of the predicted cloud exceeding the fill level. Note also that severe stratification is likely for this condition. The results indicate that eight of the vessel classes would require velocities higher than the design velocity in order to distribute any solids up to the fill level.

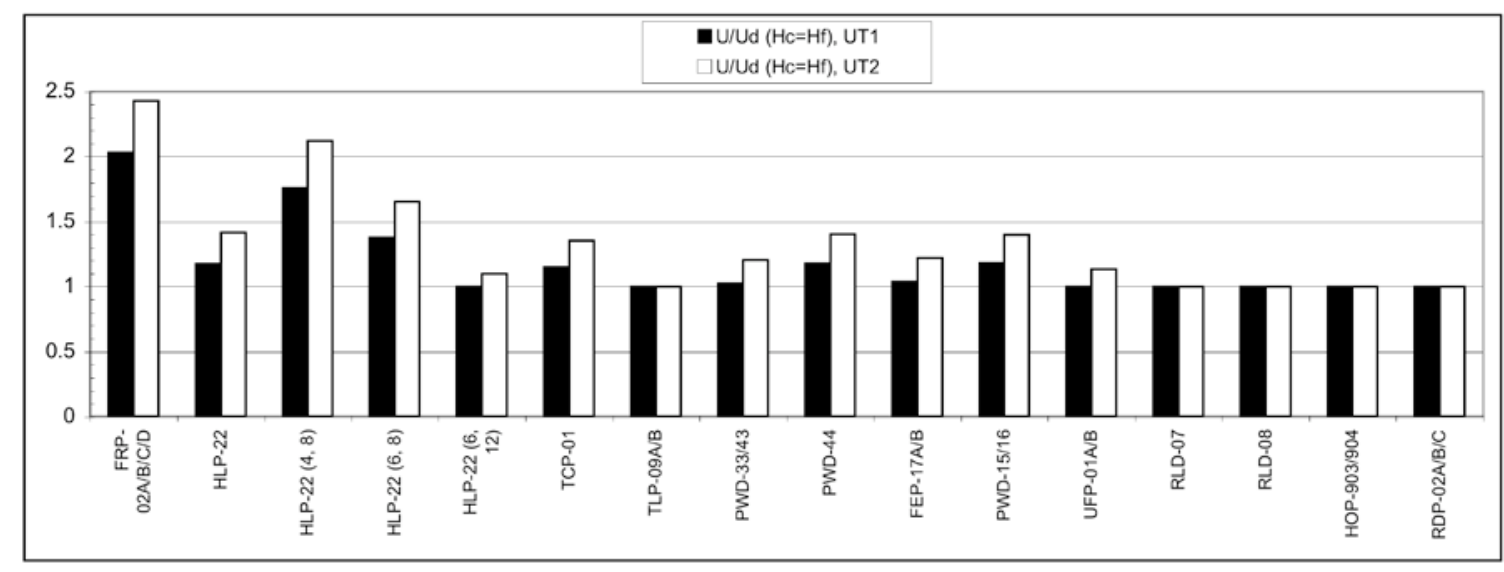

a. $\quad \mathrm{U}\left(\mathrm{H}_{\mathrm{C}}=\mathrm{H}_{\mathrm{F}}\right) / \mathrm{Ud}$, where $\mathrm{Ud}$ is the vessel design velocity

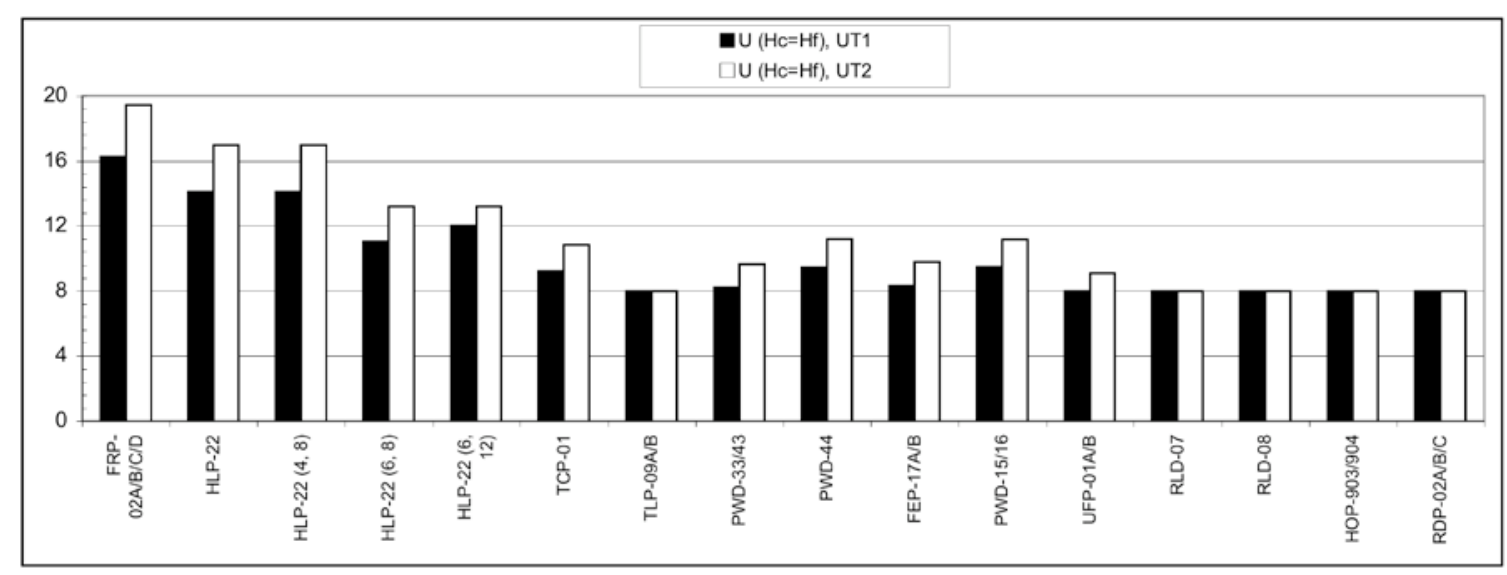

b. $\mathrm{U}\left(\mathrm{H}_{\mathrm{C}}=\mathrm{H}_{\mathrm{F}}\right)$

Figure C.12. Jet Velocity Required for $\mathrm{H}_{\mathrm{C}}=\mathrm{H}_{\mathrm{F}}$. New physical model used with min and max average settling velocities $(\mathrm{UT} 1=\mathrm{Ubar} 53=2.2 \mathrm{~mm} / \mathrm{s} ; \mathrm{UT2}=\mathrm{Ubar} 63=3.3 \mathrm{~mm} / \mathrm{s})$ 
We also used the model to predict the maximum volume-weighted average settling velocity that the current design can accommodate. In other words, we determined Ubar $n$ for $U_{C S}=U d$ and $H_{C}=H_{F}$. This was done in two ways, first by adjusting the solids density, and secondly by adjusting the solids size. This was necessary since the result for Ubar $n$ depends also on density ratio (s) and Ga. Other operating parameters are kept unchanged from those used in the vessel applications. Results of this analysis are shown in Table C.7.

Table C.7. Maximum Volume-Weighted Settling Velocity that Current WTP Vessel Design and Operating Conditions Can Accommodate

\begin{tabular}{|c|c|c|c|c|}
\hline \multirow[b]{3}{*}{ Vessel } & \multicolumn{4}{|c|}{ Criterion } \\
\hline & $\mathrm{H}_{\mathrm{C}} / \mathrm{H}_{\mathrm{F}}=1, \mathrm{~d}_{\mathrm{S}}^{1}$ & $\mathrm{H}_{\mathrm{C}} / \mathrm{H}_{\mathrm{F}}=1, \rho_{\mathrm{s}}^{2}$ & $\mathrm{U} / \mathrm{U}_{\mathrm{CS}}=1, \mathrm{~d}_{\mathrm{S}}^{1}$ & $\mathrm{U} / \mathrm{U}_{\mathrm{CS}}=1, \rho_{\mathrm{s}}^{2}$ \\
\hline & $\overline{\mathrm{U}}$ percentile & $\overline{\mathrm{U}}$ percentile & $\overline{\mathrm{U}}$ percentile & $\overline{\mathrm{U}}$ percentile \\
\hline FRP-02A/B/C/D & less than $\bar{U}$ & less than $\bar{U}$ & less than $\bar{U}$ & less than $\bar{U}$ \\
\hline HLP-22 & 0.34 & 0.40 & less than $\bar{U}$ & 0.37 \\
\hline HLP-22 $(4,8)$ & less than $\bar{U}$ & 0.05 & less than $\bar{U}$ & less than $\overline{\mathrm{U}}$ \\
\hline HLP-22 $(6,8)$ & 0.08 & 0.25 & less than $\overline{\mathrm{U}}$ & less than $\overline{\mathrm{U}}$ \\
\hline HLP-22 $(6,12)$ & $0.53^{3}$ & 0.53 & 0.53 & 0.53 \\
\hline ТСР-01 & 0.34 & 0.40 & 0.47 & 0.49 \\
\hline TLP-09A/B & 0.53 & 0.53 & 0.53 & 0.53 \\
\hline PWD-33/43 & 0.49 & 0.49 & less than $\overline{\mathrm{U}}$ & less than $\overline{\mathrm{U}}$ \\
\hline PWD-44 & 0.33 & 0.40 & 0.53 & 0.53 \\
\hline FEP-17A/B & 0.49 & 0.49 & 0.53 & 0.53 \\
\hline PWD-15/16 & 0.31 & 0.39 & 0.53 & 0.53 \\
\hline UFP-01A/B & 0.53 & 0.53 & 0.53 & 0.53 \\
\hline RLD-07 & 0.53 & 0.53 & 0.53 & 0.53 \\
\hline RLD-08 & 0.53 & 0.53 & 0.53 & 0.53 \\
\hline HOP-903/904 & 0.53 & 0.53 & 0.53 & 0.53 \\
\hline RDP-02A/B/C & 0.53 & 0.53 & 0.53 & 0.53 \\
\hline
\end{tabular}

1. Criterion is met by adjusting particulate settling velocity by altering particle diameter.

2. Criterion is met by adjusting particulate settling velocity by altering particle density.

3. All entries with $\bar{U}=0.53$ met or exceed criterion as evaluated.

\section{C.5 Conclusions and Recommendations}

Pulse jet mixing (PJM) tests with noncohesive solids in Newtonian liquid were conducted at three geometric scales to support the design of mixing systems for the Hanford Waste Treatment and Immobilization Plant. The test data were used to develop mixing models. The models predict the cloud height (the height to which solids will be lifted by the PJM action) and the critical suspension velocity (the minimum velocity needed to ensure all solids have been lifted from the floor). From the cloud height estimate, the concentration of solids near the vessel floor was estimated. Results of these calculations show that a number of the solids containing vessels would have difficulty suspending design solids loadings of expected waste feed. 


\section{C.6 References}

Bontha JR, GR Golcar, and N Hannigan. 2000. Demonstration and Optimization of BNFL's Pulsed Jet Mixing and RFD Sampling Systems Performance Using NCAW Simulant. PNWD-3054, BNFL-RPT-048 Rev. 0, Battelle - Pacific Northwest Division, Richland, Washington.

Bontha JR, TE Michener, DS Trent, JM Bates, and MD Johnson. 2003a. Development and Assessment of the TEMPEST CFD Model of the Pulsed Jet Mixing Systems. PNWD-3261, WTP-RPT-061 Rev. 0, Battelle - Pacific Northwest Division, Richland, Washington.

Bontha JR, JM Bates, CW Enderlin, and MG Dodson. 2003b. Large Tank Experimental Data for Validation of the FLUENT CFD Model of Pulsed Jet Mixers. PNWD-3303, WTP-RPT-081 Rev. 0, Battelle - Pacific Northwest Division, Richland, Washington.

Fort, JA, PA Meyer, JA Bamberger, CW Enderlin, PA Scott, MJ Minette, PA Gauglitz. 2010. "Scaled Testing to Evaluate Pulse Jet Mixer Performance in Waste Treatment Plant Mixing Vessels." In Waste Management 2010 WM2010 Conference, March 7-10, 2010, Phoenix, Arizona.

Meyer, PA, JA Bamberger, CW Enderlin, JA Fort, BE Wells, SK Sundaram, PA Scott, MJ Minette, GL Smith, CA Burns, MS Greenwood, GP Morgan, EBK Baer, SF Snyder, M White, GF Piepel, BG Amidan, A Heredia-Langner. 2009. Pulse Jet Mixing Tests With Noncohesive Solids. PNNL-18098, WTP-RPT-182 Rev. 0, Pacific Northwest National Laboratory, Richland, Washington. 
Appendix D

Adjusted Settling Velocity 



\section{Appendix D}

\section{Adjusted Settling Velocity}

In analyzing the potential reasons for the discrepancy in Phase 1 and Phase 2 test results we have revisited the prototypic refill issue as a potential cause. The effects of enhanced vertical solids entrainment due to closed loop operation in Phase 1 can be illustrated in terms of an adjusted settling velocity. The direction of the effect is to make the settling velocity essentially smaller than if the jet operation were prototypic. A smaller settling velocity would result in a correspondingly smaller value of $\mathrm{U}_{\mathrm{CS}}$. Hence this effect potentially could explain the observed differences in Phase 1 and 2 test results.

The modified settling velocity was presented in Meyer et al. (2009). A more accurate version is re-derived here in detail.

Consider the motion of solid particles on average in the vessel due to PJM drive and refill. By means of continuity, the average velocities in the vessel during drive $\left(U_{D}\right)$ and refill $\left(U_{R}\right)$ are given by the superposition of the mean fluid velocity and the settling velocity:

$$
\begin{gathered}
\mathrm{U}_{\mathrm{D}}=\mathrm{U}_{\mathrm{JD}} \frac{\mathrm{A}_{\mathrm{J}}}{\mathrm{A}_{\mathrm{J}}-\mathrm{A}_{\mathrm{PT}}}-\mathrm{U}_{\mathrm{TH}} \\
\mathrm{U}_{\mathrm{R}}=-\mathrm{f}_{\mathrm{P}} \mathrm{U}_{\mathrm{JR}} \frac{\mathrm{A}_{\mathrm{J}}}{\mathrm{A}_{\mathrm{J}}-\mathrm{A}_{\mathrm{PT}}}-\mathrm{U}_{\mathrm{TH}}
\end{gathered}
$$

where $U_{J D}$ is the average drive velocity, $U_{J R}$ is the average refill velocity, $A_{J}$ is the total jet area, $A_{P T}$ is the total pulse tube cross-sectional area, and $U_{T H}$ is the hindered settling velocity. The factor $f_{p}$ is 1 for prototypic refill and $f_{p}=0$ for closed loop drive (no PJM refill). Note also that the sign of $U_{D}$ and $U_{R}$ is important, with a negative value implying motion in the downward direction.

The average particle velocity over a complete drive/refill cycle is given by

$$
\mathrm{U}_{\mathrm{ave}}=\frac{\mathrm{U}_{\mathrm{D}} \mathrm{t}_{\mathrm{D}}+\mathrm{U}_{\mathrm{R}} \mathrm{t}_{\mathrm{R}}}{\mathrm{t}_{\mathrm{C}}}=\mathrm{U}_{\mathrm{D}} \mathrm{DC}+\mathrm{U}_{\mathrm{R}}(1-\mathrm{DC})
$$

Where $t_{D}$ is the drive time, $t_{C}$ is the cycle time, $t_{R}=t_{C}-t_{D}$ is the refill time, and duty cycle (DC) $\mathrm{DC}=\mathrm{t}_{\mathrm{D}} / \mathrm{t}_{\mathrm{C}}$.

Since drive and refill volume discharge must be the same, the drive and refill velocities are approximately related by

$$
\mathrm{U}_{\mathrm{JD}} \mathrm{DC}=\mathrm{U}_{\mathrm{JR}}(1-\mathrm{DC})
$$

The average particle velocity given by equation (D.3) can be solved by substituting Eqs. (D.1), (D.2), and D.4). For the case of prototypic refill $\left(f_{p}=1\right)$, the result is $U_{\text {ave }}=-U_{T H}$ as expected (the particle motion over a complete PJM cycle is simply the settling velocity). 
For the case of closed loop operation $\left(f_{p}=0\right)$ the result is

$$
\mathrm{U}_{\mathrm{ave}}=-\mathrm{U}_{\mathrm{TH}}+\frac{\phi_{\mathrm{J}} \mathrm{U}_{\mathrm{JD}_{\mathrm{D}}} \mathrm{DC}}{1-\phi_{\mathrm{PT}}}
$$

where $\phi_{\mathrm{J}}=\mathrm{A}_{\mathrm{J}} / \mathrm{A}_{\mathrm{T}}$ is the jet density and $\phi_{\mathrm{PT}}=\mathrm{A}_{\mathrm{PT}} / \mathrm{A}_{\mathrm{T}}$ is the ratio of pulse tube cross-sectional area to tank area.

Note the sign of Eq. (D.5) is generally negative indicating the average particle velocity is downward. By changing the sign, this can be interpreted as a modified settling velocity according to

$$
\mathrm{U}_{\mathrm{TH}}^{\prime}=\mathrm{U}_{\mathrm{TH}}-\frac{\phi_{\mathrm{J}} \mathrm{U}_{\mathrm{J}} \mathrm{DC}}{1-\phi_{\mathrm{PT}}}
$$

In Eq. (D.6) the subscript on the jet velocity has been changed as it is understood that $U_{J}$ is the same as $\mathrm{U}_{\mathrm{JD}}$.

\section{D.1 References}

Meyer, PA, JA Bamberger, CW Enderlin, JA Fort, BE Wells, SK Sundaram, PA Scott, MJ Minette, GL Smith, CA Burns, MS Greenwood, GP Morgan, EBK Baer, SF Snyder, M White, GF Piepel, BG Amidan, and A Heredia-Langner. 2009. Pulse Jet Mixing Tests With Noncohesive Solids. PNNL-18098, WTP-RPT-182 Rev. 0, Pacific Northwest National Laboratory, Richland, Washington. 


\section{Appendix E}

\section{Bench Marking the Adjusted New Physical Model with Prototypic Drive Tests}





\section{Appendix E}

\section{Bench Marking the Adjusted New Physical Model with Prototypic Drive Tests}

In March 2010, WTP provided PNNL with three days of access to the prototypic testing system at Mid-Columbia Engineering (MCE). PNNL advised MCE staff on testing conditions for the test stand operation with PNNL staff being test observers for the determination of $\mathrm{U}_{\mathrm{CS}}$ conditions. This set of tests

provided an opportunity for Phase 1 metrics to be observed and determined in the prototypic PJM testing vessel.

The data was collected at the Mid-Columbia Engineering testing facility on March 23 through March 26, 2010. These tests were conducted at short notice ( 5 hours) using the Waste Treatment Plant (WTP), Energy Solutions (ES), and MCE methods and systems. System repairs allowed the opportunity for PNNL staff to advise MCE staff on a series of tests with available simulant materials. The initial goal was to bridge to results from past Newtonian Phase 1 testing conducted by PNNL and for an initial examination of the impact of broad particle distributions on $\mathrm{U}_{\mathrm{CS}}$ performance. For purposes of this report, the test results are used for benchmarking the Adjusted New Physical Model.

The 43-in.-diameter test vessel was configured as a scaled vessel of HLP-22 geometry (18 PJM array) with 4-in. equivalent (0.379 inch actual) PJM nozzles The 12 outer nozzles were angled perpendicular to the vessel bottom and the 6 inner nozzles were pointed straight down. There were no diverters installed in the vessel. The PJM drive system was functionally prototypic of a full cycle pulse, vent, and then suction PJM operation.

\section{E.1 Test Cases}

Three main tests were conducted:

\section{E.1.1 Test Case 1 - HLP-22-007}

The test was planned to use s1d2 simulant which was a base simulant in the PNNL Newtonian Phase 1 testing. The s1d2 simulant was not available at the MCE facility that night so a Potters Bead simulant was used instead. The Potters p1d7 (Potters Ballotini Mil 8 soda glass) beads were $178 \mu \mathrm{m}$ in diameter with a 2.45 density. The p1d7 simulant was run at the following concentrations and fill levels:

0.5 reference volume percent at $271 / 2$ inches water level 1.0 reference volume percent at $271 / 2$ inches water level 1.5 reference volume percent at $271 / 2$ inches water level 3.5 reference volume percent at $27 \frac{1}{2}$ inches water level 
The p1d7 simulant particle size distribution (PSD) was provided in Table 3.6 of WTP-RPT-182 Rev 0 (Meyer 2009) and is repeated in Table E.1 below:

Table E.1. Particle Size Distribution for Simulant p1d7

\begin{tabular}{l|c|cc|c|c|c|c|c|c|c|c|c|c|c|c}
\hline \multicolumn{1}{c|}{ Simulant } & $\begin{array}{c}\text { Density } \\
\mathrm{g} / \mathrm{cm}^{3}\end{array}$ & $\begin{array}{c}\text { Packing } \\
\text { Fraction }\end{array}$ & $\begin{array}{c}\mathrm{d} \\
(0.01)\end{array}$ & $\begin{array}{c}\mathrm{d} \\
(0.05)\end{array}$ & $\begin{array}{c}\mathrm{d} \\
(0.10)\end{array}$ & $\begin{array}{c}\mathrm{d} \\
(0.20) \\
\mu \mathrm{m}\end{array}$ & $\begin{array}{c}\mathrm{d} \\
(0.30) \\
\mu \mathrm{m}\end{array}$ & $\begin{array}{c}\mathrm{d} \\
(0.40) \\
\mu \mathrm{m}\end{array}$ & $\begin{array}{c}\mathrm{d} \\
(0.50) \\
\mu \mathrm{m}\end{array}$ & $\begin{array}{c}\mathrm{d} \\
(0.60) \\
\mu \mathrm{m}\end{array}$ & $\begin{array}{c}\mathrm{d} \\
(0.70) \\
\mu \mathrm{m}\end{array}$ & $\begin{array}{c}\mathrm{d} \\
(0.80) \\
\mu \mathrm{m}\end{array}$ & $\begin{array}{c}\mathrm{d} \\
(0.90) \\
\mu \mathrm{m}\end{array}$ & $\begin{array}{c}\mathrm{d} \\
(0.95) \\
\mu \mathrm{m}\end{array}$ & $\begin{array}{c}\mathrm{d} \\
(0.99) \\
\mu \mathrm{m}\end{array}$ \\
\hline $\begin{array}{l}\text { p1d7 } \\
\text { Potters }\end{array}$ & $\mathbf{2 . 4 5}$ & $\mathbf{0 . 5 7}$ & $\mathbf{1 0 6 . 3}$ & $\mathbf{1 2 1 . 3}$ & $\mathbf{1 3 1 . 4}$ & $\mathbf{1 4 5 . 4}$ & $\mathbf{1 5 6 . 8}$ & $\mathbf{1 6 7 . 4}$ & $\mathbf{1 7 8 . 0}$ & $\mathbf{1 8 9 . 2}$ & $\mathbf{2 0 1 . 9}$ & $\mathbf{2 1 7 . 7}$ & $\mathbf{2 4 0 . 7}$ & $\mathbf{2 6 0 . 6}$ & $\mathbf{2 9 6 . 0}$ \\
Ballotine- 8 & & & & & & & & & & & & & & & \\
\hline
\end{tabular}

\section{E.1.2 Test Case 2 - HLP-22-008}

The testing in this run used the five part HLW simulant (recovered from the previous FEP-17-NQA-003 test) at the following concentrations and fill levels:

0.5 reference volume percent $\sim 2.1$ wt percent at $271 / 2$ inches water level 1.0 reference volume percent $\sim 4.3 \mathrm{wt}$ percent at $271 / 2$ inches water level 1.53 reference volume percent $\sim 6.65$ wt percent at $271 / 2$ inches water level (As a reference, 10 weight percent for the HLW simulant in HLP-22 at $27 \frac{1}{2}$ inches of water is 2.35 reference volume percent)

The HLW 5-Part Simulant is made up of:

- Tungsten Carbide, specific gravity 11.2, 4 wt\%

- Ground $\mathrm{SiO}_{2}$, specific gravity 2.65, $75 \mathrm{wt} \%$

- Coarse Gibbsite, specific gravity 2.42, 15 wt\%

- Un-sieved Sand, specific gravity 2.65, 3 wt\%

- Glass Particle, specific gravity 2.9, $3 \mathrm{wt} \%$

The particle size distributions in Figures E.1 through E.3 are for the individual components (as provided by WTP), the calculated HLW simulant PSD from the component data, and the final HLW master simulant PSD that was measured from a sample that included the HLW components mixed to the weight percent concentrations above. 


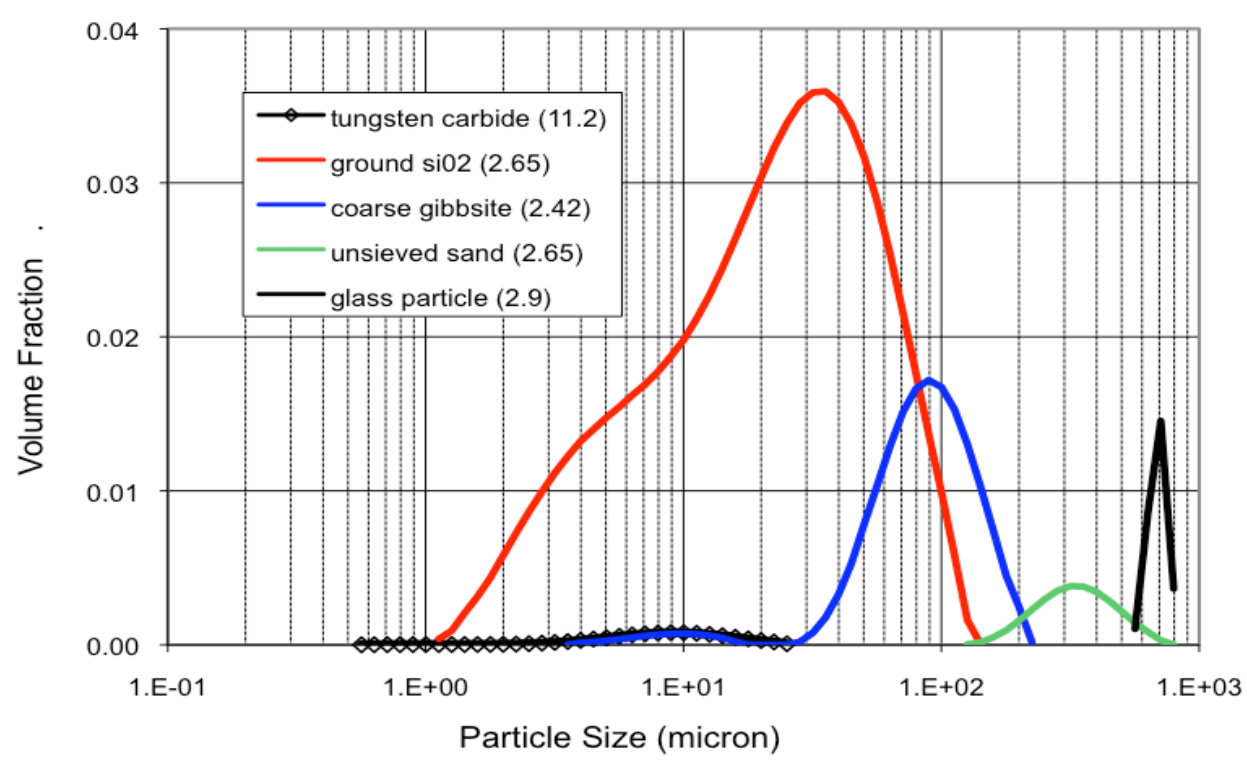

Figure E.1. HLW Simulant Component Particle Size Distribution Provided by WTP (for information only)

HLW 5 Part Simulant

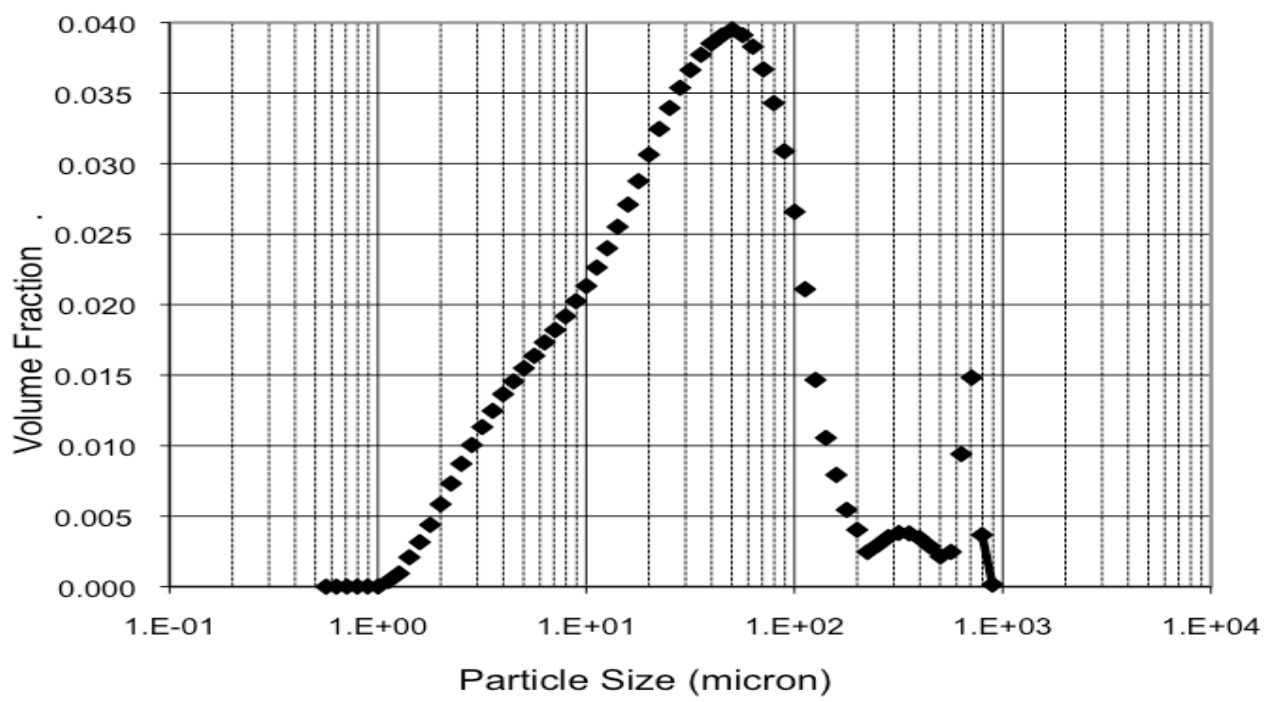

Figure E.2. HLW Simulant Combined Component Particle Size Distribution Calculated (not measured) Based on Individual Component PSDs Provided by WTP (for information only) 


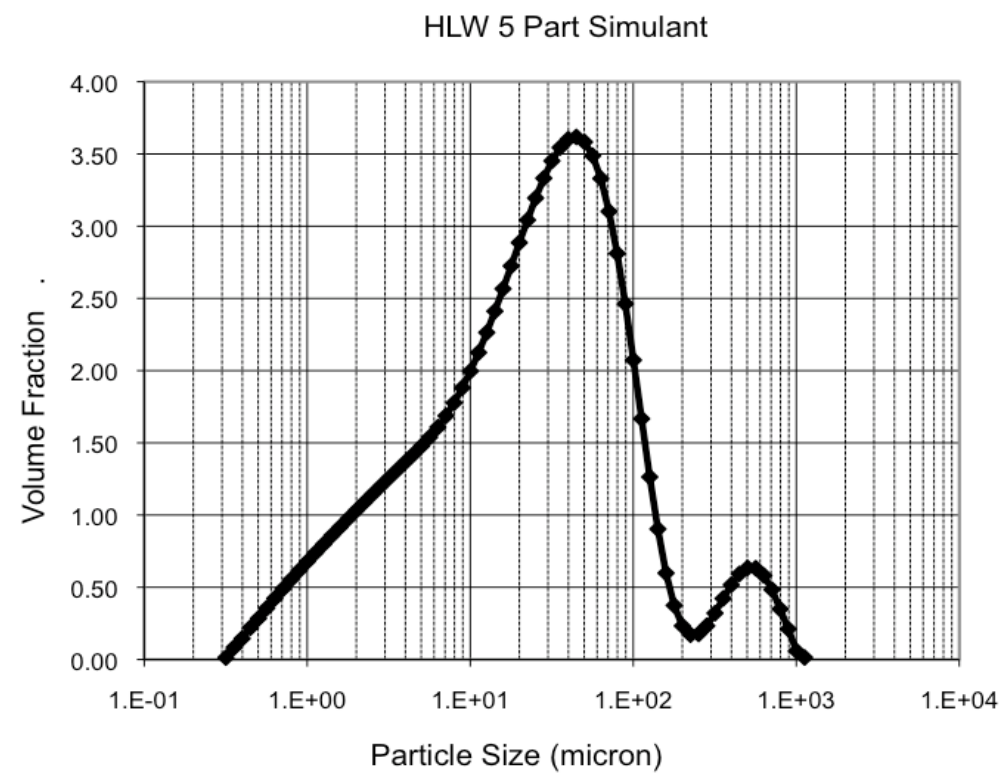

Figure E.3. HLW Master Simulant PSD that was Measured from a Sample that Included HLW Components Mixed to the Weight Percent Concentrations Above

\section{E.1.3 Test Case 3 - HLP-22-009}

The testing in this run used the three-part HLW simulant at the following concentrations:

- 0.5 vol\%: 11.006 kg 200-mesh ground silica, 2.201 kg coarse Gibbsite, 0.441 kg un-sieved sand.

- 1.0 vol\%: add 11.006 kg 200-mesh ground silica, 2.201 kg coarse Gibbsite, 0.441 kg un-sieved sand.

- 1.53 vol\%: add 11.666 kg 200-mesh ground silica, 2.333 kg coarse Gibbsite, 0.467 kg un-sieved sand.

The operating conditions and the resulting $\mathrm{U}_{\mathrm{CS}}$ (at the center of the vessel bottom) are shown in the Table E.2. 
Table E.2. Summary of Test Conditions and Results from PNNL Measurements at MCE

\begin{tabular}{|c|c|c|c|c|c|c|c|c|c|c|}
\hline Simulant & $\begin{array}{l}\text { Particle } \\
\text { Size } \\
(\mu \mathrm{m})\end{array}$ & $\begin{array}{c}\text { Density } \\
\text { Ratio }\end{array}$ & $\begin{array}{c}\text { Solids } \\
\text { Volume } \\
\text { Fraction }\end{array}$ & $\begin{array}{l}\text { Duty } \\
\text { Cycle }\end{array}$ & $\begin{array}{c}\text { Pulse } \\
\text { Volume } \\
\text { Fraction }\end{array}$ & $\begin{array}{l}\text { Measured } \\
\mathrm{U}_{\mathrm{CS}}(\mathrm{m} / \mathrm{s}) \\
\text { DAS ops }\end{array}$ & $\begin{array}{c}\text { Measured } \mathrm{U}_{\mathrm{CS}} \\
(\mathrm{m} / \mathrm{s}) \\
\text { Calculation } \\
\text { Check }\end{array}$ & $\begin{array}{c}\text { DC-Actual } \\
\text { Calculation } \\
\text { Check }\end{array}$ & $\begin{array}{c}\text { PVF } \\
\text { Calculation } \\
\text { Check }\end{array}$ & $\begin{array}{c}\mathrm{U}_{\mathrm{CS}}(\mathrm{m} / \mathrm{s}) \\
\text { Post-Process } \\
\text { Calculation }^{(\mathrm{a})}\end{array}$ \\
\hline Potter's p1d7 glass & 178 & 2.45 & 0.005 & 0.18 & 0.075 & 6.9 & 6.8 & 0.199 & 0.073 & 6.97 \\
\hline Potter's p1d7 glass & 178 & 2.45 & 0.005 & 0.33 & 0.075 & 6.7 & 6.6 & 0.344 & 0.071 & 6.75 \\
\hline Potter's p1d7 glass & 178 & 2.45 & 0.015 & 0.18 & 0.075 & 8.3 & 8.2 & 0.228 & 0.072 & 8.36 \\
\hline Potter's p1d7 glass & 178 & 2.45 & 0.015 & 0.33 & 0.075 & 8.1 & 8.0 & 0.377 & 0.071 & 8.15 \\
\hline $\begin{array}{l}\text { Potter's p1d7 } \\
\text { glass }^{(b)}\end{array}$ & 178 & 2.45 & 0.035 & 0.33 & 0.075 & 9.6 & 9.5 & 0.365 & 0.069 & 9.68 \\
\hline HLW 5-part & NA & $2.7^{(\mathrm{c})}$ & 0.005 & 0.18 & 0.075 & 7.1 & 7.0 & 0.214 & 0.071 & 7.18 \\
\hline HLW 5-part & NA & $2.7^{(\mathrm{c})}$ & 0.005 & 0.18 & 0.15 & 7.1 & 7.0 & NA & NA & NA \\
\hline HLW 5-part ${ }^{(\mathrm{d})}$ & NA & $2.7^{(\mathrm{c})}$ & 0.005 & 0.22 & 0.075 & 7.1 & 7.0 & 0.262 & 0.072 & 7.12 \\
\hline $\begin{array}{l}\text { HLW 5-part }^{(d)} \text {-- } \\
\text { inner nozzles } \\
\text { only }^{(d)}\end{array}$ & $"$ & $"$ & $"$ & $"$ & " & NA & NA & 0.262 & 0.072 & 7.31 \\
\hline HLW 5-part ${ }^{(\mathrm{d})}$ & NA & $2.7^{(\mathrm{c})}$ & 0.005 & 0.14 & 0.075 & 7.1 & NA & NA & NA & NA \\
\hline HLW 5-part ${ }^{(\mathrm{d})}$ & NA & $2.7^{(\mathrm{c})}$ & 0.01 & 0.18 & 0.075 & 8.0 & 7.9 & 0.217 & 0.071 & 8.03 \\
\hline HLW 5-part & NA & $2.7^{(\mathrm{c})}$ & 0.0153 & 0.18 & 0.075 & 8.1 & 8.0 & 0.220 & 0.071 & 8.14 \\
\hline HLW 5-part & NA & $2.7^{(\mathrm{c})}$ & 0.0153 & 0.18 & 0.15 & 8.1 & 8.0 & NA & NA & NA \\
\hline HLW 3-part & NA & $2.61^{(\mathrm{c})}$ & 0.005 & 0.18 & 0.075 & 5.3 & 5.3 & 0.198 & 0.072 & 5.37 \\
\hline HLW 3-part ${ }^{(b)}$ & NA & $2.61^{(\mathrm{c})}$ & 0.010 & 0.18 & 0.075 & 5.7 & 5.6 & 0.203 & 0.072 & 5.77 \\
\hline
\end{tabular}

(a) Integration limits for calculating the peak average velocity were chosen in a similar manner as was used to determine the peak average velocity in the Phase 1 tests.

(b) Noted as "very close" or "near $\mathrm{U}_{\mathrm{CS}}$ ” though velocities above $\mathrm{U}_{\mathrm{CS}}$ were not tested due to time constraints.

(c) Calculated weighted average density for the combined simulant solids.

(d) This data point was collected at a single velocity and not as an up sweep. The velocity was noted as "at $\mathrm{U}_{\mathrm{CS}}$ " in the comments. Higher velocities for these operating conditions were not run due to time constrains. 


\section{E.2 Measured $\mathrm{U}_{\mathrm{cs}}$ Compared with Correlation Predictions}

Measured $U_{\mathrm{CS}}$ values for the p1d7 glass particle are shown in Figures E.4 and E.5 below. The New Physical Model under predicts the measured values consistent with the general findings of this report. The modified model, which accounts for the effects of suction refill does an excellent job of predicting the measured values.

In Figure E.6 $\mathrm{U}_{\mathrm{CS}}$ values for the HLW 5-part simulant are shown. In order to apply the correlation for this simulant mixture, a weighted average particle is required. Consistent with the results of benchmarks shown in Appendix C, a value of Ubar 50 was selected. For this simulant, Ubar 50 corresponds to about $1.24 \mathrm{E}-2 \mathrm{~m} / \mathrm{s}$, and is equivalent to a $135 \mu \mathrm{m}$ particle diameter with average density of 2.7. From Figure E.6, it is seen that the modified correlation does a good job of predicting the measure values at the lower concentrations. For the higher concentration data point, the measured value of $\mathrm{U}_{\mathrm{CS}}$ changed little, whereas the correlations predict continued increase in $\mathrm{U}_{\mathrm{CS}}$ with increasing concentration.

In Figure E.7 $\mathrm{U}_{\mathrm{CS}}$ values for the HLW 3-part simulant are shown. Here the New Physical Model does a reasonable job of predicting the data points, but the modified model over-predicts $U_{\mathrm{CS}}$ values. The value of Ubar 50 for this simulant is about $3.9 \mathrm{E}-3 \mathrm{~m} / \mathrm{s}$, which corresponds to a $71 \mu \mathrm{m}$ particle with average density of 2.61. One of the consequences of the suction modification used is that it predicts very high $U_{C S}$ values for very small particles. Hence it appears that for this simulant, the suction correction is too strong.

p1d7 DC 0.2

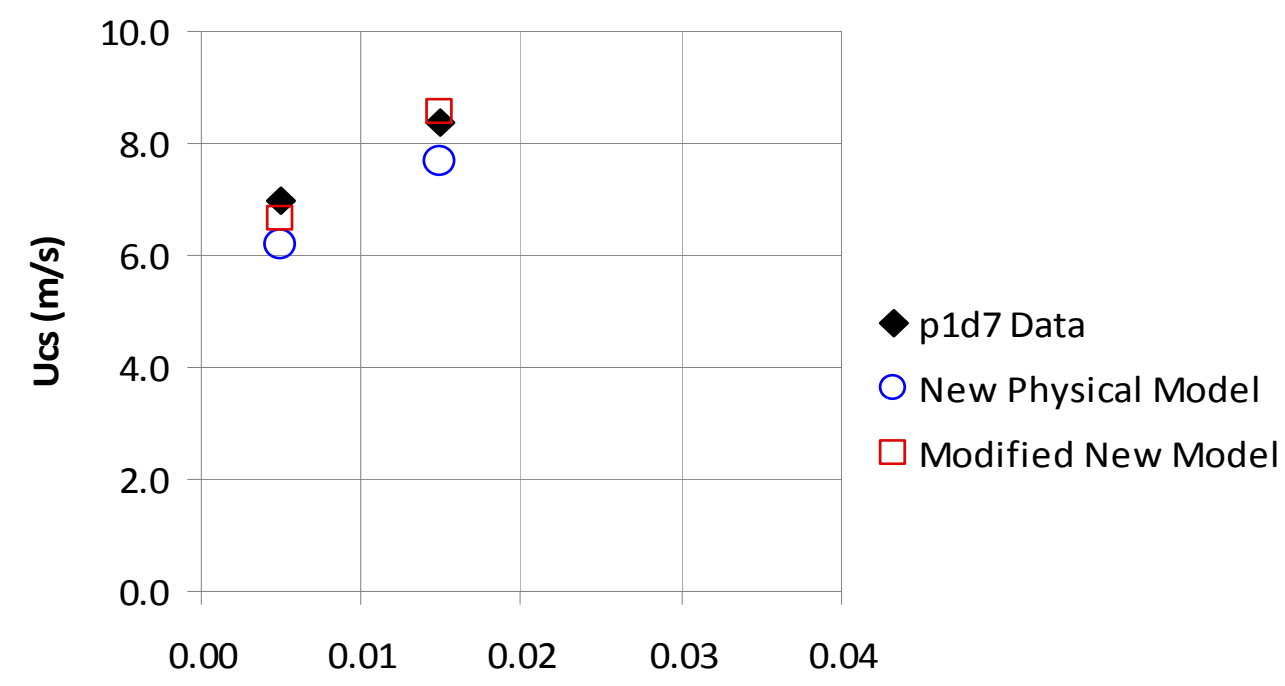

Solids Fraction

Figure E.4. HLW Comparison of Predicted and Measured $U_{C S}$ Values for the p1d7 Simulant with DC $~ 0.2$ at Two Solids Concentrations 
p1d7 DC $=0.36$

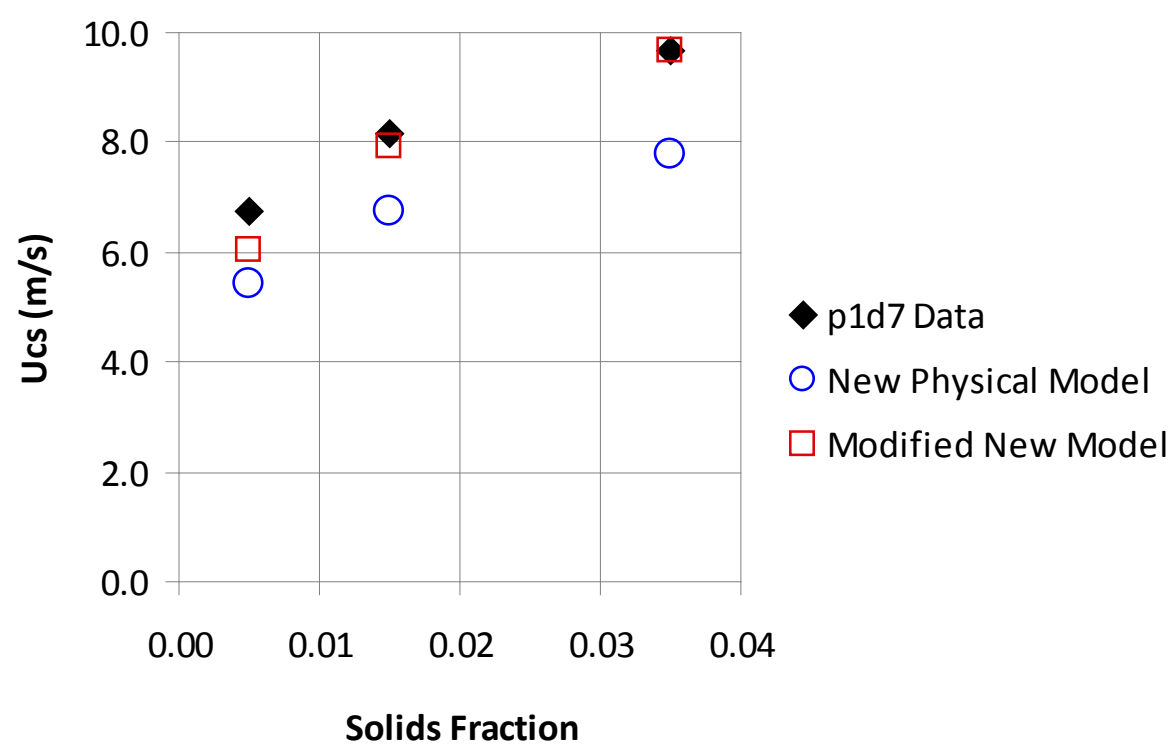

Figure E.5. Comparison of Predicted and Measured $U_{\mathrm{CS}}$ Values for the p1d7 Simulant with DC 0.36 at Three Solids Concentrations

HLW 5-Part DC 0.22

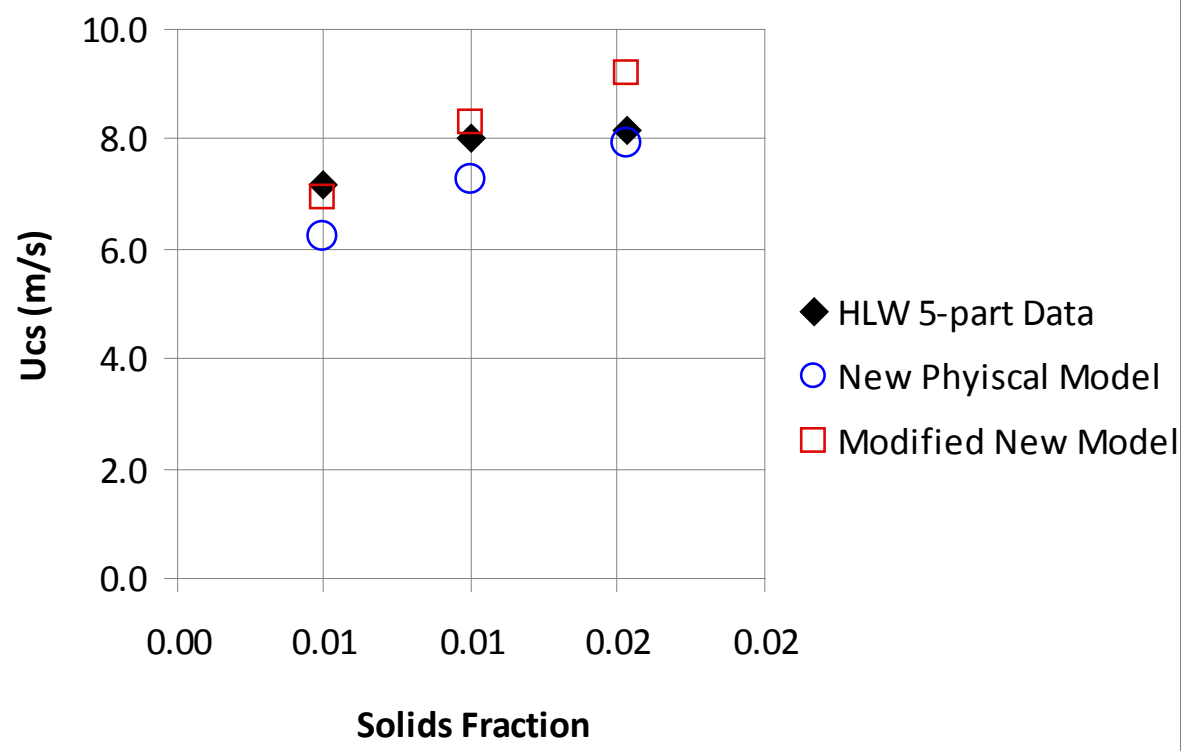

Figure E.6. Comparison of Predicted and Measured $U_{\mathrm{CS}}$ Values for the HLW 5-Part Simulant with DC $\sim 0.22$ at Three Solids Concentrations 
HLW 3-Part DC 0.2

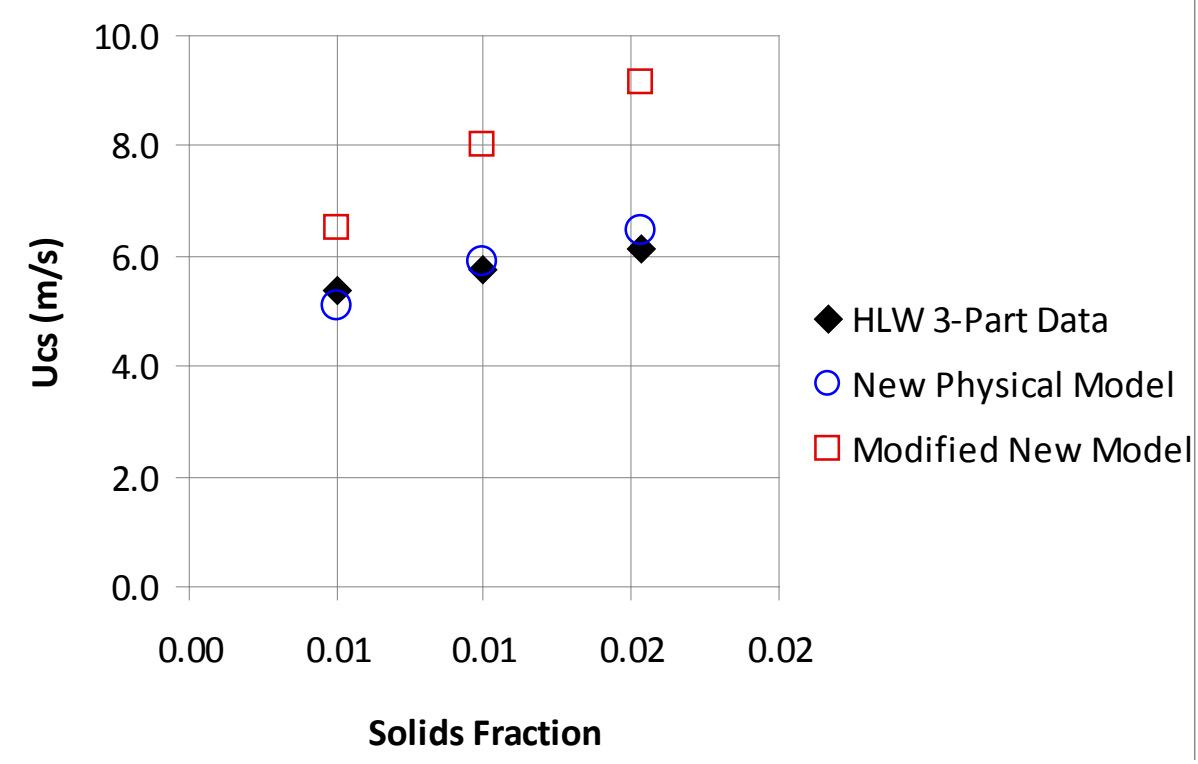

Figure E.6. Comparison of Predicted and Measured $U_{\mathrm{CS}}$ Values for the HLW 3-Part Simulant with DC $\sim 0.2$ at Three Solids Concentrations

\section{E.3 References}

Meyer, PA, JA Bamberger, CW Enderlin, JA Fort, BE Wells, SK Sundaram, PA Scott, MJ Minette, GL Smith, CA Burns, MS Greenwood, GP Morgan, EBK Baer, SF Snyder, M White, GF Piepel, BG Amidan, and A Heredia-Langner. 2009. Pulse Jet Mixing Tests With Noncohesive Solids.

PNNL-18098, WTP-RPT-182 Rev. 0, Pacific Northwest National Laboratory, Richland, Washington. 
PNNL-19085

WTP-RPT-208, Rev. 0

\section{Distribution}

No. of

Copies

ONSITE*

1 DOE Office of River Protection

DH Alexander

H6-60

2 Bechtel National Inc.

SM Barnes

WTP PETD Docs
No. of

Copies

6 Pacific Northwest National Laboratory

EBK Baer

K7-15

JA Bamberger

JA Fort

K7-15

PA Meyer

K7-15

K7-15

MJ Minette

P7-25

Information Release (pdf)

Project File (1)
K3-52

K3-52

*All distribution will be made electronically. 


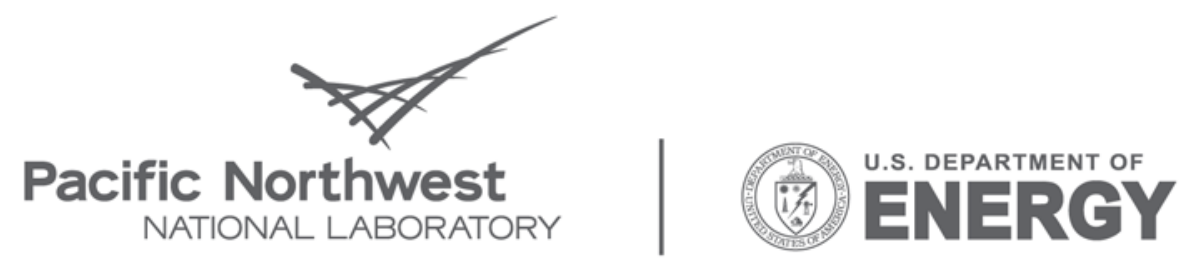

Proudly Operated by Battelle Since 1965

902 Battelle Boulevard

P.O. Box 999

Richland, WA 99352

1-888-375-PNNL (7665)

www.pnl.gov 